
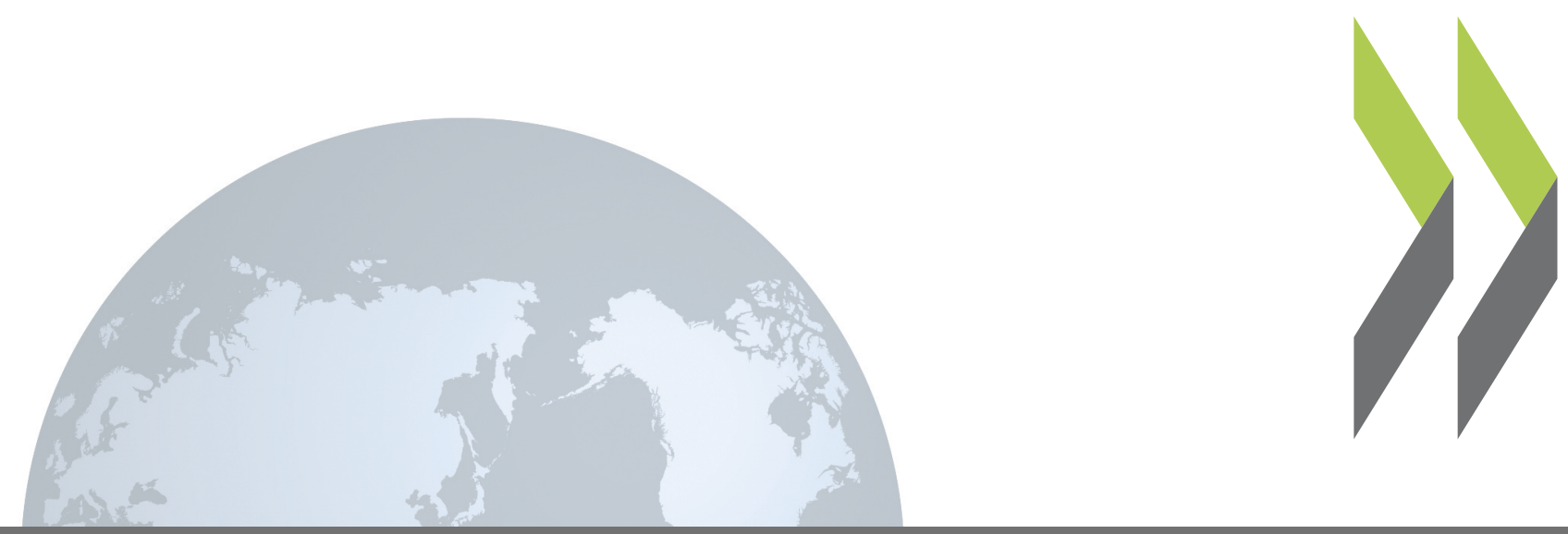

OECD Series on Adverse Outcome Pathways No. 5

Adverse Outcome Pathway on chronic binding of antagonist to N-methyl-Daspartate receptors (NMDARs) during brain development induces impairment of learning and memory abilities

Magdalini Sachana, Sharon Munn, Anna Bal-Price 


\section{Foreword}

This Adverse Outcome Pathway (AOP) on Chronic binding of antagonist to N-methyl-D-aspartate receptors (NMDARs) during brain development leading to impairment of learning and memory abilities, has been developed under the auspices of the OECD AOP Development Programme, overseen by the Extended Advisory Group on Molecular Screening and Toxicogenomics (EAGMST), which is an advisory group under the Working Group of the National Coordinators for the Test Guidelines Programme (WNT). The AOP has been reviewed internally by the EAGMST, externally by experts nominated by the WNT, and has been endorsed by the WNT and the Task Force on hazard Assessment (TFHA) in April 2016.

Through endorsement of this AOP, the WNT and the TFHA express confidence in the scientific review process that the AOP has undergone and accept the recommendation of the EAGMST that the AOP be disseminated publicly. Endorsement does not necessarily indicate that the AOP is now considered a tool for direct regulatory application.

The Joint Meeting of the Chemicals Committee and the Working Party on Chemicals, Pesticides and Biotechnology agreed to declassification of this AOP on 17 June 2016.

This document is being published under the responsibility of the Joint Meeting of the Chemicals Committee and the Working Party on Chemicals, Pesticides and Biotechnology. 


\section{Table of Contents}

Authors. . .3

Abstract .3

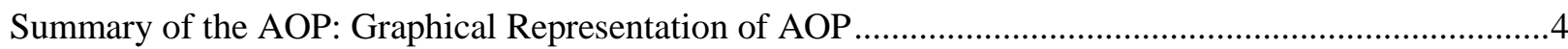

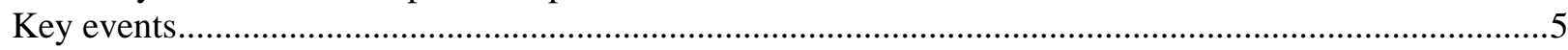

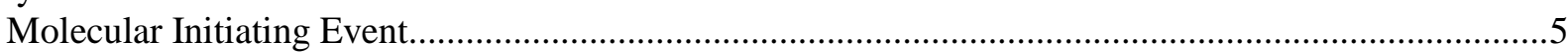

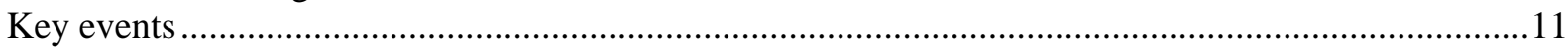

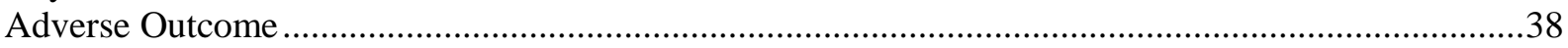

Key Event Relationships: Scientific evidence supporting the linkages in the AOP ...............................43

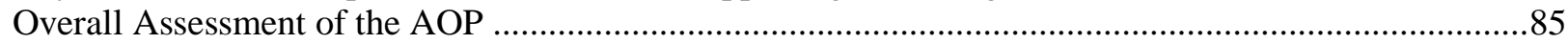

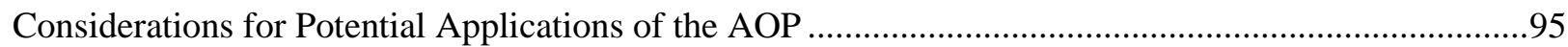

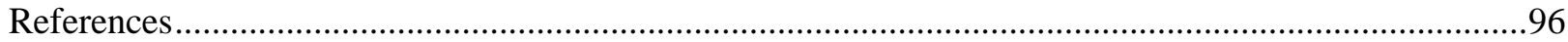




\title{
ADVERSE OUTCOME PATHWAY ON CHRONIC BINDING OF ANTAGONIST TO N- METHYL-D-ASPARTATE RECEPTORS (NMDARs) DURING BRAIN DEVELOPMENT INDUCES IMPAIRMENT OF LEARNING AND MEMORY ABILITIES
}

Short name: Binding of antagonist to NMDARs impairs cognition

\section{Authors}

Magdalini Sachana, Sharon Munn, Anna Bal-Price

Joint Research Centre Institute for Health and Consumer Protection Systems Toxicology Unit Via E. Fermi 2749 - 21020 - Ispra (VA) -Italy

Corresponding author: anna.price@ec.europa.eu

\begin{abstract}
It is well documented and accepted that learning and memory processes rely on physiological functioning of the glutamate receptor N-methyl-D-aspartate (NMDAR). Both animal and human studies investigating NMDA itself, experiments with NMDAR antagonists and mutant mice lacking NMDAR subunits strongly support this statement (Rezvani, 2006). Activation of NMDARs results in long-term potentiation (LTP), which is related to increased synaptic strength, plasticity and memory formation in the hippocampus (Johnston et al., 2009). LTP induced by activation of NMDA receptors has been found to be elevated in the developing rodent brain compared to the mature brain, partially due to 'developmental switch' of the NMDAR 2A and 2B subunits (Johnston et al., 2009). Activation of the NMDAR also enhances brain derived neurotrophic factor (BDNF) release, which promotes neuronal survival, differentiation and synaptogenesis (Tyler et al., 2002; Johnston et al., 2009). Consequently, the blockage of NMDAR by chemical substances during synaptogenesis disrupts neuronal network formation resulting in the impairment of learning and memory processes (Toscano and Guilarte, 2005). This AOP is relevant to developmental neurotoxicity (DNT). The molecular initiating event (MIE) is described as the chronic binding of antagonist to NMDAR in neurons during synaptogenesis (development) in hippocampus (one of the critical brain structures for learning and memory formation). One of the chemicals that blocks NMDAR after chronic exposure is lead $\left(\mathrm{Pb}^{2+}\right)$, a well-known developmental neurotoxicant.
\end{abstract}

\section{References}

Johnston, M.V. et al. (2009), Plasticity and injury in the developing brain. Brain Dev. 31:1-10.

Rezvani, A.H. (2006), Involvement of the NMDA System in Learning and Memory. In: Levin ED, Buccafusco JJ, editors. Animal Models of Cognitive Impairment. Boca Raton (FL): CRC Press; Chapter 4. Available from: http://www.ncbi.nlm.nih.gov/books/NBK2532/

Toscano, C.D., and T.R. Guilarte (2005), Lead neurotoxicity: From exposure to molecular effects. Brain Res Rev. 49: 529-554.

Tyler, W.J. et al. (2002), From acquisition to consolidation: on the role of brain-derived neurotrophic factor signaling in hippocampal-dependent learning. Learn Mem. 9: 224-237. 
Summary of the AOP: Graphical Representation of AOP

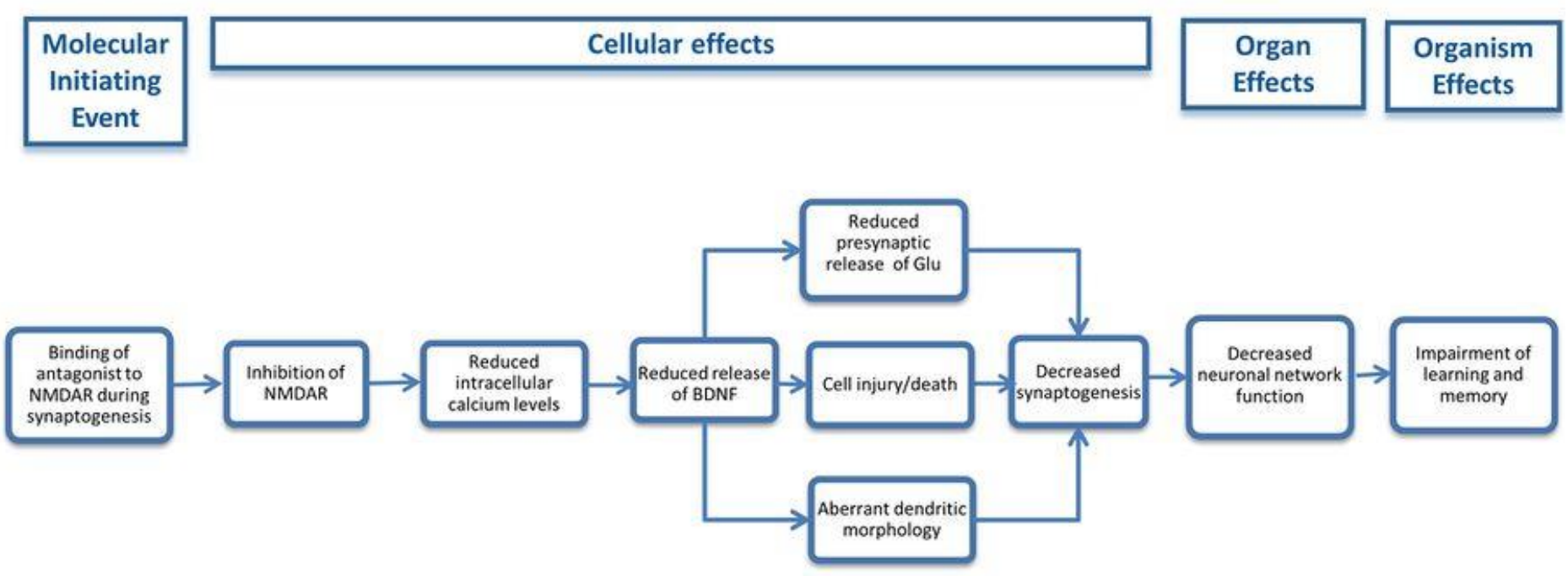




\section{Key events}

Molecular Initiating Event

Molecular Initiating Event

NMDARs, Binding of antagonist

NMDA receptors, Binding of antagonist

AOPs including this Key Event

\begin{tabular}{|l|l|l|}
\hline \multicolumn{1}{|c|}{ AOP Name } & $\begin{array}{c}\text { Event } \\
\text { Type }\end{array}$ & Essentiality \\
\hline $\begin{array}{l}\text { Chronic binding of antagonist to N-methyl-D-aspartate receptors (NMDARs) } \\
\text { during brain development induces impairment of learning and memory abilities }\end{array}$ & MIE & Strong \\
\hline $\begin{array}{l}\text { Binding of antagonist to N-methyl-D-aspartate receptors (NMDARs) during brain } \\
\text { development can trigger neuroinflammation and lead to neurodegeneration }\end{array}$ & MIE & Strong \\
\hline
\end{tabular}

\section{Chemical Initiators}

The following are chemical initiators that operate directly through this Event:

1. Lead

How this Key Event works

Level of biological organisation

Molecular

Biological state: L-glutamate (Glu) is a neurotransmitter with important role in the regulation of brain development and maturation processes. Two major classes of Glu receptors, ionotropic and metabotropic, have been identified. Due to its physiological and pharmacological properties, Glu activates three classes of ionotropic receptors named: $\alpha$-amino-3-hydroxy-5-methyl-4isoazolepropionic acid (AMPA receptors), 2-carboxy-3-carboxymethyl-4-isopropenylpyrrolidine (kainate receptors) and N-methyl-D-aspartate (NMDA receptors, NMDARs), which transduce the postsynaptic signal. Ionotropic glutamate receptors are integral membrane proteins formed by four large subunits that compose a central ion channel pore. In case of NMDA receptors, two NR1 subunits are combined with either two NR2 (NR2A, NR2B, NR2C, NR2D) subunits and less commonly are assembled together with a combination of NR2 and NR3 (A, B) subunits (reviewed in Traynelis et al., 2010). To be activated NMDA receptors require simultaneous binding of both glutamate to NR2 subunits and of glycine to either NR1 or NR3 subunits that provide the specific binding sites named extracellular ligand-binding domains (LBDs). Apart from LBDs, NMDA receptor subunits contain three more domains that are considered semiautonomous: 1) the extracellular amino-terminal domain that plays important role in assembly and trafficking of these 
receptors; 2) the transmembrane domain that is linked with LBD and contributes to the formation of the core of the ion channel and 3) the intracellular carboxyl-terminal domain that influences membrane targeting, stabilization, degradation and post-translation modifications.

Biological compartments: The genes of the NMDAR subunits are expressed in various tissues and are not only restricted to the nervous system. The level of expression of these receptors in neuronal and non-neuronal cells depends on: transcription, chromatin remodelling, mRNA levels, translation, stabilization of the protein, receptor assembly and trafficking, energy metabolism and numerous environmental stimuli (reviewed in Traynelis et al., 2010).

In hippocampus region of the brain, NR2A and NR2B are the most abundant NR2 family subunits. NR2A-containing NMDARs are mostly expressed synaptically, while NR2B-containing NMDARs are found both synaptically and extrasynaptically (Tovar and Westbrook, 1999).

General role in biology: NMDA receptors, when compared to the other Glu receptors, are characterized by higher affinity for Glu, slower activation and desensitisation kinetics, higher permeability for calcium (Ca2+) and susceptibility to potential-dependent blockage by magnesium ions $(\mathrm{Mg} 2+)$. NMDA receptors are involved in fast excitatory synaptic transmission and neuronal plasticity in the central nervous system (CNS). Functions of NMDA receptors:

1. They are involved in cell signalling events converting environmental stimuli to genetic changes by regulating gene transcription and epigenetic modifications in neuronal cells (Cohen and Greenberg, 2008).

2. In NMDA receptors, the ion channel is blocked by extracellular $\mathrm{Mg} 2+$ and $\mathrm{Zn} 2+$ ions, allowing the flow of $\mathrm{Na}+$ and $\mathrm{Ca} 2+$ ions into the cell and $\mathrm{K}+$ out of the cell which is voltage-dependent. $\mathrm{Ca} 2+$ flux through the NMDA receptor is considered to play a critical role in pre- and postsynaptic plasticity, a cellular mechanism important for learning and memory (Barria and Malinow, 2002).

3. The NMDA receptors have been shown to play an essential role in the strengthening of synapses and neuronal differentiation, through long-term potentiation (LTP), and the weakening of synapses, through long-term depression (LTD). All these processes are implicated in the memory and learning function (Barria and Malinow, 2002).

How it is measured or detected

There is no OECD advised method for measuring NMDA receptor binding of antagonists. However, there are methods described in the scientific literature that allow measuring:

1. Ex vivo: The most common assay used is the NMDA receptor (MK801 site) radioligand competition binding assays (Reynolds, 2001; Gao et al., 2013; http://pdsp.med.unc.edu/UNCCH\%20Protocol\%20Book.pdf; http://www.currentprotocols.com/WileyCDA/CPUnit/refIdph0120.html). This assay is based on the use of the most potent and specific antagonist of this receptor, MK801 that is used to detect and differentiate agonists and antagonists (competitive and non-competitive) that bind to this specific site of the receptor. Also radioligand competition binding assay can be performed using D, L-(E)-2-amino-4-[3H]-propyl-5-phosphono-3-pentenoic 
acid ([3H]-CGP 39653), a high affinity selective antagonist at the glutamate site of NMDA receptor, which is a quantitative autoradiography technique (Mugnaini et al., 1996). D-AP5, a selective N-methyl-D-aspartate (NMDA) receptor antagonist that competitively inhibits the glutamate binding site of NMDA receptors, can be studied by evoked electrical activity measurements. AP5 has been widely used to study the activity of NMDA receptors particularly with regard to researching synaptic plasticity, learning, and memory (Evans et al., 1982; Morris, 1989).

2. In silico: The prediction of NMDA receptor targeting is achievable by combining database mining, molecular docking, structure-based pharmacophore searching, and chemical similarity searching methods together (Korkut and Varnali, 2003; Koutsoukos et al., 2011; Gao et al., 2013; Mazumber and Borah, 2014; Chtitaa et al., 2015).

Evidence supporting taxonomic applicability

\begin{tabular}{|l|l|l|l|}
\hline Name & Scientific Name & Evidence & Links \\
\hline human & Homo sapiens & Strong & NCBI \\
\hline rat & Rattus sp. & Strong & NCBI \\
\hline mouse & Mus sp. & Strong & NCBI \\
\hline
\end{tabular}

The evolution of NMDAR subunits (NR1, NR2, NR3) is well-conserved throughout different species from lower organism to mammals, including humans (Ewald and Cline, 2009; Tikhonov and Magazanik, 2009; Koo and Hampson, 2010; Teng et al., 2010; Flores-soto et al., 2012).

Many of the binding sites for the noncompetitive or competitive antagonists e.g. for binding of dizocilpine (MK-801), phencyclidine, D-2-amino-5-phosphonopentanoate (AP5) and 3-((R)-2carboxypiperazin-4-yl)-propyl-1-phosphonic acid (R-CPP) are also conserved in Drosophila (reviewed in Xia and Chiang, 2009).

Cellular membranes can be prepared from different brain areas of distinct species. Using $[3 \mathrm{H}] \mathrm{MK}-801$, high affinity binding sites for MK-801 were detected in membranes of the rat brain (Woodruff et al., 1987). The same binding assay has been used in preparations from human brains mostly by patients with neurodegenerative disorders (Slater et al., 1993) as well as from different marine, avian species (Scheuhammer et al., 2008) and insects (Eldefrawi et al., 1993).

\section{Evidence for chemical initiation of this Molecular Initiating Event}

Glu and glycine are endogenous agonists that bind to LBD of specific NMDA receptor subunits. In this binding site numerous competitive exogenous antagonists have been identified to cause closure of binding site and inhibition of NMDA receptor (reviewed in Traynelis et al., 2010). Here, are listed some known competitive antagonists for NMDA receptor, some of them are specific to NR1 subunit and some to NR2 subunit:

$\alpha$-AA, $\alpha$-aminoadipate;

5,7-DCKA, 5,7-dichlorokynurenic acid;

7-CKA, 7-chlorokynurenic acid; 
ACEA-1011, 5-chloro-7-trifluoromethyl-1,4-dihydro-2,3-quinoxalinedione;

ACEA-1021, licostinel;

AP5, 2-amino-5-phosphonopentanoate;

AP7, 2-amino-7-phosphonopentanoate;

CGP-61594, ( \pm -trans-4-[2-(4-azidophyenyl)acetylamino]-5,7-dichloro-1,2,3,4-

tetrahydroquinoline-2-carboxylic acid;

CGP-40116, d-(E)-2-amino-4-methyl-5-phosphono-3-pentenoic acid;

CGP-43487, d-(E)-2-amino-4-methyl-5-phosphono-3-pentenoic acid methyl ester;

CGP-58411, 7-chloro-4-hydroxy-3-phenyl-1H-quinolin-2-one;

CGS-19755, (2R,4S)-4-(phosphonomethyl)piperidine-2-carboxylic acid;

CPP, 4-(3-phosphonopropyl) pizerazine-2-carboxylic acid;

GV150,526A, gavestinel;

GV196,771A, (E)-4,6-dichloro-3-[(2-oxo-1-phenyl-3-pyrrolidinylidene)methyl]-1H-indole-2-

carboxylic acid;

L-689,560, 4-trans-2-carboxy-5,7-dichloro-4-phenylaminocarbonylamino-1,2,3,4-

tetrahydroquinoline;

L-701,324, 7-chloro-4-hydroxy-3-(3-phenoxy)phenyl-2(1H)-quinolone;

MDL105,519, (E)-3-(2-phenyl-2-carboxyethenyl)-4, 6-dichloro-1H-indole-2-carboxylic acid;

PBPD, (2S,3R)-1-(biphenyl-4-carbonyl)piperazine-2,3-dicarboxylic acid;

PMPA, (R,S)-4-(phosphonomethyl)-piperazine-2-carboxylic acid;

PPDA, (2S,3R)-1-(phenanthren-2-carbonyl)piperazine-2,3-dicarboxylic acid

Besides competitive antagonists, noncompetitive antagonists have also been designed like phenylethanolamine ifenprodil that interacts with the NR2B extracellular amino-terminal domain. It has been suggested that they act by stabilizing an agonist-bound state in which the receptor has a low open probability. Other more potent derivatives of ifenprodil are: $\alpha$-(4-hydroxyphenyl)- $\beta$ methyl-4-(phenylmethyl)-1-piperidine propanol (Ro 25-6981), 1-[2-(4-hydroxy-phenoxy)-ethyl]4-(4-methyl-benzyl)-piperidin-4-ol (Ro 63-1908), besonprodil (CI-1041), and traxoprodil mesylate (CP-101,606). Ethanol has been proposed to be a noncompetitive antagonist of NMDA receptors, binding to NR2 subunit (Nagy, 2008). Inhibition of NMDA receptor function by ethanol and interactions between ethanol and the noncompetitive NMDA receptor antagonist ifenprodil have been examined in neocortical neurons from rat and human embryonic kidney (HEK) 293 cells expressing recombinant NMDA receptors (Lovinger, 1995). Recently, a structural model has been suggested that predicts the presence of four sites of ethanol action on the NMDA receptor, each containing four pairs of positions in the NR1/NR2 subunits (reviewed in Chandrasekar, 2013). Some other antagonists can become trapped in the pore of the NMDA receptor after channel closure and these antagonists are called uncompetitive or trapping blockers. The most well studied NMDA receptor uncompetitive antagonists are $\mathrm{Mg} 2+$, polyamines, phencyclidine, ketamine, MK-801, memantine, amantadine, pentamidine, 9tetrahydroaminoacridine, dextromethorphan, and its metabolite dextrorphan. MK-801 has been shown to prevent toluene-induced alterations in pattern-elicited visual-evoked potentials in vivo, suggesting the possibility that the binding site of toluene might be common with the one of MK801 (Bale et al., 2007). However, another study suggests that toluene interference with the NMDA receptor might not be exclusively because of the binding to the channel pore (Smothers and Woodward, 2007) but it may involve some other binding sites. Lead (Pb2+) is considered a voltage independent antagonist of NMDA receptors and it is believed that possibly shares the same binding site with Zn2+ (reviewed in Neal and Guilarte, 2010; Traynelis et al., 2010). 
However, studies done in recombinant NR2A- and NR2B- containing NMDA receptors with mutated $\mathrm{Zn} 2+$ binding sites exhibit that additional structural elements, different from those important for $\mathrm{Zn} 2+$ binding are involved in $\mathrm{Pb} 2+$ binding site (reviewed in Neal and Guilarte, 2010). Similarly, there are contradicting experimental evidence and disagreement about $\mathrm{Pb} 2+\mathrm{s}$ role as competitive or non-competitive antagonist (Neal and Guilarte, 2010).

\section{References}

Bale, A.S. et al. (2007), Evaluating the NMDA-glutamate receptor as a site of action for toluene, in vivo. Toxicol Sci. 98: 159-66.

Barria, A., and R. Malinow (2002), Subunit-specific NMDA receptor trafficking to synapses. Neuron 35: 345-353.

Chandrasekar, R. (2013), Alcohol and NMDA receptor: current research and future direction. Front Mol Neurosci. 6: 14.

Chtitaa, S. et al. (2015), DFT-based QSAR Studies of MK801 derivatives for non competitive antagonists of NMDA using electronic and topological descriptors. Journal of Taibah University for Science. 9: 143-154.

Cohen, S., and M.E. Greenberg (2008), Communication between the synapse and the nucleus in neuronal development, plasticity, and disease. Ann Rev Cell Dev Biol 24: 183-209.

Eldefrawi, M.E., N.A. Anis and A.T. Eldefrawi (1993), Glutamate receptor inhibitors as potential insecticides. Arch Insect Biochem Physiol. 22: 25-39.

Evans, R.H. et al. (1982), The Effects of a Series of $\omega$-Phosphonic $\alpha$-Carboxylic Amino Acids on Electrically Evoked and Excitant Amino Acid-Induced Responses in Isolated Spinal Cord Preparations. Br J Pharmac. 75: 65-75.

Ewald, R.C., and H.T. Cline (2009), Cloning and phylogentic analysis of NMDA receptor subunits NR1, NR2A and NR2B in Xenopus laevis tadpoles. Front Mol Neurosci. 2: 4.

Flores-soto, M.E. et al. (2012), Structure and function of NMDA-type glutamate receptor subunits. Neurologia 27: 301-310.

Gao, L. et al. (2013), In silico Target Fishing for the Potential Targets and Molecular Mechanisms of Baicalein as an Antiparkinsonian Agent: Discovery of the Protective Effects on NMDA ReceptorMediated Neurotoxicity. Chem Biol Drug Des. 81: 675-87.

Koo, J.C.P., and D.R. Hampson (2010), Phylogenic and evolutionary analysis of glutamate receptor based on extant invertebrate genes. JULS 1: 42-48.

Korkut, A., and T. Varnali (2003), Quantitative structure activity relationship (QSAR) of competitive Nmethyl-D-aspartate (NMDA) antagonists. Mol Phys 101: 3285-3291.

Koutsoukas, A. et al. (2011), From in silico target prediction to multi-target drug design: current databases, methods and applications. J Proteomics 74: 2554-2574.

Lovinger, D.M. (1995), Developmental decrease in ethanol inhibition of N-methyl-D-aspartate receptors in rat neocortical neurons: relation to the actions of ifenprodil. J Pharmacol Exp Ther. 274: 164-172.

Mazumder, M.K., and A. Borah (2014), Piroxicam inhibits NMDA receptor-mediated excitotoxicity through allosteric inhibition of the GluN2B subunit: An in silico study elucidating a novel mechanism of action of the drug. Medical Hypotheses 83: 740-746.

Morris, R.J. (1989), Synaptic Plasticity and Learning: Selective Impairment of Learning in Rats and Blockade of Long-Term Potentiation in vivo by the N-Methyl-D-Aspartate Receptor Antagonist AP5. J Neurosci 9: 3040-3057. 
Mugnaini, M. et al. (1996), Regionally different N-methyl-D-aspartate receptors distinguished by ligand binding and quantitative autoradiography of [3H]-CGP 39653 in rat brain. Br J Pharmacol 119: 819828.

Nagy, J. (2008), Alcohol related changes in regulation of NMDA receptor functions. Curr Neuropharmacol 6: 39-54.

Neal, A.P., and T.R. Guilarte (2010), Molecular Neurobiology of Lead (Pb2+): Effects on Synaptic Function. Mol Neurobiol. 42: 151-160.

Nihei, M.K., and T.R. Guilarte (1999), NMDAR-2A subunit protein expression is reduced in the hippocampus of rats exposed to $\mathrm{Pb} 2+$ during development. Brain Res Mol Brain Res. 66: 42-49.

Reynolds, I.J. (2001), [3H](+)MK801 radioligand binding assay at the N-methyl-D-aspartate receptor. Curr Protoc Pharmacol. Chapter 1:Unit 1.20. doi: 10.1002/0471141755.ph0120s11.

Scheuhammer, A.M. et al. (2008), Relationships among mercury, selenium, and neurochemical parameters in common loons (Gavia immer) and bald eagles (Haliaeetus leucocephalus). Ecotoxicology 17: 93101.

Slater, P. et al. (1993), Postnatal changes in N-methyl-D-aspartate receptor binding and stimulation by glutamate and glycine of [3H]-MK-801 binding in human temporal cortex. Br J Pharmacol. 108: 1143-1149.

Smothers, C.T., and J.J. Woodward (2007), Pharmacological characterization of glycine-activated currents in HEK 293 cells expressing N-methyl-d-aspartate NR1 and NR3 subunits. J Pharmacol Exp Ther. 322: $739-748$.

Teng, H. et al. (2010), Evolutionary mode of functional divergence of vertebrate NMDA receptor subunit 2 Genes. PLoS ONE. 5(10): e13342.

Tikhonov, D.B., and L.G. Magazanik (2009), Origin and molecular evolution of ionotropic glutamate receptors. Neurosci Behav Physiol. 39: 763-772.

Tovar, K.R., and G.L. Westbrook (1999), The incorporation of NMDA receptors with a distinct subunit composition at nascent hippocampal synapses in vitro. J Neurosci. 19: 4180-4188.

Traynelis, S. et al. (2010), Glutamate receptor ion channels: structure, regulation, and function. Pharmacol Rev. 62: 405-496.

Woodruff, G.N. et al. (1987), The interaction between MK-801 and receptors for N-methyl-D-aspartate: functional consequences. Neuropharmacology 26(7B): 903-909.

Xia, S., and A.S. Chiang (2009), NMDA Receptors in Drosophila. In: Van Dongen AM, editor. Biology of the NMDA Receptor. Boca Raton (FL): CRC Press; Chapter 10. Available from: http://www.ncbi.nlm.nih.gov/books/NBK5286/ 
Key events

\begin{tabular}{|l|}
\hline \multicolumn{1}{|c|}{ Key Event } \\
\hline NMDARs, Inhibition \\
\hline Calcium influx, Decreased \\
\hline$\underline{\text { Release of BDNF, Reduced }}$ \\
\hline Dendritic morphology, Aberrant \\
\hline Presynaptic release of glutamate, Reduced \\
\hline$\underline{\text { Cell death, N/A }}$ \\
\hline Synaptogenesis, Decreased \\
\hline$\underline{\text { Neuronal network function, Decreased }}$ \\
\hline
\end{tabular}

\section{NMDARs, Inhibition}

AOPs including this Key Event

\begin{tabular}{|l|l|l|}
\hline \multicolumn{1}{|c|}{ AOP Name } & $\begin{array}{c}\text { Event } \\
\text { Type }\end{array}$ & Essentiality \\
\hline \begin{tabular}{l|l|} 
Binding of antagonist to N-methyl-D-aspartate receptors (NMDARs) during brain \\
development can trigger neuroinflammation and lead to neurodegeneration
\end{tabular} & KE & Strong \\
\hline $\begin{array}{l}\text { Chronic binding of antagonist to N-methyl-D-aspartate receptors (NMDARs) } \\
\text { during brain development induces impairment of learning and memory abilities }\end{array}$ & KE & Strong \\
\hline
\end{tabular}

How this Key Event works

\section{Level of biological organisation}

Molecular

Biological state: L-glutamate (Glu) is a neurotransmitter with important role in the regulation of brain development and maturation processes. Two major classes of Glu receptors, ionotropic and metabotropic, have been identified. Due to its physiological and pharmacological properties, Glu activates three classes of ionotropic receptors named: $\alpha$-amino-3-hydroxy-5-methyl-4isoazolepropionic acid (AMPA receptors), 2-carboxy-3-carboxymethyl-4-isopropenylpyrrolidine (kainate receptors) and N-methyl-D-aspartate (NMDA receptors, NMDARs), which transduce the postsynaptic signal. Ionotropic glutamate receptors are integral membrane proteins formed by four large subunits that compose a central ion channel pore. In case of NMDA receptors, two NR1 subunits are combined with either two NR2 (NR2A, NR2B, NR2C, NR2D) subunits and less commonly are assembled together with a combination of NR2 and NR3 (A, B) subunits (reviewed in Traynelis et al., 2010). To be activated NMDA receptors require simultaneous binding of both 
glutamate to NR2 subunits and of glycine to either NR1 or NR3 subunits that provide the specific binding sites named extracellular ligand-binding domains (LBDs). Apart from LBDs, NMDA receptor subunits contain three more domains that are considered semiautonomous: 1) the extracellular amino-terminal domain that plays important role in assembly and trafficking of these receptors; 2) the transmembrane domain that is linked with LBD and contributes to the formation of the core of the ion channel and 3) the intracellular carboxyl-terminal domain that influences membrane targeting, stabilization, degradation and post-translation modifications.

Biological compartments: The genes of the NMDAR subunits are expressed in various tissues and are not only restricted to the nervous system. The level of expression of these receptors in neuronal and non-neuronal cells depends on: transcription, chromatin remodelling, mRNA levels, translation, stabilization of the protein, receptor assembly and trafficking, energy metabolism and numerous environmental stimuli (reviewed in Traynelis et al., 2010).

In hippocampus region of the brain, NR2A and NR2B are the most abundant NR2 family subunits. NR2A-containing NMDARs are mostly expressed synaptically, while NR2B-containing NMDARs are found both synaptically and extrasynaptically (Tovar and Westbrook, 1999).

General role in biology: NMDA receptors, when compared to the other Glu receptors, are characterized by higher affinity for Glu, slower activation and desensitisation kinetics, higher permeability for calcium ( $\mathrm{Ca} 2+)$ and susceptibility to potential-dependent blockage by magnesium ions $(\mathrm{Mg} 2+)$. NMDA receptors are involved in fast excitatory synaptic transmission and neuronal plasticity in the central nervous system (CNS). Functions of NMDA receptors:

1. They are involved in cell signalling events converting environmental stimuli to genetic changes by regulating gene transcription and epigenetic modifications in neuronal cells (Cohen and Greenberg, 2008).

2. In NMDA receptors, the ion channel is blocked by extracellular $\mathrm{Mg} 2+$ and $\mathrm{Zn} 2+$ ions, allowing the flow of $\mathrm{Na}+$ and $\mathrm{Ca} 2+$ ions into the cell and $\mathrm{K}+$ out of the cell which is voltage-dependent. $\mathrm{Ca} 2+$ flux through the NMDA receptor is considered to play a critical role in pre- and postsynaptic plasticity, a cellular mechanism important for learning and memory (Barria and Malinow, 2002).

3. The NMDA receptors have been shown to play an essential role in the strengthening of synapses and neuronal differentiation, through long-term potentiation (LTP), and the weakening of synapses, through long-term depression (LTD). All these processes are implicated in the memory and learning function (Barria and Malinow, 2002).

\section{How it is measured or detected}

No OECD methods are available to measure the activation state of NMDA receptors.

The measurement of the activation or the inhibition of NMDA receptors is done indirectly by recording the individual ion channels that are selective to $\mathrm{Na}+\mathrm{K}+$ and $\mathrm{Ca}+2$ by the patch clamp technique. This method relies on lack of measurable ion flux when NMDA ion channel is closed, whereas constant channel specific conductance is recorded at the open state of the receptor (Blanke and VanDongen, 2009). Furthermore, this method is based on the prediction that 
activation or inhibition of an ion channel results from an increase in the probability of being in the open or close state, respectively.

The whole-cell patch clamp recording techniques have also been used to study synapticallyevoked NMDA receptor-mediated excitatory or inhibitory postsynaptic currents (EPSCs and IPSCs, respectively) in brain slices and neuronal cells, allowing the evaluation of the activated or inhibited state of the receptor (Ogdon and Stanfield, 2009; Zhao et al., 2009).

Microelectrode array (MEA) recordings are used to measure electrical activity in cultured neurons in response to NMDA receptor activation or inactivation (Keefer et al., 2001, Gramowski et al., 2000 and Gopal, 2003; Johnstone et al., 2010). MEAs can also be applied in higher throughput platforms to facilitate screening of numerous chemical compounds based on electrical activity measurements (McConnell et al., 2012).

Evidence supporting taxonomic applicability

\begin{tabular}{|l|l|l|l|}
\hline Name & Scientific Name & Evidence & Links \\
\hline human & Homo sapiens & Strong & NCBI \\
\hline rat & Rattus sp. & Strong & NCBI \\
\hline mouse & Mus sp. & Strong & NCBI \\
\hline
\end{tabular}

The cellular expression of the NMDAR subunits has been studied in both adult human cortex and hippocampus (Scherzer et al., 1998) as well as during the development of the human hippocampal formation (Law et al., 2003). The whole-cell patch clamp recording techniques have been used in NMDA receptors expressed in human TsA cells (derivative of the human embryonic kidney cell line HEK-293) (Ludolph et al., 2010). Cell-attached single-channel recordings of NMDA channels has been carried out in human dentate gyrus granule cells acutely dissociated from slices prepared from hippocampi surgically removed from human patients (Lieberman and Mody, 1999).

It is important to note that in invertebrates the glutamatergic synaptic transmission has inhibitory and not excitatory role like in vertebrates. This type of neurotransmission is mediated by glutamate-gated chloride channels that are members of the 'cys-loop' ligand-gated anion channel superfamily found only in invertebrates. The subunits of glutamate-activated chloride channel have been isolated from C. elegans and from Drosophila (Blanke and VanDongen, 2009).

\section{References}

Barria, A., and R. Malinow (2002), Subunit-specific NMDA receptor trafficking to synapses. Neuron 35: 345-353.

Blanke, M.L., and A.M.J. VanDongen (2009), Activation Mechanisms of the NMDA Receptor. In: Van Dongen AM, editor. Biology of the NMDA Receptor. Boca Raton (FL): CRC Press; Chapter 13. Available from: http://www.ncbi.nlm.nih.gov/books/NBK5274/ 
Cohen, S., and M.E. Greenberg (2008), Communication between the synapse and the nucleus in neuronal development, plasticity, and disease. Ann Rev Cell Dev Biol 24: 183-209.

Gopal, K. (2003), Neurotoxic effects of mercury on auditory cortex networks growing on microelectrode arrays: a preliminary analysis. Neurotoxicol Teratol. 25: 69-76.

Gramowski, A., D. Schiffmann and G.W. Gross (2000), Quantification of acute neurotoxic effects of trimethyltin using neuronal networks cultures on microelectrode arrays. Neurotoxicology 21: 331 342.

Johnstone, A.F.M. et al. (2010), Use of microelectrode arrays for neurotoxicity testing in the 21 st century Neurotoxicology 31: 331-350.

Keefer, E. et al. (2001), Acute toxicity screening of novel AChE inhibitors using neuronal networks on microelectrode arrays. Neurotoxicology 22: 3-12.

Law, A.J, et al. (2003), Expression of NMDA receptor NR1, NR2A and NR2B subunit mRNAs during development of the human hippocampal formation. Eur J Neurosci. 18: 1197-1205.

Lieberman, D.N., and I. Mody (1999), Properties of single NMDA receptor channels in human dentate gyrus granule cells. J Physiol. 518: 55-70.

Ludolph, A.G. et al. (2010), Atomoxetine acts as an NMDA receptor blocker in clinically relevant concentrations. Br J Pharmacol. 160: 283-291.

McConnell, E.R. et al. (2012), Evaluation of multi-well microelectrode arrays for neurotoxicity screening using a chemical training set Neurotoxicology 33: 1048-1057.

Ogdon, D., and P. Stanfield (2009), Patch clamp techniques for single channel and whole-cell recording. Chapter 4, pages 53-78. http://www.utdallas.edu/ tres/microelectrode/microelectrodes_ch04.pdf

Scherzer, C.R. et al. (1998), Expression of N-methyl-D-aspartate receptor subunit mRNAs in the human brain: hippocampus and cortex. J Comp Neurol. 390: 75-90.

Tovar, K.R., and G.L. Westbrook (1999), The incorporation of NMDA receptors with a distinct subunit composition at nascent hippocampal synapses in vitro. J Neurosci. 19: 4180-4188.

Traynelis, S. et al. (2010), Glutamate receptor ion channels: structure, regulation, and function. Pharmacol Rev. 62: 405-496.

Zhao, Y. et al. (2009), Patch clamp technique: review of the current state of the art and potential contributions from Nanoengineering. Proc. IMechE 222, Part N: J. Nanoengineering and Nanosystems 149. DOI: 10.1243/17403499JNN149

\section{Calcium influx, Decreased}

AOPs including this Key Event

\begin{tabular}{|l|l|l|}
\hline \multicolumn{1}{|c|}{ AOP Name } & $\begin{array}{c}\text { Event } \\
\text { Type }\end{array}$ & Essentiality \\
\hline $\begin{array}{l}\text { Chronic binding of antagonist to N-methyl-D-aspartate receptors (NMDARs) } \\
\text { during brain development induces impairment of learning and memory abilities }\end{array}$ & KE & Strong \\
\hline $\begin{array}{l}\text { Binding of antagonist to N-methyl-D-aspartate receptors (NMDARs) during brain } \\
\text { development can trigger neuroinflammation and lead to neurodegeneration }\end{array}$ & KE & Strong \\
\hline
\end{tabular}


Level of biological organisation

Cellular

Biological state: Under physiological resting conditions of the cell, the free intracellular $\mathrm{Ca} 2+$ reaches around $100 \mathrm{nM}$, whereas the extracellular $\mathrm{Ca} 2+$ can be found at higher concentrations of $1.2 \mathrm{mM}$ that under certain stimulus may invade the cell (Berridge et al, 2000). Six to seven oxygen atoms surround $\mathrm{Ca} 2+$, whereas the protein chelator of $\mathrm{Ca} 2+$ is the $\mathrm{EF}$ motif that is present in many proteins such as calmodulin (Clapham, 2007). The EF-hand is a helix-loop-helix calcium-binding motif in which two helices pack together at an angle of approximately 90 degrees (Lewit-Bentley and Réty, 2000). The two helices are separated by a loop region where calcium actually binds. The EF notation for the motif is derived from the notation applied to the structure of parvalbumin, in which the $\mathrm{E}$ and $\mathrm{F}$ helices were originally identified as forming this calciumbinding motif.

Biological compartments: $\mathrm{Ca} 2+$ ions accumulate in the cytoplasm, cellular organelles (e.g. mitochondria and endoplasmic reticulum) and nucleus in response to diverse classes of stimuli.

General role in biology: In order to adapt to altered stimulus from exposure to different environmental factors, cells require signal transmission. However, signalling needs messengers whose concentration is modified upon stimulus (Clapham, 2007). Ca2+ ions act as an important intracellular messenger playing the role of ubiquitous signalling molecules and consequently regulate many different cellular functions (Berridge, 2012; Hagenston and Bading, 2011). Given its important role in processes that are fundamental to all cell types, $\mathrm{Ca} 2+$ homeostasis is tightly regulated by intracellular and extracellular mechanisms (Barhoumi et al., 2010). Intracellular $\mathrm{Ca} 2+$ concentration is regulated by opening or closing channels in the plasma membrane. Additionally, the $\mathrm{Ca} 2+$ ions can be released from intracellular stores of the endoplasmic reticulum (ER) through ryanodine receptors (RYRs) or inositol 1,4,5-trisphosphate receptors (InsP3Rs). $\mathrm{Ca} 2+$ homeostasis is also regulated by the mechanisms that remove $\mathrm{Ca} 2+$ from the cytosol, for example pumps in both cell membrane and ER membrane. In addition, cytosolic $\mathrm{Ca} 2+$ regulation involves accumulation of $\mathrm{Ca} 2+$ in mitochondria that have the capacity to buffer the excess of cytoplasmic $\mathrm{Ca} 2+$ ions. In neurons, $\mathrm{Ca} 2+$ ions regulate many critical functions. Firstly, they contribute to dendritic electrical signalling, producing postsynaptic depolarization by the current carried by $\mathrm{Ca} 2+$ ions. Secondly, $\mathrm{Ca} 2+$ activates $\mathrm{Ca} 2+-$-sensitive proteins such as different kinases, calcineurin and calpain, triggering signalling pathways critical for cell physiology. Modification of the gene transcription is the final outcome of the $\mathrm{Ca} 2+$ ions impact on long-term modifications affecting neurotransmitters release (reviewed in Neher and Sakaba, 2008), neuronal differentiation, synapse function and cell viability (Clapham, 2007; Higley and Sabatini, 2012). Thus, the $\mathrm{Ca} 2+$ that enters and accumulates in cytoplasm and nucleus is a central signalling molecule that regulates synapse and neuronal cell function, including learning and memory processes (Berridge, 2012; Hagenston and Bading, 2011).

How it is measured or detected

No OECD method is available to measure intracellular $\mathrm{Ca} 2+$. 
The gold standard method for measuring $\mathrm{Ca} 2+$ current through NMDA receptor is patch clamp electrophysiology (Blanke and VanDongen, 2009).

In vitro, well-established flow cytometric or high content imaging analysis with specific fluorescent dyes (Ca2+-sensitive fluorophores) such as Fura-2, Oregon Green-BAPTA, Fluo-4 and X-Rhod exist for determination of intracellular $\mathrm{Ca} 2+$ concentration. The use of different fluorometric calcium indicators in neuroscience and neurotoxicology have been recently reviewed by Grienberger and Konnerth (2012) and Calvo et al (2015).

Barhoumi et al. 2010 summarised all the methods to measure cytosolic $\mathrm{Ca} 2+$ alterations due to exposure to neurotoxic compounds, including steady state, short-term kinetic measurements of stimulated $\mathrm{Ca} 2+$ transients and dynamic measurements. This paper further discusses the strengths and weaknesses of each approach in intracellular $\mathrm{Ca} 2+$ measurements and its applicability in high throughput screening.

For quantitative estimation of $\mathrm{Ca} 2+$ in dendritic spines, besides of $\mathrm{Ca} 2+$-sensitive fluorophores the use of two-photon released caged neurotransmitters has been suggested as it allows direct stimulation of visualized spines (Higley and Sabatini, 2012). In Higley and Sabatini 2012 further technical information can be found in relation to study $\mathrm{Ca} 2+$ in dendritic spines.

Furthermore, there are three methods for measuring $\mathrm{Ca} 2+$ influx in NMDA receptors that involve the measurement of 1) relative $\mathrm{Ca} 2+$ permeability, 2) channel blockage by $\mathrm{Ca} 2+$, and 3 ) fractional $\mathrm{Ca} 2+$ currents from whole-cell currents determined in the presence of high concentrations of intracellular Fura-2 (Traynelis et al., 2010).

In vivo, two-photon $\mathrm{Ca} 2+$ imaging using $\mathrm{Ca} 2+$-sensitive fluorescent indicators that measure changes in intracellular $\mathrm{Ca} 2+$ concentration as a readout for suprathreshold and subthreshold neuronal activity has also been used to study learning and memory in live rodents (Chen et al., 2013) The last two decades the neuronal function of the larval and adult zebrafish has been extensively studied using $\mathrm{Ca} 2+$ imaging methods. By applying simple $\mathrm{Ca} 2+$ indicators such as dextran or acetoxymethyl esters to more powerful genetically encoded $\mathrm{Ca} 2+$ indicators, zebrafish provides a transparent model where live $\mathrm{Ca} 2+$ imaging can be successfully achieved (Kettunen, 2012).

Evidence supporting taxonomic applicability

\begin{tabular}{|l|l|l|l|}
\hline \multicolumn{1}{|c|}{ Name } & Scientific Name & Evidence & Links \\
\hline human & Homo sapiens & Strong & NCBI \\
\hline rat & Rattus norvegicus & Strong & NCBI \\
\hline mice & Mus gratus & Strong & NCBI \\
\hline zebrafish & Danio rerio & Strong & NCBI \\
\hline
\end{tabular}


$\mathrm{Ca} 2+$ homeostatic system is known to be highly conserved throughout evolution and is present from humans to invertebrates (Case et al., 2007).

\section{References}

Barhoumi, R. et al. (2010), Image analysis of $\mathrm{Ca} 2+$ signals as a basis for neurotoxicity assays: promises and challenges. Neurotoxicol Teratol. 32: 16-24.

Berridge, M.J., P. Lipp and M.D. Bootman (2000), The versatility and universality of calcium signalling. Nat Rev Mol Cell Biol. 1:11-21.

Berridge, M.J. (2012), Calcium signalling remodelling and disease. Biochem Soc Trans. 40: 297-309.

Blanke, M.L., and A.M.J. VanDongen (2009), Activation Mechanisms of the NMDA Receptor. In: Van Dongen AM, editor. Biology of the NMDA Receptor. Boca Raton (FL): CRC Press; Chapter 13. Available from: http://www.ncbi.nlm.nih.gov/books/NBK5274/

Calvo, M., C. Villalobos and L. Núñez (2015), Calcium imaging in neuron cell death. Methods Mol Biol. 1254: 73-85.

Case, R.M. et al. (2007), Evolution of calcium homeostasis: from birth of the first cell to an omnipresent signalling system. Cell Calcium 42: 345-350.

Chen, J.L. et al. (2013), Imaging neuronal populations in behaving rodents: paradigms for studying neural circuits underlying behavior in the mammalian cortex. J Neurosci. 33: 17631-17640.

Clapham, D.E. (2007), Calcium signaling. Cell 131: 1047-1058.

Grienberger, C., and A. Konnerth (2012), Imaging calcium in neurons. Neuron 73: 862-885.

Hagenston, A.M., and H. Bading (2011), Calcium Signaling in Synapse-to-Nucleus Communication. Cold Spring Harb Perspect Biol. 3: a004564.

Higley, M.J., and B.L. Sabatini (2012), Calcium signalling in dendritic spines. Cold Spring Harb Perspect Biol. 4: a005686.

Kettunen, P. (2012), Calcium imaging in the zebrafish. Adv Exp Med Biol. 740: 1039-1071.

Neher, E., and T. Sakaba (2008), Multiple roles of calcium ions in the regulation of neurotransmitter release. Neuron 59: 861-872.

Traynelis, S. et al. (2010), Glutamate receptor ion channels: structure, regulation, and function. Pharmacol Rev. 62: 405-496. 


\section{Release of BDNF, Reduced}

Release of BDNF, Reduced

AOPs including this Key Event

\begin{tabular}{|l|l|l|}
\hline \multicolumn{1}{|c|}{ AOP Name } & $\begin{array}{l}\text { Event } \\
\text { Type }\end{array}$ & Essentiality \\
\hline $\begin{array}{l}\text { Chronic binding of antagonist to N-methyl-D-aspartate receptors (NMDARs) } \\
\text { during brain development induces impairment of learning and memory abilities }\end{array}$ & KE & Strong \\
\hline \begin{tabular}{l|l|} 
Inhibition of Na+/I- symporter (NIS) decreases TH synthesis leading to learning \\
and memory deficits in children
\end{tabular} & KE & Strong \\
\hline $\begin{array}{l}\text { Binding of antagonist to N-methyl-D-aspartate receptors (NMDARs) during brain } \\
\text { development can trigger neuroinflammation and lead to neurodegeneration }\end{array}$ & KE & Weak \\
\hline
\end{tabular}

How this Key Event works

\section{Level of biological organisation}

Molecular

Biological state: BDNF belongs to a family of closely related neurotrophic factors named neurotrophins and is widely expressed in the developing and mature CNS. In the rodent cortex, postnatal BDNF expression is initially low but slowly increases to reach high levels around weaning. Therefore, BDNF expression peaks at a time when both structural and functional maturation of cortical circuitry occurs. During postnatal development, BDNF levels are dynamically regulated, in part by neuronal activity dependent mechanisms (Waterhouse and Xu, 2009). Glutamate has been shown to increase the transcription and release of BDNF. Indeed, BDNF is synthesized, stored and released from glutamatergic neurons (Lessmann et al., 2003).

Biological compartments: BDNF initially is synthesized as precursor proteins (proBDNF), which is processed intracellularly to be transformed in its mature form (mBDNF) after proteolytically cleaved in the synaptic cleft by plasmin which is a protease activated by tissue plasminogen activator (tPA) (Cohen-Cory et al., 2010). proBDNF is constantly secreted while tPA release and mBDNF production depends on neuronal excitation (Head et al., 2009). Storage and activity-dependent release of BDNF has been demonstrated in both dendrites and axon terminals (Waterhouse and $\mathrm{Xu}, 2009$ ). More specifically, in hippocampus, BDNF appears to be stored in dendritic processes of neurons (Balkowiec and Katz, 2002). BDNF is abundant in cerebellum and cortex and has also been measured in cerebrospinal fluid (CSF) (Zhang et al., 2008), whole blood, plasma, serum (plasma without clotting factors) and platelets (Trajkovska et al., 2007). BDNF has been found to be produced by astrocytes under both physiological and pathological conditions (Endo, 2005; Coco et al., 2013; Nelson and Alkon, 2014).

In humans, mBDNF is sequestered in platelets, consequently BDNF can reach all tissues and organs. Lymphocytic cells have been shown to express BDNF in vitro similarly to eosinophils, dendritic cells, and endothelial cells. The visceral and airway epithelium are also significant 
sources of BDNF. Female reproductive system including ovaries, placenta and uterus also express BDNF (Wessels et al., 2014).

General role in biology: The biological functions of $\mathrm{mBDNF}$ are mediated by binding to tyrosine kinase B (TrkB) receptor that leads to the activation of three major intracellular signalling pathways, including MAPK, PI3K and PLC $\gamma 1$ (Soulé et al., 2006). TrkB-mediated signaling regulates gene transcription in the nucleus through the activation of several transcription factors. These genes are involved in neurite outgrowth, synaptogenesis, synapse maturation and stabilization (Pang et al., 2004; Lu et al., 2005; Nelson and Alkon, 2014).

On the other hand, proBDNF binds to the p75 neurotrophin receptor (p75NTR) and activates RhoA, a small GTPase that regulates actin cytoskeleton polymerization leading to inhibition of axonal elongation, growth cone collapse, and apoptosis (Dubreuil et al., 2003; Yamauchi et al., 2004; Head et al., 2009).

How it is measured or detected

No OECD methods are available to measure BDNF protein and mRNA levels. Depending on the tissue or fluid measurements distinct methods are used.

Brain tissue: BDNF protein levels can be measured by commercial available antibody sandwich ELISA kits, Western blotting, immunohistochemistry and immunofluorescence. BDNF primers for different exons are available to determine mRNA levels by RT-PCR. The Bdnf gene consists of multiple alternative exons (ten in human, eight in rodents and six in lower vertebrates), and a single exon coding for the entire pro-BDNF protein (Cohen-Cory et al., 2010).

Cerebro-spinal fluid (CSF): There are available commercial antibody sandwich ELISA kits (Trajkovska et al., 2007) and immunobead-based multiplex assays for high throughput screening (Zhang et al., 2008).

Whole blood, serum, plasma and platelets: There are several commercial double antibody sandwich ELISA kits that can be used for identification of BDNF levels in biological fluids (Trajkovska et al., 2007).

Methodological considerations that have to be taken into account during sample preparation and measurement of BDNF by ELISA have been recently reviewed in Elfving et al. 2010. A study measuring BDNF by a commercially available ELISA kit in various tissues and biological liquids derived from distinct species revealed that BDNF is undetectable in mouse blood and pig plasma (Klein et al., 2011). This study also showed that in most cases BDNF levels are comparable to levels reported in humans and that there is positive correlation between blood BDNF levels and hippocampal BDNF levels in rats and pigs (Klein et al., 2011). 
Evidence supporting taxonomic applicability

\begin{tabular}{|l|l|l|l|}
\hline Name & Scientific Name & Evidence & Links \\
\hline human & Homo sapiens & Strong & NCBI \\
\hline rat & Rattus sp. & Strong & NCBI \\
\hline mouse & Mus sp. & Strong & NCBI \\
\hline
\end{tabular}

$B d n f$ gene is well conserved among species, from avian species to fish and mammals (Heinrich and Pagtakhan, 2004; Aid et al., 2007; Pruunsild et al., 2007, Brenowitz, 2013).

Klein et al. (2011) examined blood, serum, plasma and brain-tissue and measured BDNF levels in three different mammalian species: rat, pig, and mouse, using an ELISA method, whereas Trajkovska et al. 2007 determined BDNF levels in human blood.

\section{References}

Aid, T. et al. (2007), Mouse and rat BDNF gene structure and expression revisited. J Neurosci Res. 85: 525-535.

Balkowiec, A., and D.M. Katz (2002), Cellular mechanisms regulating activity-dependent release of native brain-derived neurotrophic factor from hippocampal neurons. J Neurosci. 22: 10399-10407.

Brenowitz, E.A. (2013), Testosterone and brain-derived neurotrophic factor interactions in the avian song control system. Neuroscience 239: 115-123.

Coco, M. et al. (2013), Sodium L-lactate differently affects brain-derived neurothrophic factor, inducible nitric oxide synthase, and heat shock protein $70 \mathrm{kDa}$ production in human astrocytes and SH-SY5Y cultures.J Neurosci Res. 91: 313-320.

Cohen-Cory, S. et al. (2010), Brain-derived neurotrophic factor and the development of structural neuronal connectivity. Dev Neurobiol. 70: 271-288.

Dubreuil, C.I., M.J. Winton and L. McKerracher (2003), Rho activation patterns after spinal cord injury and the role of activated Rho in apoptosis in the central nervous system. J Cell Biol. 162: 233-243.

Elfving, B., P.H. Plougmann and G. Wegener (2010), Detection of brain-derived neurotrophic factor (BDNF) in rat blood and brain preparations using ELISA: pitfalls and solutions. J Neurosci Methods 187: 73-77.

Endo, T. (2005), Glycans and glycan-binding proteins in brain: galectin-1-induced expression of neurotrophic factors in astrocytes. Curr Drug Targets. 6:427-436.

Head, B.P. et al. (2009), Inhibition of p75 neurotrophin receptor attenuates isoflurane-mediated neuronal apoptosis in the neonatal central nervous system. Anesthesiology 110: 813-825.

Heinrich, G., and C.J. Pagtakhan (2004), Both 5' and 3' flanks regulate Zebrafish brain-derived neurotrophic factor gene expression. BMC Neurosci. 5: 19.

Klein, A.B. et al. (2011), Blood BDNF concentrations reflect brain-tissue BDNF levels across species. Int J Neuropsychopharmacol. 14: 347-353.

Lessmann, V., K. Gottmann and M. Malcangio (2003), Neurotrophin secretion: current facts and future prospects. Prog Neurobiol. 69: 341-374.

Lu, B., P.T. Pang and N.H. Woo (2005), The yin and yang of neurotrophin action. Nat Rev Neurosci. 6: 603-614. 
Nelson, T.J., and D.L. Alkon (2014), Molecular regulation of synaptogenesis during associative learning and memory. Brain Res. pii: S0006-8993(14)01660-6. doi: 10.1016/j.brainres.2014.11.054.

Pang, P.T. et al. (2004), Cleavage of proBDNF by tPA/plasmin is essential for long-term hippocampal plasticity. Science. 306: 487-491.

Pruunsild, P. et al. (2007), Dissecting the human BDNF locus: bidirectional transcription, complex splicing, and multiple promoters. Genomics. 90: 397-406.

Soule', J., E. Messaoudi and C.R. Bramham (2006), Brain-derived neurotrophic factor and control of synaptic consolidation in the adult brain. Biochem Soc Trans. 34: 600-604.

Trajkovska, V. et al. (2007), Measurements of brain-derived neurotrophic factor: methodological aspects and demographical data. Brain Res Bull. 73: 143-149.

Waterhouse, E.G., and B. Xu (2009), New insights into the role of brain-derived neurotrophic factor in synaptic plasticity. Mol Cell Neurosci. 42: 81-89.

Wessels, J.M. et al. (2014), The Brain-Uterus Connection: Brain Derived Neurotrophic Factor (BDNF) and Its Receptor (Ntrk2) Are Conserved in the Mammalian Uterus. PLoS ONE 9: e94036.

Yamauchi, J., J.R. Chan and E.M. Shooter (2004), Neurotrophins regulate Schwann cell migration by activating divergent signaling pathways dependent on Rho GTPases. Proc Natl Acad Sci U S A. 101: 8774-8779.

Zhang, J. et al. (2008), CSF multianalyte profile distinguishes Alzheimer and Parkinson diseases. Am J Clin Pathol. 129: 526-529.

\section{Dendritic morphology, Aberrant}

AOPs including this Key Event

\begin{tabular}{|l|l|l|}
\hline \multicolumn{1}{|c|}{ AOP Name } & $\begin{array}{c}\text { Event } \\
\text { Type }\end{array}$ & Essentiality \\
\hline $\begin{array}{l}\text { Chronic binding of antagonist to N-methyl-D-aspartate receptors (NMDARs) } \\
\text { during brain development induces impairment of learning and memory abilities }\end{array}$ & KE & Strong \\
\hline
\end{tabular}

How this Key Event works

Level of biological organisation

Cellular

Biological state: After becoming post-mitotic and during the differentiation process, neuronal cells undergo lengthening, branching, dendrite and dendritic spine formation (Scott and Luo, 2001). In human, dendrites appear as early as 13.5 weeks gestation in the subplate neurons while arborisation begins only after 26 weeks (Mrzljak et al., 1988 and Mrzljak et al., 1990). In rodents, during the first postnatal week, both pyramidal and nonpyramidal neurons go through extensive and fast dendrite growth, branching, and elaboration. Dendrite arbor's capacity and complexity continue to increase in the second and third postnatal week, however, much slower. During the same developmental window, dendritic spines begin to appear as a group. The first spines look like filopodia (Dailey and Smith, 1996; Fiala et al., 1998). Filopodia can grow and retract within seconds to minutes, permitting them to explore and identify appropriate presynaptic targets 
(Dailey and Smith, 1996). As dendrite spines mature, these long and thin structures change and the spines shorten and acquire a bulbous ending or 'head' (Dailey and Smith, 1996). At this final stage of dendrite growth, a neuron possesses a dynamic dendrite tree, which has a greater potential for connectivity and synapse creation because of dendritic spine formation.

Biological compartments: Dendritic morphology determines many aspects of neuronal function, including action potential propagation and information processing. Postsynaptic density-95 (PSD95), a protein involved in dendritic spine maturation and clustering of synaptic signalling proteins, plays a critical role in regulating dendrite outgrowth and branching, independent of its synaptic functions. In immature neurons, over-expression of PSD-95 decreases the proportion of primary dendrites that undergo additional branching, resulting in a marked reduction of secondary dendrite number. Conversely, knocking down PSD-95 protein in immature neurons increases secondary dendrite number. Binding of cypin to PSD-95 (that regulates PSD-95 location) correlates with formation of stable dendrite branches. Finally, overexpression of PSD-95 in COS-7 cells disrupts microtubule organization, indicating that PSD-95 may modulate microtubules to regulate dendritic branching. Proteins primarily involved in synaptic functions can also play developmental roles in shaping how a neuron patterns its dendrite branches (Kornau et al., 1995). New spines containing PSDs are formed by conversion of dynamic filopodia-like spine precursors in which PSDs appeared de novo, or by direct extension of spines or spine precursors carrying preformed PSDs from the shaft. PSDs are therefore highly dynamic structures that can undergo rapid structural alteration within dendrite shafts, spines and spine precursors, permitting rapid formation and re-modelling of synaptic connections in developing CNS tissues.

Dendritic spines are important sites of excitatory synaptic transmission and changes in the strength of these synapses are likely to underlie important higher brain functions such as learning and memory. Spines form biochemical compartments for isolating reactions that occur at one synapse from those at other synapses thereby providing a possible way to ensure the specificity of connections between neurons in the brain.

The stages of dendrite development have been clearly described in neurons located in the developing rodent cortex and hippocampus (Dailey and Smith, 1996; Fiala et al., 1998; Redmond, 2008) and human prefrontal cortex (Mrzljak et al., 1988; Mrzljak et al., 1990).

General role in biology: Functionally, dendrites serve as post-synaptic part of a synapse, playing a critical role in the processing of information transmitted through synapses. They receive the majority of synaptic inputs comparing to the soma or the axon. Consequently, it is not surprising that postsynaptic activity is closely related to the properties of the dendritic arbor itself, implying that the dendrites strongly influence and control synaptic transmission and plasticity (Sjöström et al., 2008).

\section{How it is measured or detected}

No OECD methods are available to measure dendritic processes.

Elaboration of dendritic processes is measured from electron and fluorescent micrographs. These processes are identified primarily by the presence of microtubule associated protein 2 (MAP-2) and the absence of components characteristic of axons and glia (e.g. small vesicles, myelin, glial 
filaments). These measurements can also be carried out by automated imaging systems in cells prepared for immunohistochemistry with specific antibodies that recognise MAP-2 (Harrill and Mundy, 2011).

Two-photon time-lapse images can be used to visualise dendrites in GFP-transfected neurons, whereas Golgi Stain Kit is used to measure both dendrites and dendritic spines. A combination of Golgi-Cox and immunofluorescence using confocal microscopy has also been suggested for the visualisation of dendrites in brain slices derived either from rodents or non-human primates (Levine et al., 2013).

The morphological analysis of neurons, include the use of fluorescent markers, such as DiI (1,1'dioctadecyl-3,3,3',3'-tetramethylindocarbocyanine perchlorate) that permits not only the visualisation of detailed dendritic arborisations and spines in cell culture and tissue sections but also permits the quantitative analysis of dendritic spines (Cheng et al., 2014).

Fluorescent labelling for MARCM (mosaic analysis with a repressible cell marker) system can also be used but only in case of transparent larval body wall found in Drosophila.

Evidence supporting taxonomic applicability

\begin{tabular}{|l|l|l|l|}
\hline \multicolumn{1}{|c|}{ Name } & \multicolumn{1}{|c|}{ Scientific Name } & Evidence & Links \\
\hline human & Homo sapiens & Strong & NCBI \\
\hline rat & Rattus sp. & Strong & NCBI \\
\hline mouse & Mus sp. & Strong & NCBI \\
\hline chicken & Gallus sp. & Strong & NCBI \\
\hline fruit fly & Drosophila melanogaster & Strong & NCBI \\
\hline
\end{tabular}

Drosophila is one of the best-studied models that allow examining how diverse dendrite morphologies are formed during development (Grueber et al., 2002). The chick embryo (Gallus domesticus) is another important model in vertebrate developmental neurobiology where the dendritic arbor development has been extensively studied (Rubel and Fritzsch, 2002). Different methods have also been used to study dendritic arborisation and spine formation in brain sections and cell cultures derived by rodents (Stansfield et al., 2012) and primates (Khazipov et al., 2001).

\section{References}

Cheng, C., O. Trzcinski and L.C. Doering (2014), Fluorescent labeling of dendritic spines in cell cultures with the carbocyanine dye "DiI". Front Neuroanat. 8: 30.

Dailey, M.E., and S.J. Smith (1996), The dynamics of dendritic structure in developing hippocampal slices. J Neurosci. 16: 2983-2994.

Fiala, J.C. et al. (1998), Synaptogenesis via dendritic filopodia in developing hippocampal area CA1. J Neurosci. 18: 8900-8911. 
Grueber, W.B., L.Y. Jan and Y.N. Jan (2002), Tiling of the Drosophila epidermis by multidendritic sensory neurons. Development 129: 2867-2878.

Harrill, J.A., and W.R. Mundy (2011), Quantitative assessment of neurite outgrowth in PC12 cells. Methods Mol Biol. 758: 331-348.

Khazipov, R. et al. (2001), Early development of neuronal activity in the primate hippocampus in utero. J Neurosci. 21: 977097-81.

Kornau, H.C. et al. (1995), Domain interaction between NMDA receptor subunits and the postsynaptic density protein PSD-95. Science 269: 1737-1740.

Levine, N.D. et al. (2013), Advances in thin tissue Golgi-Cox impregnation: fast, reliable methods for multi-assay analyses in rodent and non-human primate brain. J Neurosci Methods 213: 214-227.

Mrzljak, L. et al. (1988), Prenatal development of neurons in the human prefrontal cortex: I. A qualitative Golgi study. J Compar Neurol. 271: 355-386.

Mrzljak, L. et al. (1990), Neuronal development in human prefrontal cortex in prenatal and postnatal stages. Prog Brain Res. 85: 185-222.

Redmond, L. (2008), Translating neuronal activity into dendrite elaboration: signaling to the nucleus. Neurosignals 16: 194-208.

Rubel, E.W., and B. Fritzsch (2002), Auditory system development: primary auditory neurons and their targets. Annu Rev Neurosci. 25: 51-101.

Scott, E.K., and L. Luo (2001), How do dendrites take their shape? Nat Neurosci. 4: 359-365.

Sjöström, P.J. et al. (2008), Dendritic excitability and synaptic plasticity. Physiol Rev. 88: 769-840.

Stansfield, K.H. et al. (2012), Dysregulation of BDNF-TrkB signaling in developing hippocampal neurons by $\mathrm{Pb}(2+)$ : implications for an environmental basis of neurodevelopmental disorders. Toxicol Sci. 127: 277-295.

\section{Presynaptic release of glutamate, Reduced}

AOPs including this Key Event

\begin{tabular}{|l|l|l|}
\hline \multicolumn{1}{|c|}{ AOP Name } & $\begin{array}{c}\text { Event } \\
\text { Type }\end{array}$ & Essentiality \\
\hline $\begin{array}{l}\text { Chronic binding of antagonist to N-methyl-D-aspartate receptors (NMDARs) } \\
\text { during brain development induces impairment of learning and memory abilities }\end{array}$ & KE & Strong \\
\hline
\end{tabular}

How this Key Event works

Level of biological organisation

Molecular

Biological state: Glutamate is an amino acid with neurotransmitter function that is stored in presynaptic vesicles by the action of vesicular glutamate transporters (VGLUTs) and under physiological conditions is found at a concentration of $100 \mathrm{mmol} / \mathrm{L}$ per vesicle. Different mechanisms are involved in the release of glutamate (reviewed in Meldrum, 2000). Glutamate is mainly released from the vesicles in a Ca2+-dependent mechanism that involves $\mathrm{N}$ - and P/Q-type 
voltage-dependent $\mathrm{Ca} 2+$ channels, closely linked to vesicle docking sites. However, glutamate can also be released by reverse operation during reduction of $\mathrm{Na}+$ and $\mathrm{K}+$ gradient across the membrane like for example during cerebral ischemia. Interestingly, the synaptic release of glutamate is controlled by a wide range of presynaptic receptors that are not only glutamatergic like Group II and Group III of glutamate metabotropic receptors but also cholinergic such as nicotinic and muscarinic, adenosine (A1), kappa opioid, $\gamma$-aminobutyric acid (GABA)B, cholecystokinin and neuropeptide Y (Y2) receptors.

The synaptic effects of glutamate are rapidly terminated by action of glutamate transporters [excitatory amino acid transporters (EAATs)] located on the plasma membrane of astrocytes and neurons. Therefore, pre-synaptically released glutamate is mostly transported via EAATs to astrocytes and only a small portion is re-uptaken from the synaptic cleft into the presynaptic terminals (Rundfeldt et al., 1994; Blanke and VanDongen, 2009).

Following its release, glutamate exerts its effects via ionotropic and metabotropic receptors. Although glutamate is available for binding to receptors for a short time, NMDA receptors show high affinity for this specific neurotransmitter that causes their activation compared to other receptors.

Biological compartments: Glutamate is the most abundant amino acid in the diet, consequently is found at higher levels in plasma compared to cerebrospinal fluid. The blood brain barrier prevents the entry of glutamate, meaning that the glutamate present in CNS is derived from de novo synthesis of this neurotransmitter relying on the recycling of the main resources. Glutamine and $\alpha$-ketoglutarate are the major precursors of glutamate. Glutamine is converted via phosphateactivated glutaminase to glutamate and ammonia, whereas $\alpha$-ketoglutarate is transaminated into glutamate (Platt, 2007). In glial cells, the glutamate is metabolised via glutamine synthase into glutamine or metabolised into $\alpha$-ketoglutarate. These products are actively transported out of the glial cells and back into the pre-synaptic terminals for subsequent re-synthesis and storage of glutamate.

Five transporters of glutamate have been identified in the CNS. Two are expressed predominantly in glia and three in neurons (reviewed in Meldrum, 2000). The presence of glutamate has also been demonstrated in other tissues and organs as glutamate receptors have been found to be expressed in pancreatic $\beta$-cells, osteoblasts and osteoclasts of bones (Nedergaard et al., 2002).

General role in biology: In mature nervous system, glutamate is known to play important role in synaptic plasticity. Similarly important is this neurotransmitter during development where it regulates neurogenesis, neurite outgrowth, synaptogenesis and apoptosis (reviewed in Mattson, 1996; Meldrum, 2000; Mattson, 2008).

The proper functioning of the central nervous system relays on the physiological homeostasis between glutamate and GABA, creating the opposite excitatory/inhibitory forces in the brain. Together, these two neurotransmitters constitute more than $90 \%$ of all neurotransmission. If this homeostasis is disturbed it could lead to anxiety disorders (Wieronska et al., 2015). 


\section{How it is measured or detected}

No OECD methods are available to measure glutamate release.

There are radioactive assays like $[3 \mathrm{H}]$ glutamate release assay and spectrophotometric commercially available kits to measure glutamate in cell culture medium (release) or intracellular (cell lysate) using LC-MS. Furthermore, neurotransmitters including glutamate can be measured by HPLC with fluorescence detector.

Evidence supporting taxonomic applicability

\begin{tabular}{|l|l|l|l|}
\hline \multicolumn{1}{|c|}{ Name } & Scientific Name & Evidence & Links \\
\hline humans & Homo sapiens & Strong & NCBI \\
\hline rat & Rattus sp. & Strong & NCBI \\
\hline mice & Mus sp. & Strong & NCBI \\
\hline
\end{tabular}

Whereas glutamatergic transmission in vertebrates is excitatory, mediated by glutamate-gated cation channels, glutamate serves as both an excitatory and an inhibitory transmitter in invertebrates (Cleland, 1996).

\section{References}

Blanke, M.L., and A.M.J. VanDongen (2009), Activation Mechanisms of the NMDA Receptor. In: Van Dongen AM, editor. Biology of the NMDA Receptor. Boca Raton (FL): CRC Press; Chapter 13. Available from: http://www.ncbi.nlm.nih.gov/books/NBK5274/

Cleland, T.A. (1996), Inhibitory glutamate receptor channels. Mol Neurobiol. 13: 97-136.

Mattson, M.P. (1996), Calcium and free radicals: mediators of neurotrophic factor and excitatory transmitter regulated developmental plasticity and cell death. Perspect Dev Neurobiol. 3: 79-91.

Mattson, M.P. (2008), Glutamate and neurotrophic factors in neuronal plasticity and disease. Ann N Y Acad Sci. 1144: 97-112.

Meldrum, B.S. (2000), Glutamate as a neurotransmitter in the brain: review of physiology and pathology. J Nutr. 130: 1007S-1015S.

Nedergaard, M., T. Takano and A.J. Hansen (2002), Beyond the role of glutamate as a neurotransmitter. Nat Rev Neurosci. 3: 748-755.

Platt, S.R. (2007), The role of glutamate in central nervous system health and disease-a review. Vet J. 173: 278-286.

Rundfeldt, C., P. Wlaź and W. Löscher (1994), Anticonvulsant activity of antagonists and partial agonists for the NMDAR-associated glycine site in the kindling model of epilepsy. Brain Res. 653: 125-130.

Wieronska, J.M. et al. (2015), mGlu ${ }_{5}-\mathrm{GABAB}$ interplay in animal models of positive, negative and cognitive symptoms of schizophrenia.Neurochem Int. 88: 97-109. 


\section{Cell injury/death, N/A}

AOPs including this Key Event

\begin{tabular}{|c|c|c|}
\hline AOP Name & $\begin{array}{l}\text { Event } \\
\text { Type }\end{array}$ & Essentiality \\
\hline $\begin{array}{l}\text { Binding of agonists to ionotropic glutamate receptors in adult brain causes } \\
\text { excitotoxicity that mediates neuronal cell death, contributing to learning and } \\
\text { memory impairment. }\end{array}$ & $\mathrm{KE}$ & Strong \\
\hline $\begin{array}{l}\text { Chronic binding of antagonist to N-methyl-D-aspartate receptors (NMDARs) } \\
\text { during brain development induces impairment of learning and memory abilities }\end{array}$ & $\mathrm{KE}$ & Strong \\
\hline Protein Alkylation leading to Liver Fibrosis & $\mathrm{KE}$ & Strong \\
\hline $\begin{array}{l}\text { Binding of antagonist to N-methyl-D-aspartate receptors (NMDARs) during brain } \\
\text { development can trigger neuroinflammation and lead to neurodegeneration }\end{array}$ & KE & Moderate \\
\hline Lysosomal damage leading to liver inflammation & KE & Strong \\
\hline
\end{tabular}

How this Key Event works

\section{Level of biological organisation}

Cellular

Two types of cell death can be distinguished by morphological features, although it is likely that these are two ends of a spectrum with possible intermediate forms. Apoptosis involves shrinkage, nuclear disassembly, and fragmentation of the cell into discrete bodies with intact plasma membranes. These are rapidly phagocytosed by neighbouring cells. An important feature of apoptosis is the requirement for adenosine triphosphate (ATP) to initiate the execution phase. In contrast, necrotic cell death is characterised by cell swelling and lysis. This is usually a consequence of profound loss of mitochondrial function and resultant ATP depletion, leading to loss of ion homeostasis, including volume regulation, and increased $\mathrm{Ca}^{2+}$. The latter activates a number of nonspecific hydrolases (i.e. proteases, nucleases, and phospholipases) as well as calcium dependent kinases. Activation of calpain $\mathrm{I}$, the $\mathrm{Ca}^{2+}$-dependent cysteine protease cleaves the death-promoting Bcl-2 family members Bid and Bax which translocate to mitochondrial membranes, resulting in release of truncated apoptosis-inducing factor (tAIF), cytochrome $\mathrm{c}$ and endonuclease in the case of Bid and cytochrome $\mathrm{c}$ in the case of Bax. tAIF translocates to cell nuclei, and together with cyclophilin $\mathrm{A}$ and phosphorylated histone $\mathrm{H} 2 \mathrm{AX}(\gamma \mathrm{H} 2 \mathrm{AX})$ is responsible for DNA cleavage, a feature of programmed necrosis. Activated calpain I has also been shown to cleave the plasma membrane $\mathrm{Na}^{+}-\mathrm{Ca}^{2+}$ exchanger, which leads to build-up of intracellular $\mathrm{Ca}^{2+}$, which is the source of additional increased intracellular $\mathrm{Ca}^{2+}$. Cytochrome $\mathrm{c}$ in cellular apoptosis is a component of the apoptosome.

DNA damage activates nuclear poly(ADP-ribose) polymerase-1(PARP-1), a DNA repair enzyme. PARP-1 forms poly(ADP-ribose) polymers, to repair DNA, but when DNA damage is extensive, PAR accumulates, exits cell nuclei and travels to mitochondrial membranes, where it, like calpain $\mathrm{I}$, is involved in AIF release from mitochondria. A fundamental distinction between necrosis and apoptosis is the loss of plasma membrane integrity; this is integral to the former but not the latter. 
As a consequence, lytic release of cellular constituents promotes a local inflammatory reaction, whereas the rapid removal of apoptotic bodies minimises such a reaction. The distinction between the two modes of death is easily accomplished in vitro but not in vivo. Thus, although claims that certain drugs induce apoptosis have been made, these are relatively unconvincing. DNA fragmentation can occur in necrosis, leading to positive TUNEL staining. Conversely, when apoptosis is massive, it can exceed the capacity for rapid phagocytosis, resulting in the eventual appearance of secondary necrosis.

Two alternative pathways - either extrinsic (receptor-mediated) or intrinsic (mitochondriamediated) - lead to apoptotic cell death. The initiation of cell death begins either at the plasma membrane with the binding of TNF or FasL to their cognate receptors or within the cell. The latter is due to the occurrence of intracellular stress in the form of biochemical events such as oxidative stress, redox changes, covalent binding, lipid peroxidation, and consequent functional effects on mitochondria, endoplasmic reticulum, microtubules, cytoskeleton, or DNA. The intrinsic mitochondrial pathway involves the initiator, caspase-9, which, when activated, forms an "apoptosome" in the cytosol, together with cytochrome c, which translocates from mitochondria, Apaf- 1 and dATP. The apoptosome activates caspase-3, the central effector caspase, which in turn activates downstream factors that are responsible for the apoptotic death of a cell (Fujikawa, 2015). Intracellular stress either directly affects mitochondria or can lead to effects on other organelles, which then send signals to the mitochondria to recruit participation in the death process (Fujikawa, 2015; Malhi et al., 2010). Constitutively expressed nitric oxide synthase (nNOS) is a $\mathrm{Ca}^{2+}$-dependent cytosolic enzyme that forms nitric oxide (NO) from L-arginine, and NO reacts with the free radical such as superoxide $\left(\mathrm{O}^{2-}\right)$ to form the very toxic free radical peroxynitrite $\left(\mathrm{ONOO}^{-}\right)$. Free radicals such as $\mathrm{ONOO}^{-}, \mathrm{O}^{2-}$ and hydroxyl radical $\left(\mathrm{OH}^{-}\right)$damage cellular membranes and intracellular proteins, enzymes and DNA (Fujikawa, 2015; Kaplowitz, 2002; Kroemer et al., 2009; Malhi et al., 2010).

\section{How it is measured or detected}

\section{Necrosis:}

LDH is a soluble cytoplasmic enzyme that is present in almost all cells and is released into extracellular space when the plasma membrane is damaged. To detect the leakage of LDH into cell culture medium, a tetrazolium salt is used in this assay. In the first step, LDH produces reduced nicotinamide adenine dinucleotide (NADH) when it catalyses the oxidation of lactate to pyruvate. In the second step, a tetrazolium salt is converted to a colored formazan product using newly synthesised NADH in the presence of an electron acceptor. The amount of formazan product can be colorimetrically quantified by standard spectroscopy. Because of the linearity of the assay, it can be used to enumerate the percentage of necrotic cells in a sample (Chan et al., 2013).

The MTT assay is a colorimetric assay for assessing cell viability. NAD(P)H-dependent cellular oxidoreductase enzymes may reflect the number of viable cells present. These enzymes are capable of reducing the tetrazolium dye MTT 3-(4,5-dimethylthiazol-2-yl)-2,5diphenyltetrazolium bromide to its insoluble formazan, which has a purple color. Other closely related tetrazolium dyes including XTT, MTS and the WSTs. Tetrazolium dye assays can also be used to measure cytotoxicity (loss of viable cells) or cytostatic activity (shift from proliferation to 
quiescence) of potential medicinal agents and toxic materials. MTT assays are usually done in the dark since the MTT reagent is sensitive to light (Berridge et al., 2005).

Propidium iodide (PI) is an intercalating agent and a fluorescent molecule used to stain necrotic cells. It is cell membrane impermeant so it stains only those cells where the cell membrane is destroyed. When PI is bound to nucleic acids, the fluorescence excitation maximum is $535 \mathrm{~nm}$ and the emission maximum is $617 \mathrm{~nm}$ (Moore et al., 1998).

\section{Apoptosis:}

TUNEL is a common method for detecting DNA fragmentation that results from apoptotic signalling cascades. The assay relies on the presence of nicks in the DNA which can be identified by terminal deoxynucleotidyl transferase or TdT, an enzyme that will catalyse the addition of dUTPs that are secondarily labeled with a marker. It may also label cells that have suffered severe DNA damage.

Caspase activity is measured by fluorescence. During apoptosis, mainly caspase- 3 and -7 cleave PARP to yield an $85 \mathrm{kDa}$ and a $25 \mathrm{kDa}$ fragment. PARP cleavage is considered to be one of the classical characteristics of apoptosis. Antibodies to the $85 \mathrm{kDa}$ fragment of cleaved PARP or to caspase-3 both serve as markers for apoptotic cells that can be monitored using immunofluorescence (Li et al., 2004).

Hoechst 33342 staining: Hoechst dyes are cell-permeable and bind to DNA in live or fixed cells. Therefore, these stains are often called supravital, which means that cells survive a treatment with these compounds. The stained, condensed or fragmented DNA is a marker of apoptosis (Didenko, 2002; Kubbies and Rabinovitch, 1983).

\section{Evidence supporting taxonomic applicability}

\begin{tabular}{|l|l|l|l|}
\hline \multicolumn{1}{|c|}{ Name } & Scientific Name & Evidence & Links \\
\hline human & Homo sapiens & Strong & NCBI \\
\hline human and other cells in culture & & Strong & NCBI \\
\hline Rattus norvegicus & Rattus norvegicus & Strong & NCBI \\
\hline mouse & Mus musculus & Strong & NCBI \\
\hline
\end{tabular}

Cell death is a universal event occurring in cells of any species (Fink and Cookson, 2005).

\section{References}

Berridge, M.V., P.M. Herst and A.S. Tan (2005), Tetrazolium dyes as tools in cell biology: new insights into their cellular reduction. Biotechnol An Rev. 11: 127-152.

Chan, F.K., K. Moriwaki and M.J. De Rosa (2013), Detection of necrosis by release of lactate dehydrogenase (LDH) activity. Methods Mol Biol. 979: 65-70. 
Fink, S.L., and B.T. Cookson (2005), Apoptosis, pyroptosis, and necrosis: mechanistic description of dead and dying eukaryotic cells. Infect Immun. 73: 1907-1916.

Fujikawa, D.G. (2015), The role of excitotoxic programmed necrosis in acute brain injury. Comput Struct Biotechnol J. 13: 212-221.

Kaplowitz, N. (2002), Biochemical and Cellular Mechanisms of Toxic Liver Injury, Semin Liver Dis, vol. 22, no. 2, www.medscape.com/viewarticle/433631 accessed on 20 January 2016.

Kroemer, G. et al. (2009), Classification of cell death: recommendations of the Nomenclature Committee on Cell Death. Cell Death Differ. 16: 3-11.

Kubbies, M., and P.S. Rabinovitch (1983), Flow cytometric analysis of factors which influence the BrdUrd-Hoechst quenching effect in cultivated human fibroblasts and lymphocytes. Cytometry 3: 276-281.

Li, P. et al. (2004), Mitochondrial activation of apoptosis. Cell 116: S57-59.

Loo, D.T. (2002), TUNEL Assay an overview of techniques. Methods in Molecular Biology, vol. 203: In

Situ Detection of DNA Damage, chapter 2, Didenko VV (ed.), Humana Press Inc.

Malhi, H. et al. (2010), Hepatocyte death: a clear and present danger. Physiol Rev. 90: 1165-1194.

Moore, A. et al. (1998), Simultaneous measurement of cell cycle and apoptotic cell death. Methods Cell Biol. 57: 265-278.

\section{Synaptogenesis, Decreased}

Synaptogenesis, Decreased

AOPs including this Key Event

\begin{tabular}{|l|l|l|}
\hline \multicolumn{1}{|c|}{ AOP Name } & $\begin{array}{l}\text { Event } \\
\text { Type }\end{array}$ & Essentiality \\
\hline $\begin{array}{l}\text { Chronic binding of antagonist to N-methyl-D-aspartate receptors (NMDARs) } \\
\text { during brain development induces impairment of learning and memory abilities }\end{array}$ & KE & Strong \\
\hline \begin{tabular}{l|l|} 
Inhibition of Na+/I- symporter (NIS) decreases TH synthesis leading to learning \\
and memory deficits in children
\end{tabular} & KE & Strong \\
\hline $\begin{array}{l}\text { Binding of antagonist to N-methyl-D-aspartate receptors (NMDARs) during brain } \\
\text { development can trigger neuroinflammation and lead to neurodegeneration }\end{array}$ & KE & Moderate \\
\hline
\end{tabular}

How this Key Event works

\section{Level of biological organisation}

Cellular

Biological state: Synaptogenesis is a multi-step process that is crucial for brain development and involves the formation of synapses. It follows axonal migration, at which stage presynaptic and postsynaptic differentiation occurs (Garner et al., 2002). "Synaptic assembly" that refers to the gathering of the appropriate components and "synaptic formation" that is defined by the mechanisms involved in recruitment of molecules required for differentiation, stabilization and maturation of synapse, are the main phases that characterise synaptogenesis (Colón-Ramos, 
2009). Elimination is a physiological step involved in synaptogenesis regarding the synapses that fail to get stabilised and mature.

The first step is the recognition and the establishment of contact between an axon and a dendritic spine in which pre- and postsynaptic neurons play important role. The presynaptic differentiation occurs followed by excretion of neurotransmitters that bind to appropriate receptors located on the target spine. However, a postsynaptic neuron does not passively receive guidance from a presynaptic axon but are the same dendritic filopodia that gradually are transformed into spines that select and engage their presynaptic neurons. The transformation of dendritic filopodia into dendritic spines that involves the expression of the whole postsynaptic machinery such as postsynaptic density (PSD), receptor subunits, scaffolding proteins and actin cytoskeleton, is the first step to give nascent synapses. However, to become functional and mature these synapses need an important number of cell-cell interactions, including stimulation from glutamatergic synapses as well as the influence of neurotrophic factors (Munno and Syed, 2003).

However, all this is true for glutamatergic synapses because GABAergic synapses do not appear in dendritic spines, but rather form on dendritic shafts, nerve cell somata and axon initial segments. These inhibitory synapses besides their distinct location are also structurally different compared to excitatory synapses (reviewed in Gatto and Broadie, 2010).

Biological compartments: Synaptogenesis is spatially and temporally strictly controlled process. It does not happen in a uniform way in all brain regions and there important differences between the times of appearance of the main two types of synapses (reviewed in Erecinska et al., 2004). For example, in rat hippocampus excitatory synapses are well established or fully mature within the two first postnatal weeks, whereas inhibitory synapses cannot be found prior to PND 18, after which it increases steadily to reach adult levels at PND 28. In addition, in rat neostriatal neurons the excitatory responses to both cortical and thalamic stimuli can be observed by PND 6, but the long-lasting hyperpolarization and late depolarization is never seen before PND 12.

Structural remodelling of synapses and formation of new synaptic contacts has been postulated as a possible mechanism underlying the late phase of long-term potentiation (LTP), a form of plasticity which is involved in learning and memory. LTP induction results in a sequence of morphological changes consisting of a transient remodelling of the postsynaptic membrane followed by a marked increase in the proportion of axon terminals contacting two or more dendritic spines. Three-dimensional reconstruction revealed that these spines arose from the same dendrite. As pharmacological blockade of LTP prevented these morphological changes, it is suggested that LTP is associated with the formation of new, mature and probably functional synapses contacting the same presynaptic terminal and thereby duplicating activated synapses (Erik et al., 2006).

In human, synaptogenesis does not happen at the same time in all brain regions, as the prefrontal cortex lags behind in terms of synapse formation compared to the auditory and visual cortices. In contrast, synaptogenesis appears to proceed concurrently in different brain areas for rhesus monkey (Erecinska et al., 2004).

General role in biology: The period of rapid synaptogenesis or the so-called brain growth spurt is considered one of the most important processes that take place during brain development (Garner 
et al., 2002). This process is crucial not only in neurodevelopment but also plays a vital role in synaptic plasticity, learning and memory and adaptation throughout life. Without this process no complex brain network can be established as synapse is the fundamental unit of connectivity and communication between neurons (Tau and Peterson, 2010). Cell adhesion represents the most direct way of coordinating synaptic connectivity in the brain. Recent evidence highlights the importance of a trans-synaptic interaction between postsynaptic neuroligins and presynaptic neurexins. These transmembrane molecules bind each other extracellularly to promote adhesion between dendrites and axons, facilitating synapse establishment (Dean and Dresbach, 2006). Furthermore, the number of excitatory versus inhibitory synapses created at single neuron dictates neuronal excitability and function (Schummers et al., 2002).

\section{How it is measured or detected}

There is no OECD advised method for measuring synaptogenesis.

Anatomical methods can be used to structurally estimate the number of excitatory or inhibitory synapses. Immunostaining can be employed with specific antibodies that recognize vesicular glutamate transporters (VGLUTs) and the postsynaptic density protein-95 kDa (PSD-95) that are characteristic of excitatory synapses, while inhibitory synapses are identified by the presence of the vesicular GABA (VGAT) and vesicular inhibitory amino acid (VIAAT) transporters and the postsynaptic adaptor protein gephryin (Gatto and Broadie, 2010). There are commercial available synaptogenesis assay kits that rely on the immunostaining of cells with MAP-2, PSD-95 and synaptophysin. Some other presynaptic (Bassoon) and postsynaptic (ProSAP1/Shank2) markers have been suggested and showed to correlate well with the ultrastructural studies in cultured hippocampus primary cells (Grabrucker et al., 2009). Electron microscopy can also be applied to assess the prevalence of excitatory and inhibitory synapses amongst convergent contacts (Megias et al., 2001). Recently, a high content image analysis based on RNAi screening protocols has been suggested as a useful tool to create imaging algorithm for use in both in vitro and in vivo synaptic punctae analysis (Nieland et al., 2014).

Evidence supporting taxonomic applicability

\begin{tabular}{|l|l|l|l|}
\hline Name & Scientific Name & Evidence & Links \\
\hline human & Homo sapiens & Strong & NCBI \\
\hline rat & Rattus sp. & Strong & NCBI \\
\hline mouse & Mus sp. & Strong & NCBI \\
\hline
\end{tabular}

The mechanisms governing synapse formation is considered conserved among both vertebrates and invertebrates (Munno and Syed, 2003). Invertebrates have served as simple animal models to study synapse formation. Indeed, Colón-Ramos (2009) has recently reviewed the early developmental events that take place in the process of synaptogenesis pointing out the importance of this process in neural network formation and function. The experimental evaluation of synaptogenesis has been performed using invertebrates and in particular C. elegans and Drosophila as well as vertebrates (Colón-Ramos, 2009). 
This vulnerable period of synaptogenesis appears to happen in different developmental stages across species. For example, in rodents primarily synaptogenesis occurs during the first two weeks after birth (Bai et al., 2013). For rhesus monkeys, this period ranges from approximately 115-day gestation up to PND 60 (Bai et al., 2013). In humans, it starts from the third trimester of pregnancy and continues 2-3 years following birth (Bai et al., 2013).

\section{References}

Bai, X., D. Twaroski and Z.J. Bosnjak (2013), Modeling anesthetic developmental neurotoxicity using human stem cells. Semin Cardiothorac Vasc Anesth. 17: 276-287.

Colón-Ramos, D.A. (2009), Synapse formation in developing neural circuits. Curr Top Devel Biol. 87: 53-79.

Dean, C., and T. Dresbach (2006), Neuroligins and neurexins: linking cell adhesion, synapse formation and cognitive function. Trends Neurosci. 29:21-29.

Erecinska, M., S. Cherian and I.A. Silver (2004), Energy metabolism in mammalian brain during development. Prog Neurobiol. 73: 397-445.

Erik, I. et al. (2006), Activity-Independent Regulation of Dendrite Patterning by Postsynaptic Density Protein PSD-95. J Neurosci. 26: 10164-10176.

Garner, C.C. et al. (2002), Molecular mechanisms of CNS synaptogenesis. Cell Press 25: 243-250.

Gatto, C.L., and K. Broadie (2010), Genetic controls balancing excitatory and inhibitory synaptogenesis in neurodevelopmental disorder models. Front Syn Neurosci. 2: 4.

Grabrucker, A. et al. (2009), Synaptogenesis of hippocampal neurons in primary cell culture. Cell Tissue Res. 338: 333-341.

Megias, M. et al. (2001), Total number and distribution of inhibitory and excitatory synapses on hippocampal CA1 pyramidal cells. Neuroscience 102: 527-540.

Munno, D.W., and N.I. Syed (2003), Synaptogenesis in the CNS: an odyssey from wiring together to firing together. J Physiol. 552: 1-11.

Nieland, T.J.F. et al. (2014), High Content Image Analysis Identifies Novel Regulators of Synaptogenesis in a High-Throughput RNAi Screen of Primary Neurons. PLoS ONE. 9: e91744.

Schummers, J., J. Mariño and M. Sur (2002), Synaptic integration by V1 neurons depends on location within the orientation map. Neuron 36: 969-978.

Tau, G.Z., and B.S. Peterson (2010), Normal Development of Brain Circuits. Neuropsychopharmacology 35: 147-168. 


\section{Neuronal network function, Decreased}

AOPs including this Key Event

\begin{tabular}{|l|l|l|}
\hline \multicolumn{1}{|c|}{ AOP Name } & $\begin{array}{l}\text { Event } \\
\text { Type }\end{array}$ & Essentiality \\
\hline $\begin{array}{l}\text { Chronic binding of antagonist to N-methyl-D-aspartate receptors (NMDARs) } \\
\text { during brain development induces impairment of learning and memory abilities }\end{array}$ & KE & Strong \\
\hline $\begin{array}{l}\text { Nicotinic acetylcholine receptor activation contributes to abnormal foraging and } \\
\text { leads to colony loss/failure }\end{array}$ & KE & \\
\hline $\begin{array}{l}\text { Nicotinic acetylcholine receptor activation contributes to abnormal roll change } \\
\text { within the worker bee caste leading to colony loss/failure }\end{array}$ & KE & \\
\hline \begin{tabular}{l|l|l|} 
Nicotinic acetylcholine receptor activation contributes to abnormal foraging and \\
leads to colony loss/failure
\end{tabular} & KE & \\
\hline $\begin{array}{l}\text { Nicotinic acetylcholine receptor activation contributes to abnormal foraging and } \\
\text { leads to colony loss/failure }\end{array}$ & KE & \\
\hline $\begin{array}{l}\text { Nicotinic acetylcholine receptor activation contributes to abnormal foraging and } \\
\text { leads to colony loss/failure }\end{array}$ & KE & \\
\hline $\begin{array}{l}\text { Nicotinic acetylcholine receptor activation contributes to abnormal roll change } \\
\text { within the worker bee caste leading to colony loss/failure }\end{array}$ & KE & \\
\hline $\begin{array}{l}\text { Inhibition of Na+/I- symporter (NIS) decreases TH synthesis leading to learning } \\
\text { and memory deficits in children }\end{array}$ & KE & Moderate \\
\hline
\end{tabular}

How this Key Event works

Level of biological organisation

Organ

Biological state: There are striking differences in neuronal network formation and function among the developing and mature brain. The developing brain shows a slow maturation and a transient passage from spontaneous, long-duration action potentials to synaptically-triggered, short-duration action potentials.

Furthermore, at this precise developmental stage the neuronal network is characterised by "hyperexcitability", which is related to the increased number of local circuit recurrent excitatory synapses and the lack of $\gamma$-amino-butyric acid A (GABAA)-mediated inhibitory function that appears much later. This "hyperexcitability" disappears with maturation when pairing of the preand postsynaptic partners occurs and synapses are formed generating population of postsynaptic potentials and population of spikes followed by developmental GABA switch. Glutamatergic neurotransmission is dominant at early stages of development and NMDA receptor-mediated synaptic currents are far more times longer than those in maturation, allowing more calcium to enter the neurons. The processes that are involved in increased calcium influx and the subsequent intracellular events seem to play a critical role in establishment of wiring of neural circuits and 
strengthening of synaptic connections during development (reviewed in Erecinska et al., 2004). Neurons that do not receive glutaminergic stimulation are undergoing developmental apoptosis.

During the neonatal period, the brain is subject to profound alterations in neuronal circuitry due to high levels of synaptogenesis and gliogenesis. For example, in neuroendocrine regions such as the preoptic area-anterior hypothalamus (POA-AH), the site of gonadotropin-releasing hormone $(\mathrm{GnRH})$ system is developmentally regulated by glutamatergic neurons. The changes in the expression of the N-methyl-D-aspartate (NMDA) receptor subunits NR1 and NR2B system begin early in postnatal development, before the onset of puberty, thereby playing a role in establishing the appropriate environment for the subsequent maturation of $\mathrm{GnRH}$ neurons (Adams et al., 1999).

Biological compartments: Neural network formation and function happen in all brain regions but it appears to onset at different time points of development (reviewed in Erecinska et al., 2004). Glutamatergic neurotransmission in hippocampus is poorly developed at birth. Initially, NMDA receptors play important role but the vast majority of these premature glutamatergic synapses are "silent" possibly due to delayed development of hippocampal AMPA receptors. In contrast, in the cerebral cortex the maturation of excitatory glutamatergic neurotransmission happens much earlier. The "silent" synapses disappear by PND 7-8 in both brain regions mentioned above.

There is strong evidence suggesting that NMDA receptor subunit composition controls synaptogenesis and synapse stabilization (Gambrill and Barria, 2011). It is established fact that during early postnatal development in the rat hippocampus, synaptogenesis occurs in parallel with a developmental switch in the subunit composition of NMDA receptors from NR2B to NR2A. It is suggested that early expression of NR2A in organotypic hippocampal slices reduces the number of synapses and the volume and dynamics of spines. In contrast, overexpression of NR2B does not affect the normal number and growth of synapses. However, it does increase spine motility, adding and retracting spines at a higher rate. The $\mathrm{C}$ terminus of NR2B, and specifically its ability to bind CaMKII, is sufficient to allow proper synapse formation and maturation. Conversely, the $\mathrm{C}$ terminus of NR2A was sufficient to stop the development of synapse number and spine growth. These results indicate that the ratio of synaptic NR2B over NR2A controls spine motility and synaptogenesis, and suggest a structural role for the intracellular $\mathrm{C}$ terminus of NR2 in recruiting the signalling and scaffolding molecules necessary for proper synaptogenesis. Interestingly, it was found that genetic deletion of NR3A accelerates glutamatergic synaptic transmission, as measured by AMPAR-mediated postsynaptic currents recorded in hippocampal CA1. Consistent, the deletion of NR3A accelerates the expression of the glutamate receptor subunits NR1, NR2A, and GluR1 sugesting that glutamatergic synapse maturation is critically dependent upon activation of NMDA-type glutamate receptors (Henson et al., 2012).

General role in biology: The development of neuronal networks can be distinguished into two phases: an early 'establishment' phase of neuronal connections, where activity-dependent and independent mechanisms could operate, and a later 'maintenance' phase, which appears to be controlled by neuronal activity (Yuste and Sur, 1999). These neuronal networks facilitate information flow that is necessary to produce complex behaviors, including learning and memory (Mayford et al., 2012). 


\section{How it is measured or detected}

In vivo: The recording of brain activity by using electroencephalography (EEG), electrocorticography (ECoG) and local field potentials (LFP) assists towards the collection of signals generated by multiple neuronal cell networks. Advances in computer technology have allowed quantification of the EEG and expansion of quantitative EEG (qEEG) analysis providing a sensitive tool for time-course studies of different compounds acting on neuronal networks' function (Binienda et al., 2011). The number of excitatory or inhibitory synapses can be functionally studied at an electrophysiological level by examining the contribution of glutamatergic and GABAergic synaptic inputs. The number of them can be determined by variably clamping the membrane potential and recording excitatory and inhibitory postsynaptic currents (EPSCs or IPSCs) (Liu, 2004).

In vitro: Microelectrode array (MEA) recordings are also used to measure electrical activity in cultured neurons (Keefer et al., 2001, Gramowski et al., 2000; Gopal, 2003; Johnstone et al., 2010). MEAs can be applied in high throughput platforms to facilitate screening of numerous chemical compounds (McConnell et al., 2012). Using selective agonists and antagonists of different classes of receptors their response can be evaluated in a quantitative manner (Novellino et al., 2011; Hogberg et al., 2011). Patch clamping technique can also be used to measure neuronal network activity.

Evidence supporting taxonomic applicability

\begin{tabular}{|l|l|l|l|}
\hline \multicolumn{1}{|c|}{ Name } & Scientific Name & Evidence & Links \\
\hline humans & Homo sapiens & Strong & NCBI \\
\hline rat & Rattus rattus & Strong & NCBI \\
\hline mice & Mus sp. & Strong & NCBI \\
\hline cat & Felis sp. & Strong & NCBI \\
\hline
\end{tabular}

In vitro studies in brain slices applying electrophysiological techniques showed significant variability among species (immature rats, rabbits and kittens) related to synaptic latency, duration, amplitude and efficacy in spike initiation (reviewed in Erecinska et al., 2004).

\section{References}

Adams, M.M., R.A. Flagg and A.C. Gore (1999), Perinatal changes in hypothalamic N-methyl-D-aspartate receptors and their relationship to gonadotropin-releasing hormone neurons. Endocrinology 140: 2288-2296.

Binienda, Z.K. et al. (2011), Analysis of electrical brain waves in neurotoxicology: $\gamma$-hydroxybutyrate. Curr Neuropharmacol. 9: 236-239.

Erecinska, M., S. Cherian and I.A. Silver (2004), Energy metabolism in mammalian brain during development. Prog Neurobiol. 73: 397-445.

Gambrill, A.C., and A. Barria (2011), NMDA receptor subunit composition controls synaptogenesis and synapse stabilization. Proc Natl Acad Sci U S A. 108: 5855-5860. 
Gopal, K. (2003), Neurotoxic effects of mercury on auditory cortex networks growing on microelectrode arrays: a preliminary analysis. Neurotoxicol Teratol. 25: 69-76.

Gramowski, A., D. Schiffmann and G.W. Gross (2000), Quantification of acute neurotoxic effects of trimethyltin using neuronal networks cultures on microelectrode arrays. Neurotoxicology 21: 331342.

Henson, M.A. et al. (2012), Genetic deletion of NR3A accelerates glutamatergic synapse maturation. PLoS One. 7(8).

Hogberg, H.T. et al. (2011), Application of micro-electrode arrays (MEAs) as an emerging technology for developmental neurotoxicity: evaluation of domoic acid-induced effects in primary cultures of rat cortical neurons. Neurotoxicology 32: 158-168.

Johnstone, A.F.M. et al. (2010), Use of microelectrode arrays for neurotoxicity testing in the 21 st century Neurotoxicology 31: 331-350.

Keefer, E. et al. (2001), Acute toxicity screening of novel AChE inhibitors using neuronal networks on microelectrode arrays. Neurotoxicology 22: 3-12.

Liu, G. (2004), Local structural balance and functional interaction of excitatory and inhibitory synapses in hippocampal dendrites. Nat Neurosci. 7: 373-379.

Mayford, M., S.A. Siegelbaum and E.R. Kandel (2012), Synapses and memory storage. Cold Spring Harb Perspect Biol. 4. pii: a005751.

McConnell, E.R. et al. (2012), Evaluation of multi-well microelectrode arrays for neurotoxicity screening using a chemical training set. Neurotoxicology 33: 1048-1057.

Novellino, A. et al. (2011), Development of micro-electrode array based tests for neurotoxicity: assessment of interlaboratory reproducibility with neuroactive chemicals. Front Neuroeng. 4: 4.

Yuste, R., A. Peinado and L.C. Katz (1992), Neuronal domains in developing neocortex. Science 257: 665669. 
Adverse Outcome

\begin{tabular}{|c|}
\hline Adverse Outcome \\
\hline Learning and memory, Impairment \\
\hline
\end{tabular}

\section{Learning and memory, Impairment}

AOPs including this Key Event

\begin{tabular}{|c|c|c|}
\hline AOP Name & $\begin{array}{l}\text { Event } \\
\text { Type }\end{array}$ & Essentiality \\
\hline $\begin{array}{l}\text { Chronic binding of antagonist to N-methyl-D-aspartate receptors (NMDARs) } \\
\text { during brain development induces impairment of learning and memory abilities }\end{array}$ & $\mathrm{AO}$ & \\
\hline $\begin{array}{l}\text { Binding of agonists to ionotropic glutamate receptors in adult brain causes } \\
\text { excitotoxicity that mediates neuronal cell death, contributing to learning and } \\
\text { memory impairment. }\end{array}$ & $\mathrm{AO}$ & \\
\hline $\begin{array}{l}\text { Inhibition of Na+/I- symporter (NIS) decreases TH synthesis leading to learning } \\
\text { and memory deficits in children }\end{array}$ & $\mathrm{AO}$ & \\
\hline $\begin{array}{l}\text { Nicotinic acetylcholine receptor activation contributes to abnormal foraging and } \\
\text { leads to colony loss/failure }\end{array}$ & $\mathrm{KE}$ & \\
\hline $\begin{array}{l}\text { Nicotinic acetylcholine receptor activation contributes to abnormal roll change } \\
\text { within the worker bee caste leading to colony loss/failure }\end{array}$ & KE & \\
\hline $\begin{array}{l}\text { Nicotinic acetylcholine receptor activation contributes to abnormal foraging and } \\
\text { leads to colony loss/failure }\end{array}$ & KE & \\
\hline $\begin{array}{l}\text { Nicotinic acetylcholine receptor activation contributes to abnormal foraging and } \\
\text { leads to colony loss/failure }\end{array}$ & $\mathrm{KE}$ & \\
\hline $\begin{array}{l}\text { Nicotinic acetylcholine receptor activation contributes to abnormal foraging and } \\
\text { leads to colony loss/failure }\end{array}$ & $\mathrm{KE}$ & \\
\hline $\begin{array}{l}\text { Nicotinic acetylcholine receptor activation contributes to abnormal roll change } \\
\text { within the worker bee caste leading to colony loss/failure }\end{array}$ & $\mathrm{KE}$ & \\
\hline
\end{tabular}

How this Key Event works

\section{Level of biological organisation}

Individual

Learning can be defined as the process by which new information is acquired to establish knowledge by systematic study or by trial and error (Ono, 2009). Two types of learning are considered in neurobehavioral studies: a) associative learning and b) non-associative learning.

Associative learning is learning by making associations between different events. In associative learning, a subject learns the relationship among two different stimuli or between the stimulus and the subject's behaviour. Classical conditioning, operant conditioning and category learning are 
some examples of associative learning. On the other hand, non-associative learning can be defined as an alteration in the behavioral response that occurs over time in response to a single type of stimulus. Habituation and sensitization are some examples of non-associative learning. Another important type of learning is emotional learning and the simplest form of emotional regulation is extinction (Quirk and Mueller, 2008). During extinction, conditioned response to a stimulus decreases when the reinforcer is omitted. Fear conditioning experiments help to elucidate the underlined mechanism.

The memory to be formed requires acquisition, retention and retrieval of information in the brain, which is characterised by the non-conscious recall of information (Ono, 2009). Memory is considered very important as it allows the subjects to access the past, to form experience and consequently to acquire skills for surviving purposes. There are three main categories of memory, including sensory memory, short-term or working memory (up to a few hours) and long-term memory (up to several days or even much longer). At the cellular level the storage of long-term memory is associated with increased gene expression and protein synthesis as well as formation of novel synaptic connections (Lynch, 2004).

Learning-related processes require neural networks to detect correlations between events in the environment and store these as changes in synaptic strength (Abbott and Nelson, 2000). Longterm potentiation (LTP) and long-term depression (LTD) are two fundamental processes involved in cognitive functions (Abbott and Nelson, 2000; Malenka and Bear, 2004), which respectively, strengthen synaptic inputs that are effective at depolarizing the postsynaptic neuron and weaken inputs that are not, thus reinforcing useful pathways in the brain. Synapses that are strengthened become more effective at depolarizing the postsynaptic neuron, eventually driving neuronal activity to saturation (Abbott and Nelson, 2000). As correlated activity of presynaptic and postsynaptic neurons drives strengthening of specific synapses, the postsynaptic neuron will be driven more strongly, and so presynaptic inputs that were initially only poorly correlated with postsynaptic firing will be better able to trigger firing of the postsynaptic neuron. This implies that nervous systems must have a matching set of plasticity mechanisms that counteract these destabilizing forces. The cortical and hippocampal pyramidal neurons have a target firing rate, and synaptic strengths are regulated to maintain these rates relatively constant in the face of perturbations in input channel (Burrone et al., 2002). This provides a robust mechanism for generating stability in network function in the face of learning-related changes in synaptic input. In principle, neurons could maintain stable firing rates through homeostatic regulation of many aspects of neuronal excitability. These possibilities include balancing inward and outward voltage-dependent conductances that determine firing properties generally called "intrinsic excitability" (Marder and Goaillard, 2006; Zhang and Linden 2003), regulating inhibitory and/or excitatory synaptic strength (Turrigiano, 2011) or synapse number (Kirov et al., 1999) or by adjusting the ease with which other forms of plasticity can be induced, so-called "metaplasticity" (Abraham and Bear, 1996). Evidence suggests that all of these mechanisms can contribute to the homeostatic regulation of neuronal firing rates in central circuits. Activity-dependent alteration in synaptic strength is a fundamental property of the vertebrate central nervous system and is thought to underlie learning and memory.

A major expression mechanism of synaptic scaling is changes in the accumulation of synaptic glutamate receptors. Central synapses typically cluster both AMPA receptors and NMDA receptors. AMPA receptors are ionotropic and carry out the majority of excitatory synaptic current 
in the central nervous system; NMDA receptors are also ionotropic but open as a function of voltage, flux calcium, and mediate a number of calcium-dependent forms of synaptic plasticity (Malenka and Bear, 2004). Synaptic scaling results in postsynaptic changes in both types of glutamate receptors (Stellwagen and Malenka, 2006; Watt et al., 2000) and can therefore be monitored by measuring changes in receptor accumulation at synapses.

The best characterized form of LTP occurs in the CA1 region of the hippocampus, in which LTP is initiated by transient activation of receptors and is expressed as a persistent increase in synaptic transmission through AMPA receptors followed by activation of NMDARs. This increase is due, at least in part, to a postsynaptic modification of AMPA-receptor function; this modification could be caused by an increase in the number of receptors, their open probability, their kinetics or their single-channel conductance. Summing up activity-dependent alteration in synaptic strength is a fundamental property of the vertebrate central nervous system that underlies learning and memory processes.

It is appropriate to state that while much emphasis has been given on the key role of the hippocampus in memory, it would probably be simplistic to attribute memory deficits solely to hippocampal damage (Barker and Warburton, 2011). There is substantial evidence that fundamental memory functions are not mediated by hippocampus alone but require a network that includes, in addition to the hippocampus, anterior thalamic nuclei, mammillary bodies cortex, cerebellum and basal ganglia (Aggleton and Brown, 1999; Doya, 2000; Mitchell et al., 2002, Toscano and Guilarte, 2005). Each of these brain structures can be potentially damaged leading to more or less severe impairment of learning and memory.

Amnesia is defined as the impairment or loss of memory. Depending on the cause amnesia can be characterised as functional, organic amnesia or infantile amnesia. Dementia, is a brain disease that causes a long term and often gradual decrease in the ability to think and remember as well as problems with language, and a decrease in motivation (Solomon and Budson, 2011). It is an intellectual impairment observed mainly in elderly people due to the progress of a neudegenerative disease. In younger people this type of impairment is known as presenile dementia. The most common affected areas include memory, visual-spatial, language, attention, and executive function (problem solving). Therefore, very often, short-time memory, mind, speech and motor skills are affected. Certain forms of dementia can be treated, to some extent. The most common form of dementia is Alzheimer's disease, which accounts for between 50 and 60 percent of all cases. Other types include vascular dementia and Lewy body dementia (Burns, 2009).

In the past, the study of infant memory has relied in models and tests used in adults and more specific amnesic patients with hippocampal damage. For this reason, the infant memory has been distinguished to declarative or explicit memory and nondeclarative or implicit memory. However, in recent years this distinction such as explicit/implicit are no longer accepted especially in relation to hippocampal function as new theories have been emerged (reviewed in Mullally and Maguire, 2014). Furthermore, there are findings that even very young infants have a more adept and flexible memory system than was previously thought and neurobiological data derived from non-humans provide support to the new hypotheses about hippocampal development that would facilitate to interpret infant memory data from humans. 


\section{How it is measured or detected}

In humans: The neuropsychological tests have been used for neurosensory assessment of humans including identification of altered neurobehaviours in vulnerable populations such as children (Rohlman et al., 2008). Intelligence tests, perceptual motor tests, planning tests, and logical, spatial, short term, long term, and working memory tasks can be used in neurobehavioral studies to assess learning and memory. The same test is also used to identify risks from occupational exposure to chemicals.

In laboratory animals: Current behavioural tests used for evaluating learning and memory processes in rats such as the Morris water maze, Radial maze, Passive avoidance and Spontaneous alternation are characterised in the KE Decreased Neuronal Network Function.

Cognitive function including learning and memory is an important endpoint required by the US EPA and OECD Developmental Neurotoxicity (DNT) Guidelines (OCSPP 870.6300 or OECD 426). The methods applied to assess learning and memory have been reviewed (Markis et al., 2009) and discussed in the OECD Series on testing and assessment number 20, Guidance document for Neurotoxicity Testing (2004). This document is considered an essential supplement to a substantial number of already existing OECD Test Guidelines relevant for neurotoxicity testing.

Evidence supporting taxonomic applicability

\begin{tabular}{|l|l|l|l|}
\hline \multicolumn{1}{|c|}{ Name } & \multicolumn{1}{|c|}{ Scientific Name } & Evidence & Links \\
\hline human & Homo sapiens & Strong & NCBI \\
\hline rat & Rattus norvegicus & Strong & NCBI \\
\hline fruit fly & Drosophila melanogaster & Strong & NCBI \\
\hline zebrafish & Danio rerio & Strong & NCBI \\
\hline gastropods & Physa heterostropha & Strong & NCBI \\
\hline
\end{tabular}

Learning and memory have been studied in invertebrates such as gastropod molluscs and drosophila and vertebrates such as rodents and primates. Recently, larval zebrafish has also been suggested as a model for the study of learning and memory (Roberts et al., 2013).

\section{References}

Abbott, L.F., and S.B. Nelson (2000), Synaptic plasticity: Taming the beast. Nat Neurosci 3: 1178-1183.

Abraham, H.A.J., and M.F. Bear (1996), Bidirectional modification of CA1 synapses in the adult hippocampus in vivo. Nature 381: 163-166.

Aggleton, J.P., and M.W. Brown (1999), Episodic memory, amnesia, and the hippocampal-anterior thalamic axis. Behav Brain Sci. 22: 425-489.

Barker, G.R., and E.C. Warburton (2011), When is the hippocampus involved in recognition memory? J Neurosci. 31: 10721-10731. 
Burns, A., and S. Iliffe (2009), Dementia. BMJ (Clinical research ed.) 338: b75.

Burrone, J., M. O’Byrne and V.N. Murthy (2002), Multiple forms of synaptic plasticity triggered by selective suppression of activity in individual neurons. Nature 420: 414-418.

Doya, K. (2000), Complementary roles of basal ganglia and cerebellum in learning and motor control. Curr Opin Neurobiol. 10: 732-739.

Gilbert, M.E. et al. (2012), Developmental thyroid hormone disruption: prevalence, environmental contaminants and neurodevelopmental consequences. Neurotoxicology 33: 842-52.

Kirov, S.A, K.E. Sorra and K.M. Harris (1999), Slices have more synapses than perfusion-fixed hippocampus from both young and mature rats. J Neurosci. 19: 2876-2886.

Lynch, M.A. (2004), Long-term potentiation and memory. Physiol Rev. 84: 87-136.

Makris, S.L. et al. (2009), A retrospective performance assessment of the developmental neurotoxicity study in support of OECD test guideline 426. Environ Health Perspect. 117:17-25.

Malenka, R.C., and M.F. Bear (2004), LTP and LTD: An embarrassment of riches. Neuron 44: 5-21.

Marder, E., and J.M. Goaillard (2006), Variability, compensation and homeostasis in neuron and network function. Nat Rev Neurosci. 7: 563-574.

Mitchell, A.S., J.C. Dalrymple-Alford and M.A. Christie (2002), Spatial working memory and the brainstem cholinergic innervation to the anterior thalamus. J Neurosci. 22: 1922-1928.

Mullally, S.L., and EA. Maguire (2014), Learning to remember: the early ontogeny of episodic memory. Dev Cogn Neurosci. 9: 12-29.

OECD (2004), Series on testing and assessment number 20, Guidance document for neurotoxicity testing, Organisation of Econimic Cooperation and Development, Paris.

OECD (2007), Test Guideline 426. OECD Guideline for Testing of Chemicals. Developmental Neurotoxicity Study, Organisation of Econimic Cooperation and Development, Paris.

OECD (2008), Nr 43 Guidance Document on Mammalian Reproductive Toxicity Testing and Assessment. Organisation of Econimic Cooperation and Development, Paris.

Ono, T. (2009), Learning and Memory. Encyclopedia of neuroscience. M D. Binder, N. Hirokawa and U. Windhorst (Eds). Springer-Verlag GmbH Berlin Heidelberg. pp 2129-2137.

Quirk, G.J., and D. Mueller (2008), Neural mechanisms of extinction learning and retrieval. Neuropsychopharmacology 33: 56-72.

Roberts, A.C., B.R. Bill and D.L. Glanzman (2013), Learning and memory in zebrafish larvae. Front Neural Circuits 7: 126.

Rohlman, D.S. et al. (2008) Neurobehavioral testing in human risk assessment. Neurotoxicology 29: 556567.

Solomon, A., E. Budson and R. Paul (2011), Memory loss: a practical guide for clinicians. Elsevier Saunders. ISBN 9781416035978

Stellwagen, D., and R.C. Malenka (2006), Synaptic scaling mediated by glial TNF- $\alpha$. Nature 440: 10541059.

Toscano, C.D., and T.R. Guilarte (2005), Lead neurotoxicity: From exposure to molecular effects. Brain Res Rev. 49: 529-554.

Turrigiano, G. (2011), Too many cooks? Intrinsic and synaptic homeostatic mechanisms in cortical circuit refinement. Annu Rev Neurosci. 34: 89-103.

Watt, A.J. et al. (2000), Activity coregulates quantal AMPA and NMDA currents at neocortical synapses. Neuron 26: 659-670.

Zhang, W., and D.J. Linden (2003), The other side of the engram: Experience-driven changes in neuronal intrinsic excitability. Nat Rev Neurosci. 4: 885-900. 
Key Event Relationships: Scientific evidence supporting the linkages in the AOP

\begin{tabular}{|c|c|c|}
\hline Event & Description & Triggers \\
\hline NMDARs, Binding of antagonist & Directly Leads to & NMDARs, Inhibition \\
\hline NMDARs, Inhibition & Directly Leads to & $\underline{\text { Calcium influx, Decreased }}$ \\
\hline Calcium influx, Decreased & $\begin{array}{l}\text { Indirectly Leads } \\
\underline{\text { to }}\end{array}$ & $\underline{\text { Release of BDNF, Reduced }}$ \\
\hline$\underline{\text { Release of BDNF, Reduced }}$ & $\begin{array}{ll}\text { Indirectly } \quad \text { Leads } \\
\underline{\text { to }}\end{array}$ & Dendritic morphology, Aberrant \\
\hline$\underline{\text { Release of BDNF, Reduced }}$ & $\begin{array}{ll}\text { Indirectly } \quad \text { Leads } \\
\underline{\text { to }}\end{array}$ & $\begin{array}{l}\text { Presynaptic release of glutamate, } \\
\underline{\text { Reduced }}\end{array}$ \\
\hline Release of BDNF, Reduced & $\underline{\text { Indirectly Leads }}$ & Cell death, N/A \\
\hline Dendritic morphology, Aberrant & $\underline{\text { Indirectly Leads }}$ & Synaptogenesis, Decreased \\
\hline $\begin{array}{l}\text { Presynaptic release of glutamate, } \\
\underline{\text { Reduced }}\end{array}$ & $\underline{\text { Indirectly } \quad \text { Leads }}$ & Synaptogenesis, Decreased \\
\hline Cell death, N/A & $\underline{\text { Indirectly Leads }}$ & Synaptogenesis, Decreased \\
\hline Synaptogenesis, Decreased & Directly Leads to & $\underline{\text { Neuronal network function, Decreased }}$ \\
\hline Neuronal network function, Decreased & $\begin{array}{ll}\underline{\text { Indirectly }} \text { Leads } \\
\underline{\text { to }}\end{array}$ & Learning and memory, Impairment \\
\hline
\end{tabular}




\title{
1. NMDARs, Binding of antagonist leads to NMDARs, Inhibition
}

\author{
How Does This Key Event Relationship Work
}

It is well documented that prolonged/chronic antagonism of NMDARs triggers the downstream KE named inhibition of NMDARs. Shorter term binding to the same receptors may trigger different downstream KEs, such as up-regulation of the NMDARs, resulting in toxic increased influx of calcium and to cell death. Consequently, this information can be captured in other KERs and AOP.

\section{Weight of Evidence}

\section{Biological Plausibility}

There is structural mechanistic understanding supporting the relationship between MIE (NMDARs, binding of antagonists) and KE (NMDARs, inhibition). Crystal structure studies are used to study the binding of antagonists/agonists to NMDA receptors. In case of NMDAR antagonists, the binding to the receptor causes LBD conformation changes which promote channel closure leading to reduced $\mathrm{Ca}+2$ influx (Blanke and VanDongen, 2009). This lack of measurable ion flux is applied as an indication of NMDAR inhibition.

\section{Empirical Support for Linkage}

In slices of cerebellum derived from postnatal days 6-30 (PND 6-30) Sprague Dawley rats, $10 \mu \mathrm{M}$ MK-801 completely blocked evoked NMDA excitatory postsynaptic currents (EPSCs) as it has been demonstrated by patch clamp technique (Rumbaugh and Vicini, 1999). The same technique has been employed in cortical slices from C57BL/6 mice of both genders and different age groups (P8-12, P21-28 or P45-90), showing that $1 \mu \mathrm{M}$ APV and $50 \mathrm{nM}$ NVP-AAM077 antagonise a similar amount of NMDA receptor current independently of the age (de Marchena et al., 2008).

$\mathrm{Pb} 2+$ has potent inhibitory effects on the NMDA receptor (Alkondon et al., 1990; Guilarte and Miceli, 1992; Guilarte, 1997; Gavazzo et al., 2001). In rat hippocampal neurons, Pb2+ (2.5-50 $\mu \mathrm{M})$ inhibits NMDA-induced whole-cell and single-channel currents in a concentration-dependent manner, suggesting that $\mathrm{Pb} 2+$ can decrease the frequency of NMDA-induced channel activation (Alkondon et al., 1990). In the same study, they have examined the effect of $\mathrm{Pb} 2+$ on the binding of $[3 \mathrm{H}] \mathrm{MK}-801$ to the rat brain hippocampal membranes and showed that $\mathrm{Pb} 2+$ inhibits the binding of $[3 \mathrm{H}]-\mathrm{MK}-801$ in a concentration dependent manner with an IC50 value close to $7 \mu \mathrm{M}$ (Alkondon et al., 1990). These inhibitory effects of $\mathrm{Pb} 2+$ on NMDA receptors activation appear to be age and brain region specific (Guilarte, 1997; Guilarte and Miceli, 1992). The Pb2+ IC50 is significantly lower in cortical membranes prepared from neonatal than from adult rats, whereas the hippocampus is more sensitive than the cerebral cortex since the Pb2+ IC50 is significantly lower in the hippocampus (Guilarte and Miceli, 1992). The number of [3H]-MK-801 binding sites associated with the high and low affinity sites of $\mathrm{Pb} 2+$ inhibition in the hippocampus of rats is increased as a function of age, peaking at PND 28 and 21 (Guilarte, 1997). High and low affinity $\mathrm{Pb}(2+)$-sensitive $[3 \mathrm{H}]-\mathrm{MK}-801$ binding sites have also been measured in the cerebral cortex during early development, but that has not been possible to evaluate after PND 14. 
The developing brain is more sensitive than the adult brain to $\mathrm{Pb} 2+$-induced effects mediated through the NMDA receptor. Moreover, the hippocampus appears to be particularly vulnerable as in this brain structure NMDA receptors undergo subunit specific changes during developmental $\mathrm{Pb} 2+$ exposure (Guilarte and McGlothan, 1998). Exposure to $\mathrm{Pb} 2+$ during synaptogenesis causes decreased expression of hippocampal NR2A-subunit of NMDARs at synapses and increased targeting of NR2B-NMDARs to dendritic spines (without increased NR2B-NMDARs expression) (Nihei and Guilarte, 1999; Neal et al., 2011; Zhang et al., 2002).

\section{Uncertainties or Inconsistencies}

$\mathrm{Pb} 2+$ has been found to produce either potentiation or inhibition depending on: a) the subunit composition of NMDA receptors, b) endogenous glutamate concentration and c) $\mathrm{Pb} 2+$ dosage. In case that the NMDA receptors are saturated by agonist, $\mathrm{Pb} 2+$ at low concentrations $(<1 \mu \mathrm{M})$ acts as a positive modulator of agonist action at NR1b-2AC and NR1a-2AB subunit complexes, whereas at higher concentrations, $\mathrm{Pb} 2+$ it behaves as a potent inhibitor of all recombinant NMDA receptors tested and was least potent at NR1b-2AC (Omelchenko et al., 1996; 1997), meaning that $\mathrm{Pb} 2+$ is not always acting as NMDAR inhibitor but it can also behave as NMDAR activator under certain conditions.

\section{Quantitative understanding of the linkage}

To predict how potent an antagonist can be, the half maximal inhibition concentrations (IC50) and the half maximal effective concentration (EC50) of glutamate/glycine induced currents is measured in NMDA receptors from brain slices and cells or in recombinantly expressed receptors. Traynelis et al. 2010 summarised the IC50 values for competitive, noncompetitive and uncompetitive antagonists in different subunits of NMDA receptors. The inhibitory effect (efficacy) of antagonists on NMDA receptors has been found to be dependent on:

-the type of subunits that form the NMDA receptors depending on the developmental stage -the chemical structure of the antagonists

-the binding site of receptor that the antagonists prefer

-how tightly an antagonist binds to the receptor (affinity)

At CA3-CA1 synapses, NMDARs are largely composed of NR1 (NMDA receptor subunit 1)NR2A or NR1-NR2B containing subunits. Recent, but controversial, evidence has correlated NR1-NR2A receptors with the induction of LTP and NR1-NR2B receptors with LTD. However, LTP can be induced by activation of either subtype of NMDAR and the ratio of NR2A:NR2B receptors has been proposed as an alternative determinant of the direction of synaptic plasticity (Mac Donald et al., 2006).

Pb2+: Although the NR2 subunits have different $\mathrm{Zn2+}$ binding sites i.e. the NR2A-NMDAR binds Zn2+ at a high-affinity site (nM affinity) while the NR2B-NMDAR binds Zn2+ with lower affinity ( $\mu \mathrm{M}$ range); the Pb2+ IC50 for wild type NR2A-NMDARs was reported to be $1.3 \mu \mathrm{M}$, while the Pb2+ IC50 of wild type NR2B-NMDARs was $1.2 \mu \mathrm{M}$ (Gavazzo et al., 2008). Similar findings were published by Lasley and Gilbert (1999) using cortical neurons from adult rats. The IC50 for $\mathrm{Pb} 2+$ ranged from 1.52 to $4.86 \mu \mathrm{M}$, with the ranking of $\mathrm{Pb} 2+$ potency in inhibition of NMDA receptor subunits to be NR1b-2A $>N R 1 b-2 C>N R 1 b-2 D>N R 1 b-2 A C$ after experiments 
that have been conducted in Xenopus oocytes injected with cRNAs for different combinations of NMDA receptor subunits (Omelchenko et al., 1997).

\section{Evidence supporting taxonomic applicability}

The biophysical properties of rat and human receptors have been mostly assessed through recombinant studies, whereas the pharmacological properties of rat and human NMDA receptors have not been fully explored and compared yet (Hedegaard et al., 2012). Mean channel open times for human NMDA receptor subtypes in recombinant protein studies are similar to those of the corresponding rat NMDA receptor subtypes. However, mean single-channel conductances for human NMDA receptor subtypes appear lower than those of the corresponding rat NMDA receptor subtypes. Regarding pharmacological properties of the receptors, the differences were less than 2-fold and were not observed at the same subtypes for all the antagonists tested, suggesting that the molecular pharmacology of NMDA receptor is conserved between human and rat, although some inter-species differences are seen in IC50 values using two-electrode voltageclamp recordings (Hedegaard et al., 2012).

\section{References}

Alkondon, M. et al. (1990), Selective blockade of NMDA-activated channel currents may be implicated in learning deficits caused by lead. FEBS Lett. 261: 124-130.

Blanke, M.L., and A.M.J. VanDongen (2009), Activation Mechanisms of the NMDA Receptor. In: Van Dongen AM, editor. Biology of the NMDA Receptor. Boca Raton (FL): CRC Press; Chapter 13. Available from: http://www.ncbi.nlm.nih.gov/books/NBK5274/

de Marchena, J. et al. (2008), NMDA receptor antagonists reveal age-dependent differences in the properties of visual cortical plasticity. J Neurophysiol. 100: 1936-1948.

Gavazzo, P. et al. (2001), Lead inhibition of NMDA channels in native and recombinant receptors. NeuroReport. 12: 3121-3125.

Gavazzo, P. et al. (2008), Molecular determinants of $\mathrm{Pb} 2+$ interaction with NMDA receptor channels. Neurochem Int. 52: 329-337.

Guilarte, T.R., and R.C. Miceli (1992), Age-dependent effects of lead on [3H]-MK-801 binding to the NMDA receptor-gated ionophore: In vitro and in vivo studies. Neurosci Lett. 148: 27-30.

Guilarte, T.R. (1997), Pb2+ Inhibits Nmda Receptor Function at High and Low Affinity Sites: Developmental and Regional Brain Expression. Neurotoxicology 18: 43-51.

Guilarte, T.R., and J.L. McGlothan (1998), Hippocampal Nmda Receptor Mrna Undergoes Subunit Specific Changes During Developmental Lead Exposure. Brain Res. 790: 98-107.

Hedegaard, M.K. et al. (2012), Molecular pharmacology of human NMDA receptors. Neurochem Int. 61: 601-609.

Lasley, S.M., and M.E. Gilbert (1999), Lead inhibits the rat N-methyl-d-aspartate receptor channel by binding to a site distinct from the zinc allosteric site. Toxicol Appl Pharmacol. 159: 224-233.

MacDonald, J.F., M.F. Jackson and M.A. Beazely (2006), Hippocampal long-term synaptic plasticity and signal amplification of NMDA receptors. Crit Rev Neurobiol. 18: 71-84.

Neal, A.P., P.F. Worley and T.R. Guilarte (2011), Lead exposure during synaptogenesis alters NMDA receptor targeting via NMDA receptor inhibition. Neurotoxicology 32: 281-289.

Omelchenko, I.A. et al. (1996), The sensitivity of N-methyl-d-aspartate receptors to lead inhibition is dependent on the receptor subunit composition. J Pharmacol Exp Ther. 278: 15-20. 
Omelchenko, I.A., CS, Nelson and C.N. Allen (1997), Lead inhibition of N-Methyl-D-aspartate receptors containing NR2A, NR2C and NR2D subunits. J Pharmacol Exp Ther. 282: 1458-1464.

Rumbaugh, G., and S. Vicini (1999), Distinct Synaptic and Extrasynaptic NMDA Receptors in Developing Cerebellar Granule Neurons. J Neurosc. 19: 10603-10610.

Traynelis, S. et al. (2010), Glutamate receptor ion channels: structure, regulation, and function. Pharmacol Rev. 62: 405-496.

Zhang, X.Y. et al. (2002), Effect of developmental lead exposure on the expression of specific NMDA receptor subunit mRNAs in the hippocampus of neonatal rats by digoxigenin-labeled in situ hybridization histochemistry. Neurotox Teratol 24: 149-160.

\section{NMDARs, Inhibition leads to Calcium influx, Decreased}

\section{How Does This Key Event Relationship Work}

The NMDA receptor is distinct in two ways: firstly, it is both ligand-gated and voltage-dependent and secondly, it requires co-activation by two ligands: glutamate and either D-serine or glycine. NMDA receptor activation allows the influx of $\mathrm{Ca} 2+$ only when the receptor is occupied by Lglutamate or other agonists (and removal of $\mathrm{Mg}++$ block) resulting in the postsynaptic membrane depolarization. In contrast, binding of antagonist to NMDA receptor decreases or eliminates $\mathrm{Ca} 2+$ influx and consequently dramatically decreases intracellular influx of $\mathrm{Ca} 2+$ levels (reviewed in Higley and Sabatini, 2012).

\section{Weight of Evidence}

Biological Plausibility

The relationship between KE (NMDARs, Inhibition) and KE (Calcium influx, Decreased) is plausible as the function evaluation of NMDA receptors is commonly carried out by measurement of intracellular influx of $\mathrm{Ca} 2+$ upon NMDA receptor stimulation by agonist. Calcium imaging techniques have been extensively utilized to investigate the relationship between these two KEs. Almost $15 \%$ of the current through NMDA receptors is mediated by $\mathrm{Ca} 2+$ under physiological conditions (Higley and Sabatini, 2012).

It has been shown that less than five and, occasionally only a single NMDA receptor opens under physiological conditions, causing a total $\mathrm{Ca} 2+$ influx of about 6000 ions into a dendritic spine head reaching a concentration of $\sim 10 \mu \mathrm{M}$ (Higley and Sabatini, 2012). However, the majority of the ions are rapidly eliminated by binding $\mathrm{Ca} 2+$ proteins, reaching $\sim 1 \mu \mathrm{M}$ of free $\mathrm{Ca} 2+$ concentration (Higley and Sabatini, 2012).

In rat primary forebrain cultures, the intracellular $\mathrm{Ca} 2+$ increases after activation of the NMDA receptor and this increase is blocked when the cells are cultured under $\mathrm{Ca} 2+$ free conditions, demonstrating that the NMDA-evoked increase in intracellular $\mathrm{Ca} 2+$ derives from extracellular and not intracellular sources (Liu et al., 2013). 
Neurons in brain slices from wild-type (GluRe2+/+) mice showed increase of intracellular Ca2+ in the presence of $100 \mu \mathrm{M}$ NMDA that was completely inhibited after exposure to $100 \mathrm{mM}$ APV. In contrast, the NMDA-mediated increase in $\mathrm{Ca} 2+$ was absent in brain slices from GluRe2-/mice that do not possess any functional NMDA receptors in the developing neocortex (Okada et al., 2003).

\section{Empirical Support for Linkage}

Pb2+: There are a few studies examining the effect of $\mathrm{Pb} 2+$ exposure on the changes in intracellular $\mathrm{Ca} 2+$. Incubation of rat synaptosomes with $\mathrm{Pb} 2+$ stimulates the activity of calmodulin reaching the higher effect at $30 \mu \mathrm{M}$, whereas higher concentrations of $\mathrm{Pb} 2+$ causes inhibition (Sandhir and Gill, 1994). Pb2+ exposure increases the activity of calmodulin by $45 \%$ in animal models. The IC50 values for inhibition of $\mathrm{Ca} 2+$ ATPase by $\mathrm{Pb} 2+$ has been found to be 13.34 and $16.69 \mu \mathrm{M}$ in calmodulin-rich and calmodulin-depleted synaptic plasma membranes, respectively. Exposure of rats to $\mathrm{Pb} 2+$ has also inhibitory effect on $\mathrm{Ca} 2+$ ATPase activity, causing increase in intrasynaptosomal Ca2+ (Sandhir and Gill, 1994). In embryonic rat hippocampal neurons, exposure to $100 \mathrm{nM} \mathrm{Pb} 2+$ for periods from 1 hour to 2 days shows decrease of intracellular $\mathrm{Ca} 2+$ by a calmodulin-dependent mechanism (Ferguson et al., 2000).

There is evidence that $\mathrm{Pb} 2+$ exposure affects $\mathrm{Ca} 2+$ homeostasis causing alterations in the phosphorylation state of different kinases. For example, $\mathrm{Pb} 2+$ has been shown to interfere with MAPK signaling as it increases the phosphorylation of both ERK1/2 and p38(MAPK) (Cordova et al., 2004). However, the findings regarding calcium/calmodulin kinase II (CamKII) activity are not clear (Toscano and Guilarte, 2005). On one hand, $\mathrm{Pb} 2+$ has been found to cause reduction of CREB phosphorylation in the hippocampus of rats exposed during brain development (Toscano et al., 2003; Toscano et al., 2002). On the other hand, the levels of phosphorylation of CamKII have not been explored but only the mRNA expression levels have been studied in rat pups on PND 25 that received $\mathrm{Pb} 2+(180$ and 375-ppm lead acetate in food for 30 days) and reached blood $\mathrm{Pb} 2+$ levels 5.8 to $10.3 \mu \mathrm{g} / \mathrm{dl}$ on PND 55 (Schneider et al., 2012). More specifically, CamKII $\alpha$ gene expression has been found to be very sensitive to $\mathrm{Pb} 2+$ exposure in the frontal cortex but not in the hippocampus, whereas CamKII $\beta$ gene expression in both brain structures remained unchanged (Schneider et al., 2012).

Acute $\mathrm{Pb} 2+(10 \mu \mathrm{M})$ exposure impairs LTP $(125.8 \%$ reduction of baseline) in CA1 region of hippocampus derived from Sprague-Dawley rats (15-18 PND) as it has been recorded by whole cell patch-clamp technique ( $\mathrm{Li}$ et al., 2006). In the same study, through calcium imaging, it has been shown in the $10 \mathrm{mM}$ caffeine-perfused cultured hippocampal neurons that $10 \mu \mathrm{M} \mathrm{Pb} 2+$ reduces intracellular Fluo-4 fluorescence ratio to 0.44 (Li et al., 2006).

$\mathrm{Pb} 2+$ chronically or acutely applied, significantly reduces LTP in CA1 region of hippocampus from Wistar or Sprague-Dawley rats (30 and 60 PND) (Carpenter et al., 2002). These animals were exposed to $\mathrm{Pb} 2+$ via the mother's drinking water either through gestation and lactation (upto day 21) (perinatal), only by lactation through the mother's drinking water and then in the pup's drinking water (post) or from gestation (pre and post). The concentrations of $\mathrm{Pb} 2+$ used in the drinking water were 0.1 and $0.2 \%$. In CA1, LTP has been reduced at both ages and $\mathrm{Pb} 2+$ concentrations or duration of exposure. In CA3, there have been no differences with time of exposure, but there was a dramatic difference in response as the age of animals increased. At 30 
days LTP was significantly reduced, but at 60 days LTP was increased by about $30 \%$ (Carpenter et al., 2002). In the same brain structure and area (CA3) the effects of Pb2+ on LTP have been different in $30 \mathrm{PND}$ and $60 \mathrm{PND}$ rats after either acute perfusion of $\mathrm{Pb} 2+$ or from slices derived from rats after chronic developmental exposure to $\mathrm{Pb} 2+$, as inhibition of LTP has been recorded in 30 PND CA3, whereas potentiation has been measured in 60 PND CA3 with either exposure paradigm that have been attributed to possible involvement of protein kinase $\mathrm{C}$ (Hussain et al., 2000). 


\begin{tabular}{|c|c|c|c|c|c|c|c|}
\hline Stressor & $\begin{array}{c}\text { Experimental } \\
\text { Model }\end{array}$ & $\begin{array}{c}\text { Tested } \\
\text { concentrations }\end{array}$ & $\begin{array}{c}\text { Exposure } \\
\text { route }\end{array}$ & Exposure duration & $\begin{array}{c}\text { Inhibition of NMDAR (KE } \\
\text { up) }\end{array}$ & $\begin{array}{l}\text { Reduced Ca 2+ } \\
\text { influx (KE down) }\end{array}$ & References \\
\hline Lead & $\begin{array}{l}\text { CA1 pyramidal } \\
\text { neurons derived } \\
\text { from Sprague- } \\
\text { Dawley rats (15- } \\
18 \text { PND) }\end{array}$ & $5-20 \mu \mathrm{M}$ & & $25 \mathrm{~min}$ & $\begin{array}{l}\text { By bath application of } 5 \mu \mathrm{M} \\
\text { lead for } 15 \text { min prior to and } 10 \\
\text { min after the tetanus, the LTP } \\
\text { was induced to } 151.4 \pm 3.5 \% \text { of } \\
\text { baseline. In the presence of } 10 \\
\mu \mathrm{M} \text { lead, the LTP was reduced } \\
\text { significantly to } 125.8 \pm 2.9 \% \text { of } \\
\text { baseline. The reduction of } 20 \\
\mu \mathrm{M} \text { to LTP was not significant } \\
\text { with that of } 10 \mu \mathrm{M} \text {. }\end{array}$ & $\begin{array}{l}\text { In the } 10 \mathrm{mM} \\
\text { caffeine-perfused } \\
\text { cultured } \\
\text { hippocampal } \\
\text { neurons, } 10 \mu \mathrm{M} \\
\text { lead reduced } \\
\text { intracellular Fluo- } \\
4 \text { fluorescence } \\
\text { ratio to } 0.44 \pm 0.08\end{array}$ & $\begin{array}{l}\text { Li et al., } \\
2006\end{array}$ \\
\hline Lead & $\begin{array}{l}\text { CA1 region of } \\
\text { hippocampus } \\
\text { from Wistar or } \\
\text { Sprague-Dawley } \\
\text { rats ( } 30 \text { and } 60 \\
\text { PND) }\end{array}$ & $\begin{array}{l}\text { Two } \\
\text { concentrations of } \\
\text { lead were used in } \\
\text { the drinking water } \\
0.1 \text { and } 0.2 \% \text {. }\end{array}$ & $\begin{array}{l}\text { in utero } \\
\text { and per os }\end{array}$ & $\begin{array}{l}\text { Rats exposed to lead } \\
\text { via the mother's } \\
\text { drinking water either } \\
\text { through gestation and } \\
\text { lactation (to day 21) } \\
\text { (perinatal), only by } \\
\text { lactation through the } \\
\text { mother's drinking } \\
\text { water and then in the } \\
\text { pup's drinking water } \\
\text { until use (post) or } \\
\text { from gestation until } \\
\text { use (pre and post). }\end{array}$ & $\begin{array}{l}\text { In CA1, LTP is reduced at } \\
\text { both ages, and there were no } \\
\text { significant differences in the } \\
\text { effects of the two lead } \\
\text { concentrations or with the } \\
\text { duration of exposure. In CA3, } \\
\text { there were no differences with } \\
\text { time of exposure, but there } \\
\text { was a dramatic difference in } \\
\text { response as a function of age. } \\
\text { At } 30 \text { days, LTP was } \\
\text { significantly reduced but at } 60 \\
\text { days LTP was increased by } \\
\text { about } 30 \% \text {. As in the chronic } \\
\text { exposure studies, lead reduced } \\
\text { LTP in CA1 at both ages but } \\
\text { reduced LTP in CA3 in } 30 \text {-day } \\
\text { animals while potentiating } \\
\text { LTP in } 60 \text {-day animals. }\end{array}$ & & $\begin{array}{l}\text { Carpenter } \\
\text { et al., } 2002\end{array}$ \\
\hline
\end{tabular}


Uncertainties or Inconsistencies

The structural diversity of NMDA subunits can influence the functionality of the receptors and their permeability to $\mathrm{Ca} 2+$. For example, NR2B subunits show higher affinity for glutamate binding and higher $\mathrm{Ca} 2+$ permeability (reviewed in Higley and Sabatini, 2012). But NMDA receptor subunit composition is not the only parameter that influences $\mathrm{Ca} 2+$ entrance in the cytosol. Membrane potential due to pore blockade by extracellular $\mathrm{Mg} 2+$ and receptor phosphorylation are two additional regulator of $\mathrm{Ca} 2+$ influx through NMDA receptors (reviewed in Higley and Sabatini, 2012).

Entrance of $\mathrm{Ca} 2+$ into neuronal cell can also happen through KA and AMPA receptors but to a smaller extend compared to NMDA receptors (reviewed in Higley and Sabatini, 2012). However, recent findings suggest that AMPA receptors may also contribute to $\mathrm{Ca} 2+$ signalling during CNS development (reviewed in Cohen and Greenberg, 2008). Early in development cortical pyramidal neurons express calcium-permeable, GluR2 subunit-lacking AMPA receptors. During postnatal development these neurons undergo a switch in the subunit composition of AMPA receptors, expressing instead GluR2-containing, calcium-impermeable AMPA receptor suggesting that the main point entrance of $\mathrm{Ca} 2+$ at this developmental stage are NMDA receptors.

Furthermore, $\mathrm{Ca} 2+$ entry occurs through L- and H-type voltage-dependent Ca2+channels (LVDCCs) (Perez-Reyes and Schneider, 1994; Berridge, 1998; Felix, 2005) that are encountered in neurons, suggesting that there are more possible entrance sites for $\mathrm{Ca} 2+$ to get into the cytosol rather than only through NMDA receptors.

Interestingly, $\mathrm{Pb} 2+$ has the ability to mimic or even compete with $\mathrm{Ca} 2+$ in the CNS (Flora et al., 2006). Indeed, $\mathrm{Pb} 2+$ is accumulated in the same mitochondrial compartment as $\mathrm{Ca} 2+$ and it has been linked to disruptions in intracellular calcium metabolism (Bressler and Goldstein, 1991). So, it can be that the reduced levels of $\mathrm{Ca} 2+$ after $\mathrm{Pb} 2+$ exposure may not be attributed to NMDA receptor inhibition but also to the ability of this heavy metal to compete with $\mathrm{Ca} 2+$. To make things more complicated, recent findings suggest that BDNF can also acutely elicit an increase in intracellular $\mathrm{Ca} 2+$ concentration, which is attributed not only to the influx of extracellular $\mathrm{Ca} 2+$ but also to $\mathrm{Ca} 2+$ mobilization from intracellular calcium stores (Numakawa et al., 2002; He et al., 2005). These finding derive from primary cultures of cortical neurons (E18 or 2-3 PND), where BDNF-evoked $\mathrm{Ca} 2+$ signals have not been altered neither by tetrodotoxin nor by a cocktail of glutamate receptor blockers (CNQX and APV), pointing out the importance of BDNF in $\mathrm{Ca} 2+$ homeostasis (Numakawa et al., 2002; He et al., 2005).

Quantitative understanding of the linkage

No enough data is available to address the questions above.

Evidence supporting taxonomic applicability

Besides the above studies described in rodents, intracellular $\mathrm{Ca} 2+$ regulation has been studied at the neuromuscular junction of larval Drosophila exposed to $0,100 \mu \mathrm{M}$ or $250 \mu \mathrm{M} \mathrm{Pb} 2+(\mathrm{He}$ et al., 2009). 


\section{References}

Berridge, M.J. (1998), Neuronal calcium signaling. Neuron 21: 13-26.

Bressler, J.P., and G.W. Goldstein (1991), Mechanisms of lead neurotoxicity. Biochem Pharmacol. 41: 479-484.

Carpenter, D.O. et al. (2002), Electrophysiologic and behavioral effects of perinatal and acute exposure of rats to lead and polychlorinated biphenyls. Environ Health Perspect. 110: 377-386.

Cohen, S., and M.E. Greenberg (2008), Communication between the synapse and the nucleus in neuronal development, plasticity and disease. Annu Rev Cell Dev Biol. 24: 183-209.

Cordova, F.M. et al. (2004), Lead stimulates ERK1/2 and p38MAPK phosphorylation in the hippocampus of immature rats. Brain Res. 998: 65-72.

Felix, R. (2005), Molecular regulation of voltage-gated Ca2+ channels. J Recept Signal Transduct Res. 25: 57-71.

Ferguson, C., M. Kern and G. Audesirk (2000), Nanomolar concentrations of inorganic lead increase Ca2+ efflux and decrease intracellular free $\mathrm{Ca} 2+$ ion concentrations in cultured rat hippocampal neurons by a calmodulin-dependent mechanism. Neurotoxicology 21: 365-378.

Flora, S.J.S., G. Flora and G. Saxena (2006), Environmental occurrence, health effects and management of lead poisoning, in Lead: Chemistry, Analytical Aspects, Environmental Impacts and Health Effects (Cascas SB and Sordo J eds) Elsevier, Amsterdam, The Netherlands, pp 158-228.

He, J., H. Gong and Q. Luo (2005), BDNF acutely modulates synaptic transmission and calcium signalling in developing cortical neurons. Cell Physiol Biochem. 16: 69-76.

He, T. et al. (2009), Chronic lead exposure alters presynaptic calcium regulation and synaptic facilitation in Drosophila larvae. Neurotoxicology 30: 777-784.

Higley, M.J., and B.L. Sabatini (2012), Calcium signalling in dendritic spines. Cold Spring Harb Perspect Biol 4: a005686.

Hussain, R.J., P.J. Parsons and D.O. Carpenter (2000), Effects of lead on long-term potentiation in hippocampal CA3 vary with age. Brain Res Dev Brain Res. 121: 243-252.

Li, X.M. et al. (2006), Lead inhibited N-methyl-D-aspartate receptor-independent long-term potentiation involved ryanodine-sensitive calcium stores in rat hippocampal area CA1. Neuroscience 139: 463473.

Liu, F. et al. (2013), Ketamine-induced neuronal damage and altered N-methyl-D-aspartate receptor function in rat primary forebrain culture. Toxicol Sci. 131: 548-557.

Numakawa, T. et al. (2002), Brain-derived neurotrophic factor-induced potentiation of Ca2+ oscillations in developing cortical neurons. J Biol Chem. 277: 6520-6529.

Okada, H. et al. (2003), NMDA receptors in cortical development are essential for the generation of coordinated increases in [Ca2+](i) in "neuronal domains". Cereb Cortex. 13: 749-757.

Perez-Reyes, E., and T. Schneider (1994), Calcium channels: Structure, function, and classification. Drug Dev Res. 33: 295-318.

Sandhir, R., and K.D. Gill (1994), Alterations in calcium homeostasis on lead exposure in rat synaptosomes. Mol Cell Biochem. 131: 25-33.

Schneider, J.S., W. Mettil and D.W. Anderson (2012), Differential Effect of Postnatal Lead Exposure on Gene Expression in the Hippocampus and Frontal Cortex. J Mol Neurosci. 47: 76-88.

Sinner, B. et al. (2005), Ketamine stereoselectively inhibits spontaneous Ca2+-oscillations in cultured hippocampal neurons. Anesthesia and analgesia 100: 1660-1666.

Toscano, C.D. and T.R. Guilarte (2005), Lead neurotoxicity: From exposure to molecular effects. Brain Res Rev. 49: 529-555. 
Toscano, C.D. et al. (2002), Developmental Pb2+ exposure alters NMDAR subtypes and reduces CREB phosphorylation in the rat brain. Dev Brain Res. 139: 217-226.

Toscano, C.D., J.L. McGlothan and T.R. Guilarte (2003), Lead exposure alters cyclic-AMP response element binding protein phosphorylation and binding activity in the developing rat brain. Dev Brain Res. 145: 219-228.

\section{Calcium influx, Decreased leads to Release of BDNF, Reduced}

\section{How Does This Key Event Relationship Work}

Mainly, NMDA receptor activation initiates $\mathrm{Ca} 2+$-dependent signaling events that regulate the expression of genes involved in regulation of neuronal function including bdnf (reviewed in Cohen and Greenberg, 2008). Inhibition of NMDA receptors results in low levels of $\mathrm{Ca} 2+$ and decreased transcription of BDNF and consequently to low level of BDNF protein production and release.

Weight of Evidence

Biological Plausibility

BDNF transcription is induced by $\mathrm{Ca} 2+$ entering through either $\mathrm{L}$ type voltage gated calcium channel (L-VGCC) (Tao et al., 1998) or NMDA receptor (Tabuchi et al., 2000; Zheng et al., 2011) that can last up to $6 \mathrm{~h}$. BDNF IV that is the most studied among its different exons has been shown to bind three $\mathrm{Ca} 2+$ elements within the regulatory region (reviewed in Zheng et al., 2012). One of these $\mathrm{Ca} 2+$ elements binds to CREB facilitating transcription. However, more transcription factors rather than only CREB are implicated in the transcription process of BDNF such as NFAT (nuclear factor of activated T cell), MEF2 (myocyte enhancer factor 2) and NFKB (nuclear factor $\mathrm{\kappa B}$ ) (reviewed in Zheng et al., 2012). The activation of the relevant transcription factor is triggered by the initial activation of CaM kinase, cAMP/PKA and Ras/ERK1/2 pathways mediated by the elevated intracellular $\mathrm{Ca} 2+$. Interestingly, inhibitory studies targeting different elements of these pathways report reduction at mRNA BDNF levels (reviewed in Zheng et al., 2012).

In particular, exon IV BDNF mRNA transcription is regulated by a transcriptional silencer, methyl-CpG binding protein 2 (MeCP2), demonstrating that epigenetic alterations can also regulate BDNF transcription. Increase of intracellular $\mathrm{Ca} 2+$ levels phosphorylates $\mathrm{MeCP} 2$, which inactivates its repressor function and permits the transcription of BDNF exon IV (Chen et al., 2003; Greer and Greenberg, 2008; Tao et al., 2009; Zhou et al., 2006). Indeed, NMDA receptor activation has been shown to upregulate BDNF transcripts containing exon IV not only via Ca2+dependent CREB but also through Ca2+ activation of MeCP2 transcription (Metsis et al., 1993; Shieh et al., 1998, Tao et al., 1998; Tabuchi et al., 2000; Chen et al., 2003; Jiang et al., 2005; Zheng et al., 2011), whereas NMDAR antagonists decrease BDNF exon IV expression (Zafra et al., 1991; Stansfield et al., 2012). Furthermore, BDNF mRNA is also targeted in different locations within the cell during the process of translation, depending on the promoter used (reviewed in Tongiorgi et al., 2006). 


\section{Empirical Support for Linkage}

There is no direct evidence linking reduced levels of $\mathrm{Ca} 2+$ to decreased BDNF levels as they have not been ever measured both in the same study after exposure to stressors. However, there are findings that strongly link the different elements of $\mathrm{Ca} 2+$-dependent signalling events to transcription of BDNF.

Pb2+: $\mathrm{Pb} 2+$ decreases the ratio of phosphorylated versus total MeCP2 and consequently MeCP2 maintains its repressor function and prevents BDNF exon IV transcription (Stansfield et al., 2012). MeCP2 gene expression in the frontal cortex is very sensitive to $\mathrm{Pb} 2+$ exposure while in the hippocampus, the same gene is affected only at the higher exposure group in rat pups with blood $\mathrm{Pb} 2+$ levels 5.8 to $10.3 \mu \mathrm{g} / \mathrm{dl}$ on PND 55 (Schneider et al., 2012). In two different in vivo studies from the same research group, the use of doses of $\mathrm{Pb} 2+$ that result in learning and LTP deficits in rats causes decrease in phosphorylation of CREB in cerebral cortex at 14 PND and the same reduction in phosphorylation state of CREB in both cortex and hippocampus at PND 50 (Toscano et al., 2002; 2003). Interestingly, under similar experimental conditions no alteration at the phosphorylation state of CAMKII has been recorded (Toscano et al., 2005). In primary hippocampal neurons exposed to $1 \mu \mathrm{M} \mathrm{Pb} 2+$ for 5 days during the period of synaptogenesis (DIV7-DIV12), both the cellular and extracellular proBDNF protein levels of mBDNF decrease with the latter to smaller extend (Neal et al., 2010). In the same in vitro model, $\mathrm{Pb} 2+$ also decreases dendritic proBDNF protein levels throughout the length of the dendrites and causes impairment of BDNF vesicle transport to sites of release in dendritic spines (Stansfield et al., 2012). Furthermore, $\mathrm{Pb} 2+$ treatment resulted in a specific reduction of Bdnf exon IV and IX mRNA transcripts causing no alteration in the expression of exons I and II (Stansfield et al., 2012). Rat pups on PND 25 exposed to $\mathrm{Pb} 2+$ (180 and 375-ppm lead acetate in food for 30 days) demonstrated blood $\mathrm{Pb} 2+$ levels 5.8 to $10.3 \mu \mathrm{g} / \mathrm{dl}$ on PND 55 and show no change at gene levels of BDNF (Schneider et al., 2012). In mouse embryonic stem cells (ESCs), Bdnf exon IV has been found to be down-regulated in cells treated with $0.1 \mu \mathrm{M} \mathrm{Pb}$, whereas Bdnf exon IX has been found up-regulated (Sánchez-Martín et al., 2013).

Uncertainties or Inconsistencies

In a gene expression study, where gene analysis has been performed in the hippocampus derived from male or female rats fed with $1500 \mathrm{ppm} \mathrm{Pb} 2+$-containing chow for 30 days beginning at weaning, two molecular networks have been identified that were different between male and female treated rats. In these networks, CREB was the highly connected node, common for both networks (Schneider et al., 2011). However, no change has been reported in the expression of bdnf gene neither in male nor in female rats treated with $\mathrm{Pb} 2+$ (Schneider et al., 2011).

Quantitative understanding of the linkage

No enough data is available to address the questions above.

\section{References}

Chen, W.G. et al. (2003), Derepression of BDNF transcription involves calcium-dependent phosphorylation of MeCP2. Science 302: 885-889. 
Cohen, S., and M.E. Greenberg (2008), Communication between the synapse and the nucleus in neuronal development, plasticity and disease. Annu Rev Cell Dev Biol. 24: 183-209.

Greer, P.L. and M.E. Greenberg (2008), From synapse to nucleus: Calcium-dependent gene transcription in the control of synapse development and function. Neuron 59: 846-860.

Heaton, M.B., J.J. Mitchell and M. Paiva (1999), Ethanol-induced alterations in neurotrophin expression in developing cerebellum: relationship to periods of temporal susceptibility. Alcohol Clin Exp Res. 23: 1637-1642.

Jiang, X. et al. (2005), The excitoprotective effect of N-methyl-D-aspartate receptors is mediated by a brain-derived neurotrophic factor autocrine loop in cultured hippocampal neurons. J Neurochem. 94: 713-722.

Metsis, M. et al. (1993), Differential usage of multiple brain-derived neurotrophic factor promoters in the rat brain following neuronal activation. Proc Natl Acad. Sci USA. 90: 8802-8806.

Neal, A.P. et al. (2010), Lead exposure during synaptogenesis alters vesicular proteins and impairs vesicular release: Potential role of NMDA receptor-dependent BDNF signaling. Toxicol Sci. 116: 249-263.

Sánchez-Martín, F.J. et al. (2013), Lead Induces Similar Gene Expression Changes in Brains of Gestationally Exposed Adult Mice and in Neurons Differentiated from Mouse Embryonic Stem Cells. PLoS One 8: e80558.

Schneider, J.S. et al. (2011), Sex-based differences in gene expression in hippocampus following postnatal lead exposure. Toxicol Appl Pharmacol. 256: 179-190.

Schneider, J.S., W. Mettil and D.W. Anderson (2012), Differential Effect of Postnatal Lead Exposure on Gene Expression in the Hippocampus and Frontal Cortex. J Mol Neurosci. 47: 76-88.

Shieh, P.B. et al. (1998), Identification of a signaling pathway involved in calcium regulation of BDNF expression. Neuron 20: 727-740.

Stansfield, K.H. et al. (2012), Dysregulation of BDNF-TrkB signaling in developing hippocampal neurons by $\mathrm{Pb}(2+)$ : implications for an environmental basis of neurodevelopmental disorders. Toxicol Sci. 127: 277-295.

Toscano, C.D. et al. (2002), Developmental Pb2+ exposure alters NMDAR subtypes and reduces CREB phosphorylation in the rat brain. Brain Res Dev Brain Res. 139: 217-226.

Toscano, C.D., J.L. McGlothan and T.R. Guilarte (2003), Lead exposure alters cyclic-AMP response element binding protein phosphorylation and binding activity in the developing rat brain. Brain Res. Dev. Brain Res. 145: 219-228.

Toscano, C.D., J.P. O'Callaghan and T.R. Guilarte (2005), Calcium/calmodulin-dependent protein kinase II activity and expression are altered in the hippocampus of Pb2+-exposed rats. Brain Res. 1044: 5158.

Tabuchi, A. et al. (2000), Differential activation of brain-derived neurotrophic factor gene promoters I and III by $\mathrm{Ca} 2+$ signals evoked via L-type voltage-dependent and N-methyl-D-aspartate receptor $\mathrm{Ca} 2+$ channels. J Biol Chem. 275: 17269-17275.

Tao, X. et al. (1998), Ca2+ influx regulates BDNF transcription by a CREB family transcription factordependent mechanism. Neuron 20: 709-726.

Tao, J. et al. (2009), Phosphorylation of MeCP2 at Serine 80 regulates its chromatin association and neurological function. Proc Natl Acad Sci USA. 106: 4882-4887.

Tongiorgi, E., L. Domenici and M. Simonato (2006), What is the biological significance of BDNF mRNA targeting in the dendrites? Clues from epilepsy and cortical development. Mol Neurobiol. 33: 17-32.

Zheng, F. et al. (2011), Regulation of brain-derived neurotrophic factor exon IV transcription through calcium responsive elements in cortical neurons. PLoS One 6: e28441. 
Zheng, F. et al. (2012), Regulation of brain-derived neurotrophic factor expression in neurons. In J Pathophysiol Pharmacol 4: 188-200.

Zafra, F. et al. (1991), Interplay between glutamate and gamma-aminobutyric acid transmitter systems in the physiological regulation of brain-derived neurotrophic factor and nerve growth factor synthesis in hippocampal neurons. Proc Natl Acad Sci U S A. 88: 10037-10041.

Zhou, Z. et al. (2006), Brain-specific phosphorylation of MeCP2 regulates activity-dependent Bdnf transcription, dendritic growth, and spine maturation. Neuron 52: 255-269.

\section{Release of BDNF, Reduced leads to Dendritic morphology, Aberrant}

How Does This Key Event Relationship Work

The dendritically synthesized BDNF when secreted activates tyrosine kinase B (TrkB) receptors that induce the synthesis of a number of proteins involved in the development of proper dendritic spine morphology.

\section{Weight of Evidence}

Biological Plausibility

After activation of tyrosine kinase B (TrkB) receptors by BDNF proteins such as Arc, Homer2, LIMK1 (Kang and Schuman, 1996, Schratt et al., 2004 and Yin et al., 2002) that are known to promote actin polymerization and consequently enlargement of spine heads (Sala et al., 2001) are released. Recently, it has been shown that BDNF promotes dendritic spine formation by interacting with Wnt signaling. Indeed, Wnt signaling inhibition in cultured cortical neurons caused disruption in dendritic spine development, reduction in dendritic arbor size and complexity and blockage of BDNF-induced dendritic spine formation and maturation (Hiester et al., 2013).

In addition, it has been shown that the inhibition of BDNF synthesis reduces the size of spine heads and impairs LTP (An et al., 2008; Waterhouse and $\mathrm{Xu}, 2009$ ). BDNF has been characterized as a critical factor in promoting dendritic morphogenesis in various types of neurons (reviewed in Jan and Jan, 2010; Park and Poo, 2013).

BDNF that is synthesised in dendrites is known to regulate the morphology of spines (Tyler and Pozzo-Miller, 2003; An et al., 2008). For example, spines in the absence of spontaneous electrical activity are significantly smaller than normal (Harvey et al., 2008). On the other hand, simultaneous electrical activity and glutamate release increase the size of the spine head, which has been shown to be dependent on BDNF (Tanaka et al., 2008).

Mice harboring the Val66Met mutation of Bdnf gene show dendritic arborisation defects in the hippocampus. Interestingly, human subjects with the Val66Met SNP demonstrate similar anatomical features (reviewed in Cohen and Greenberg, 2008).

More targeted studies have shown that, within the physiological range of expression, dendritic spine density is tightly regulated by BDNF in the dentate gyrus but not in CA1 pyramidal cells (Alexis and Stranahan, 2011). 
Exposure of rat hippocampal neurons in culture to BDNF causes increase in cypin mRNA and protein levels, which is a known guanine deaminase that activates dendritic arborisation. This increase of cypin induced by BDNF appears after $72 \mathrm{~h}$ but not at earlier time points (Kwon et al., 2011), meaning that BDNF has to act first in order to stimulate dendritic arbor formation.

Pb2+: The first hint for involvement of $\mathrm{Pb} 2+$ in dendritic morphology was described by Alfano and Petit. 1982. They have demonstrated reduction in the length of dendritic processes and the number of dendritic branches in hippocampal dentate granule cells after developmental $\mathrm{Pb} 2+$ exposure of Long-Evans hooded rat pups (Alfano and Petit, 1982). More recently, it has been shown that the chronic exposure of rats to environmentally relevant levels ( $\mathrm{Pb} 2+$ blood levels 25.8 $\pm 1.28 \mu \mathrm{g} / \mathrm{dL}$ ) during early life alters cell morphology in the dentate gyrus as immature granule cells immunolabeled with doublecortin display aberrant dendritic morphology (Verina et al., 2007).

Exposure of rats to $\mathrm{Pb} 2+$ that initiated at embryonic phase and terminated at PND 21 have revealed that at PND $14(\mathrm{~Pb} 2+$ concentration in the hippocampus $0.249 \pm 0.06 \mu \mathrm{g} / \mathrm{g}$ ) and PND 21 $(\mathrm{Pb} 2+$ concentration in the hippocampus $0.471 \pm 0.11 \mu \mathrm{g} / \mathrm{g})$ the number of dendritic spine on hippocampal CA1 area decreases by $32.83 \%$ and $24.11 \%$, respectively ( $\mathrm{Hu}$ et al., 2014). The length-density of the doublecortin-positive apical dendrites in the outer portion of the dentate gyrus molecular layer has been found significantly decreased up to $36 \%$ in chronically exposed rats to environmentally relevant levels of $\mathrm{Pb} 2+(\mathrm{Pb} 2+$ blood levels $25.8 \pm 1.28 \mu \mathrm{g} / \mathrm{dL})$ (Verina et al., 2007). In another in vivo study, lower blood levels of $\mathrm{Pb} 2+(10 \pm 1.28 \mu \mathrm{g} / \mathrm{dL})$ in similar age of rats has led to significant decrease of BDNF concentration ( $\mathrm{pg} / \mathrm{mg}$ protein) that is $39 \%$ in forebrain cortex and 29\% in hippocampus (Baranowska-Bosiacka et al., 2013).

In cultured rat hippocampal neurons, low levels of $\mathrm{Pb} 2+(0.1$ and $1 \mu \mathrm{M})$ cause reduction of dendritic spine density in a dose-dependent manner (Hu et al., 2014). In a similar in vitro model, exposure to $1 \mu \mathrm{M} \mathrm{Pb} 2+$ for 5 days during the period of synaptogenesis (DIV7-DIV12), significantly reduces proBDNF protein and extracellular levels of mBDNF (Neal et al., 2010). When mouse embryonic stem cells are differentiated into neurons, exposure to lead (II) acetate causes reduction in the percentage of microtubule-associated protein 2 (MAP-2)-positive cells and in the mRNA levels of MAP-2 in a dose-dependent manner (Baek et al., 2011). Similar effects were found in dissociated cells derived from neuro-spheres generated from neural stem cells (NSCs) originating from E15 rat cortex (CX), striatum (ST) or ventral mesencephalon (VM) exposed for 7 days to lead acetate (Huang and Schneider, 2004). More specifically, lead exposure $(0.1-10 \mu \mathrm{M})$ decreases MAP-2-positive cells of ST and VM-derived NSCs, whereas there is no effect in CX-derived NSCs. VM-derived NSCs have the greatest sensitivity to the inhibitory effects of lead exposure causing 25\% decrease in MAP-2-positive cells at $0.1 \mu \mathrm{M}$ and almost $50 \%$ at $10 \mu \mathrm{M}$ (Huang and Schneider, 2004). 


\begin{tabular}{|c|c|c|c|c|c|c|c|}
\hline Stressor & $\begin{array}{c}\text { Experimental } \\
\text { Model }\end{array}$ & Tested concentrations & $\begin{array}{c}\text { Exposure } \\
\text { route }\end{array}$ & Exposure duration & $\begin{array}{l}\text { Release of BDNF, } \\
\text { Reduced (KE up) }\end{array}$ & $\begin{array}{c}\text { Dendritic } \\
\text { morphology, } \\
\text { Aberrant (KE } \\
\text { down) }\end{array}$ & References \\
\hline Lead & SD rats & $\begin{array}{l}\text { SD rat dams were } \\
\text { given drinking distilled } \\
\text { water and lead water } \\
\text { ( } 250 \text { ppm lead acetate } \\
\text { in distilled water, } 30 \\
\text { ml/day). The lead- } \\
\text { exposed pups acquired } \\
\text { lead via milk of dams } \\
\text { during lactation period. } \\
\text { In vivo experiments } \\
\text { were carried out at the } \\
\text { age of } 14 \text { and } 21 \text { days. } \\
\text { PND } 14(\mathrm{~Pb} 2+ \\
\text { concentration in the } \\
\text { hippocampus } \\
0.249 \pm 0.06 \mu \mathrm{g} / \mathrm{g}) \text { and } \\
\text { PND } 21(\mathrm{~Pb} 2+ \\
\text { concentration in the } \\
\text { hippocampus } \\
0.471 \pm 0.11 \mu \mathrm{g} / \mathrm{g})\end{array}$ & $\begin{array}{l}\text { in utero } \\
\text { and per os }\end{array}$ & $\begin{array}{l}\text { Exposure of rats to } \\
\mathrm{Pb} 2+\text { that initiated at } \\
\text { embryonic phase and } \\
\text { terminated at PND } 14 \\
\text { and } 21\end{array}$ & & $\begin{array}{l}\text { Dendritic spine on } \\
\text { hippocampal CA1 } \\
\text { area decreases by } \\
32.83 \% \text { (PND 14) } \\
\text { and } 24.11 \% \text { (PND } \\
21 \text { ) }\end{array}$ & $\begin{array}{l}\text { Hu et al., } \\
2014\end{array}$ \\
\hline
\end{tabular}




\begin{tabular}{|c|c|c|c|c|c|c|}
\hline Lead & Long-Evans rats & $\begin{array}{l}\text { Female rats }(225-250 \\
\text { g) were fed } 0 \text { or } 1500- \\
\text { ppm Pb2+ acetate } \\
(\mathrm{Pb} 2+\text { blood levels } \\
25.8 \pm 1.28 \mu \mathrm{g} / \mathrm{dL})\end{array}$ & $\begin{array}{l} \\
\text { in utero } \\
\text { and per os }\end{array}$ & $\begin{array}{l}\text { Feeding of the Pb2+- } \\
\text { containing and } \\
\text { control diets was } \\
\text { initiated } 10 \text { days } \\
\text { before breeding } \\
\text { females to untreated } \\
\text { Long-Evans male } \\
\text { rats. Dams were } \\
\text { maintained on their } \\
\text { respective diets } \\
\text { during gestation and } \\
\text { lactation. Litters were } \\
\text { culled to } 10 \text { animals } \\
\text { one day after birth } \\
\text { and weaned at } \\
\text { postnatal day (PN) } 21 \\
\text { at which time they } \\
\text { were fed the same } \\
\text { diet as their } \\
\text { corresponding mother }\end{array}$ & $\begin{array}{l}\text { The length-density of } \\
\text { the doublecortin- } \\
\text { positive apical } \\
\text { dendrites in the outer } \\
\text { portion of the dentate } \\
\text { gyrus molecular layer } \\
\text { has been found } \\
\text { significantly } \\
\text { decreased up to } 36 \% \\
\text { in chronically } \\
\text { exposed rats }\end{array}$ & $\begin{array}{l}\text { Verina et al., } \\
2007\end{array}$ \\
\hline
\end{tabular}




\begin{tabular}{|c|c|c|c|c|c|c|c|}
\hline Lead & Wistar rats & $\begin{array}{l}\text { Pregnant females } \\
\text { received } 0.1 \% \text { lead } \\
\text { acetate }(\mathrm{PbAc}) \text { and led } \\
\text { to blood levels of } \mathrm{Pb} 2+ \\
(10 \pm 1.28 \mu \mathrm{g} / \mathrm{dL}) \text { in } \\
\text { pups }\end{array}$ & in utero & $\begin{array}{l}\text { Offspring (males and } \\
\text { females) stayed with } \\
\text { their mothers and } \\
\text { were fed by them. } \\
\text { During the feeding of } \\
\text { pups, mothers from } \\
\text { the experimental } \\
\text { group were still } \\
\text { receiving PbAc in } \\
\text { drinking water ad } \\
\text { libitum. Pups were } \\
\text { weaned at postnatal } \\
\text { day } 21 \text { (PND 21) and } \\
\text { received only } \\
\text { distilled water ad } \\
\text { libitum until PND } 28 .\end{array}$ & $\begin{array}{l}\text { Decrease of BDNF } \\
\text { concentration (pg/mg } \\
\text { protein) that is } 39 \% \text { in } \\
\text { forebrain cortex and } \\
29 \% \text { in hippocampus }\end{array}$ & & $\begin{array}{l}\text { Baranowska- } \\
\text { Bosiacka et } \\
\text { al., } 2013\end{array}$ \\
\hline Lead & $\begin{array}{l}\text { Primary } \\
\text { hippocampal } \\
\text { cultures were } \\
\text { prepared from } \\
\text { brains of SD rats } \\
\text { at postnatal day } 0 \\
\text { (P0) }\end{array}$ & $0.1 \mu \mathrm{M}$ and $1 \mu \mathrm{M}$ & & $\begin{array}{l}\text { Exposure from DIV7 } \\
\text { to DIV12 }\end{array}$ & & $\begin{array}{l}\text { The dendritic spine } \\
\text { density was } \\
\text { significantly } \\
\text { decreased about } \\
25.84 \% \text { and } 42.70 \% \text {, } \\
\text { compared to the } \\
\text { control group }\end{array}$ & $\begin{array}{l}\text { Hu et al., } \\
2014\end{array}$ \\
\hline Lead & $\begin{array}{l}\text { Primary } \\
\text { hippocampal } \\
\text { cultures obtained } \\
\text { from E18 } \\
\text { Sprague-Dawley } \\
\text { rat pups }\end{array}$ & $1 \mu \mathrm{M}$ & & $\begin{array}{l}\text { Exposure from DIV7 } \\
\text { to DIV12 }\end{array}$ & $\begin{array}{l}\mathrm{Pb} 2+\text { exposure during } \\
\text { synaptogenesis } \\
\text { reduces cellular levels } \\
\text { of proBDNF protein } \\
\text { by } 40 \% \text { and reduces } \\
\text { the amount of BDNF } \\
\text { found in the neuron } \\
\text { culture medium } \\
\text { determined by ELISA } \\
\text { by almost } 30 \%\end{array}$ & & $\begin{array}{l}\text { Neal et al., } \\
2010\end{array}$ \\
\hline
\end{tabular}




\begin{tabular}{|c|c|c|c|c|c|}
\hline Lead & $\begin{array}{l}\text { Primary } \\
\text { hippocampal } \\
\text { cultures obtained } \\
\text { from E18 } \\
\text { Sprague-Dawley } \\
\text { rat pups }\end{array}$ & 1 and $2 \mu \mathrm{M}$ & $\begin{array}{l}\text { } \\
\text { Exposure from DIV7 } \\
\text { to DIV12 }\end{array}$ & $\begin{array}{l}\text { Quantitative real-time } \\
\text { PCR of BDNF exon I, } \\
\text { II, IV, and IX showed } \\
\text { a significant effect of } \\
\text { Pb2+ exposure on } \\
\text { exons IV and IX } \\
\text { transcripts with no } \\
\text { effects on exons I and } \\
\text { II ( } 2 \text { fold reduction } \\
\text { compared to controls. } \\
\text { Found significant } \\
\text { reductions in dendritic } \\
\text { proBDNF levels that } \\
\text { were apparent } \\
\text { throughout the length } \\
\text { of the dendrites. } \\
\text { Western blots } \\
\text { confirmed that whole- } \\
\text { cell proBDNF protein } \\
\text { levels were } \\
\text { significantly } \\
\text { decreased after } \\
\text { exposure to } 1 \text { and } \\
2 \mu \mathrm{M} \text { Pb2+ by } 20 \text { and } \\
25 \%, \text { respectively. In } \\
\text { addition, extracellular } \\
\text { levels of BDNF } \\
\text { measured by ELISA } \\
\text { were also significantly } \\
\text { reduced by Pb2+ after } \\
\text { exposure to } 1 \text { and } \\
2 \mu \mathrm{M} \text { Pb2+ by } 40 \text { and } \\
60 \%, \text { respectively. }\end{array}$ & $\begin{array}{l}\text { Stansfield et } \\
\text { al., } 2012\end{array}$ \\
\hline
\end{tabular}




\begin{tabular}{|c|c|c|c|c|c|}
\hline Lead & $\begin{array}{l}\text { Neural stem cells } \\
\text { (NSCs) } \\
\text { originating from } \\
\text { E15 rat cortex } \\
(\mathrm{CX}), \text { striatum } \\
(\mathrm{ST}) \text { or ventral } \\
\text { mesencephalon } \\
(\mathrm{VM}) \text {. }\end{array}$ & $0.1-10 \mu \mathrm{M}$ & $\begin{array}{l}\text { Neuro-spheres } \\
\text { generated from NSCs } \\
\text { originating in } \\
\text { different brain } \\
\text { regions were primed } \\
\text { with lead acetate for } \\
3 \text { days and then } \\
\text { dissociated into } \\
\text { single cells and } \\
\text { plated on poly-d- } \\
\text { ornithine pre-coated } \\
\text { chamber slides. Cells } \\
\text { were allowed to grow } \\
\text { in differentiation } \\
\text { medium for } 7 \text { days } \\
\text { with or without } \\
\text { addition of lead } \\
\text { acetate. }\end{array}$ & $\begin{array}{l}\text { Lead exposure (0.1- } \\
10 \mu \mathrm{M}) \text { had no } \\
\text { significant effect on } \\
\text { MAP2 levels in CX- } \\
\text { derived NSCs. Lead } \\
\text { exposure decreased } \\
\text { MAP-2-positive cells } \\
\text { of ST and VM- } \\
\text { derived NSCs at } \\
\text { concentrations of } 0.1- \\
10 \mu \mathrm{M} \text {. VM-derived } \\
\text { NSCs had the greatest } \\
\text { sensitivity to the } \\
\text { inhibitory effects of } \\
\text { lead exposure causing } \\
25 \% \text { decrease in } \\
\text { MAP-2-positive cells } \\
\text { at } 0.1 \mu \mathrm{M} \text { and almost } \\
50 \% \text { at } 10 \mu \mathrm{M} \text {. }\end{array}$ & $\begin{array}{l}\text { Huang and } \\
\text { Schneider, } \\
2004\end{array}$ \\
\hline
\end{tabular}




\begin{tabular}{|c|c|c|c|c|c|}
\hline Lead & $\begin{array}{l}\text { D3 mouse ES } \\
\text { (ES-D3) cells } \\
\text { and 3T3 mouse } \\
\text { embryonic } \\
\text { fibroblast cells }\end{array}$ & 0.3 to $30 \mu \mathrm{g} / \mathrm{mL}$ & $\begin{array}{l}\text { Lead (II) acetate was } \\
\text { applied to ES cells } \\
\text { during neuronal } \\
\text { differentiation }\end{array}$ & $\begin{array}{l}\text { The number of MAP- } \\
\text { 2-positive cells } \\
\text { decreased when more } \\
\text { than } 0.3 \mu \mathrm{g} / \mathrm{mL} \text { of } \\
\text { lead (II) acetate was } \\
\text { applied and no MAP- } \\
\text { 2-positive cells were } \\
\text { found when more } \\
\text { than } 30 \mu \mathrm{g} / \mathrm{mL} \text { of } \\
\text { lead (II) acetate was } \\
\text { applied. Flow } \\
\text { cytometry analysis of } \\
\text { MAP-2-positive cells } \\
\text { and real-time PCR } \\
\text { analysis of MAP2 } \\
\text { mRNA were } \\
\text { performed to confirm } \\
\text { the ID50 of neuronal } \\
\text { differentiation in the } \\
\text { presence of } 0.3 \text { to } 30 \\
\mu \mathrm{g} / \mathrm{mL} \text { of lead (II) } \\
\text { acetate. The ID50 } \\
\text { value of lead (II) } \\
\text { acetate as determined } \\
\text { by flow cytometry } \\
\text { was } 12.75 \text {. The ID50 } \\
\text { of lead (II) acetate as } \\
\text { determined by real- } \\
\text { time PCR analysis } \\
\text { was } 5.09 \mu \mathrm{g} / \mathrm{mL}\end{array}$ & $\begin{array}{l}\text { Beak et al., } \\
2011\end{array}$ \\
\hline
\end{tabular}


Uncertainties or Inconsistencies

Various molecular mechanisms have been identified as regulators of dendritic arborisation patterns and dendtitic spine formation (Jan and Jan, 2010). More specific, transcription factors, growth factors, receptor-ligand interactions, various signalling pathways, local translational machinery, cytoskeletal elements, Golgi outposts and endosomes have been identified as contributors to the organization of dendrites of individual neurons and the contribution of these dendrites in the neuronal circuitry (Jan and Jan, 2010). This study suggests that more parameters rather than only BDNF may be involved in dendritic arbor and spine formation during development.

Quantitative understanding of the linkage

No enough data is available to address the questions above.

\section{Evidence supporting taxonomic applicability}

In organotypic slice cultures derived from the ferret visual cortex application of exogenous BDNF increased the length and complexity especially of Layer IV pyramidal neurons (McAllister et al., 1995) that was also activity-dependent (McAllister et al., 1996). Several studies conducted in rodents further support that the in vitro treatment of hippocampal cultures with exogenous BDNF increases dendritic growth in developing neurons (reviewed in Zagrebelsky and Korte, 2014).

\section{References}

Alexis, M., and A.M. Stranahan (2011), Physiological variability in brain-derived neurotrophic factor expression predicts dendritic spine density in the mouse dentate gyrus. Neurosci Lett. 495: 60-62.

Alfano, D.P., and T.L. Petit (1982), Neonatal lead exposure alters the dendritic development of hippocampal dentate granule cells. Exp Neurol. 75: 275-288.

An, J.J. et al. (2008), Distinct role of long 3' UTR BDNF mRNA in spine morphology and synaptic plasticity in hippocampal neurons. Cell 134: 175-187.

Baek, D.H. et al. (2011), Embryotoxicity of lead (II) acetate and aroclor 1254 using a new end point of the embryonic stem cell test. Int J Toxicol. 30: 498-509.

Baranowska-Bosiacka, I. et al. (2013), Perinatal exposure to lead induces morphological, ultrastructural and molecular alterations in the hippocampus. Toxicology 303: 187-200.

Cohen, S., and M.E. Greenberg (2008), Communication between the synapse and the nucleus in neuronal development, plasticity and disease. Annu Rev Cell Dev Biol. 24: 183-209.

Harvey, C.D. et al. (2008), The spread of Ras activity triggered by activation of a single dendritic spine. Science. 321: 136-140.

Hiester, B.G. et al. (2013), Neurotrophin and Wnt signaling cooperatively regulate dendritic spine formation. Mol Cell Neurosci. 56: 115-127.

Hu, F. et al. (2014), Developmental Lead Exposure Alters Synaptogenesis through Inhibiting Canonical Wnt Pathway In Vivo and In Vitro. PLoS ONE 9(7): e101894.

Huang, F., and J.S. Schneider (2004), Effects of lead exposure on proliferation and differentiation of neural stem cells derived from different regions of embryonic rat brain. Neurotoxicology 25: 1001-1012. 
Jan, Y.N., and L.Y. Jan (2010), Branching out: mechanisms of dendritic arborization. Nat Rev Neurosci. 11: 316-328.

Kang, H., and E.M. Schuman (1996), A requirement for local protein synthesis in neurotrophin-induced hippocampal synaptic plasticity. Science 273: 1402-1406.

Kwon, M. et al. (2011), BDNF-promoted increases in proximal dendrites occur via CREB-dependent transcriptional regulation of cypin. J Neurosci. 31: 9735-9745.

McAllister, A.K., D.C. Lo, and L.C. Katz (1995), Neurotrophins regulate dendritic growth in developing visual cortex. Neuron 15: 791-803.

McAllister, A.K., L.C. Katz and D.C. Lo (1996), Neurotrophin regulation of cortical dendritic growth requires activity. Neuron 17: 1057-1064.

Neal, A.P. et al. (2010), Lead exposure during synaptogenesis alters vesicular proteins and impairs vesicular release: Potential role of NMDA receptor-dependent BDNF signaling. Toxicol Sci. 116: 249-263.

Park, H., and M.M. Poo (2013), Neurotrophin regulation of neural circuit development and function. Nat Rev Neurosci 14: 7-23.

Sala, C. et al. (2001), Regulation of dendritic spine morphology and synaptic function by Shank and Homer. Neuron 31: 115-130.

Schratt, G.M. et al. (2004), BDNF regulates the translation of a select group of mRNAs by a mammalian target of rapamycin-phosphatidylinositol 3-kinase-dependent pathway during neuronal development. J Neurosci. 24: 7366-7377.

Stansfield, K.H. et al. (2012), Dysregulation of BDNF-TrkB signaling in developing hippocampal neurons by $\mathrm{Pb}(2+)$ : implications for an environmental basis of neurodevelopmental disorders. Toxicol Sci. 127: $277-295$.

Tanaka, J.I. et al. (2008), Protein synthesis and neurotrophin-dependent structural plasticity of single dendritic spines Science 319: 1683-1687.

Tyler, W.J., and L. Pozzo-Miller (2003), Miniature synaptic transmission and BDNF modulate dendritic spine growth and form in rat CA1 neurones. J Physiol 553: 497-509.

Verina, T., C.A. Rohde and T.R. Guilarte (2007), Environmental lead exposure during early life alters granule cell neurogenesis and morphology in the hippocampus of young adult rats. Neuroscience 145: 1037-1047.

Waterhouse, E.G., and B. Xu (2009), New insights into the role of brain-derived neurotrophic factor in synaptic plasticity. Mol Cell Neurosci. 42: 81-89.

Yin, Y., G.M. Edelman and P.W. Vanderklish (2002), The brain-derived neurotrophic factor enhances synthesis of Arc in synaptoneurosomes. Proc Natl Acad Sci USA. 99: 2368-2373.

Zagrebelsky, M., and M. Korte (2014), Form follows function: BDNF and its involvement in sculpting the function and structure of synapses. Neuropharmacology 76 PtC: 628-638. 


\title{
5. Release of BDNF, Reduced leads to Presynaptic release of glutamate, Reduced
}

\author{
How Does This Key Event Relationship Work
}

BDNF, acting via its specific presynaptic receptor TrkB, has been shown to increase excitatory synaptic transmission by triggering presynaptic glutamate release in hippocampal cultures as well as in hippocampal and cortical slices (Lessmann et al., 1994; Kang and Schuman, 1995; Carmignoto et al., 1997; Mohajerani et al., 2007).

\section{Weight of Evidence}

Biological Plausibility

Experimentally, it has been shown that presynaptically, BDNF enhances glutamate release and increases the frequency of mEPSCs in hippocampal neurons of rat (Lessmann and Heumann, 1998; Takei et al., 1998; Minichiello, 2009). It has been reported that BDNF rapidly induces glutamate transporter-mediated glutamate release via phospholipase $\mathrm{C}-\gamma(\mathrm{PLC}-\gamma) / \mathrm{Ca} 2+$ signaling and that antidepressants enhance PLC- $\gamma / \mathrm{Ca} 2+$ signaling leading to reduced levels of BDNF that cause decreased glutamate release (Numakawa et al., 2002; Yagasaki et al., 2006).

Empirical Support for Linkage

- In cortical cultured neurons obtained from PND 2-3 rat pups, BDNF fails to induce glutamate release at DIV 3 and 4. However, after 5 days in vitro culture or more (DIV 6-9), BDNF (100 $\mathrm{ng} / \mathrm{ml}$ ) induces significant glutamate release (2-2.8 fold) within 1 min after exogenous application (Numakawa et al., 2002).

- It has been shown that there is a dose-dependent effect of BDNF on the glutamate release. The glutamate release is initially observed at $5 \mathrm{ng} / \mathrm{ml} \mathrm{BDNF}$ and reaches a plateau at $100 \mathrm{ng} / \mathrm{ml}$ (Numakawa et al., 2002).

- No studies have been found in the literature measuring both KEs after exposure to the stressors. Interestingly, proton magnetic resonance spectroscopy in adults with childhood lead exposure shows decrease in a composite of glutamate and glutamine in vermis and in parietal white matter of the brain (Cecil et al., 2011).

Uncertainties or Inconsistencies

Recently, in heterozygous BDNF-knockout (BDNF+/-) mice it has been demonstrated that the reduced BDNF levels did not affect presynaptic glutamate release (Meis et al., 2012).

Quantitative understanding of the linkage

No enough data is available to address the questions above.

\section{References}

Carmignoto, G. et al. (1997), Brain-derived neurotrophic factor and nerve growth factor potentiate excitatory synaptic transmission in the rat visual cortex. J Physiol. 498: 153-164. 
Cecil, K.M. et al. (2011), Proton magnetic resonance spectroscopy in adults with childhood lead exposure. Environ Health Perspect. 119: 403-408.

Kang, H., and E.M. Schuman (1995), Long-lasting neurotrophin-induced enhancement of synaptic transmission in the adult hippocampus. Science. 267: 1658-1662.

Lessmann, V., K. Gottmann and R. Heumann (1994), BDNF and NT-4/5 enhance glutamatergic synaptic transmission in cultured hippocampal neurones. Neuroreport 6: 21-25.

Lessmann, V., and R. Heumann (1998), Modulation of unitary glutamatergic synapses by neurotrophin-4/5 or brain-derived neurotrophic factor in hippocampal microcultures: presynaptic enhancement depends on pre-established paired-pulse facilitation. Neuroscience 86: 399-413.

Meis, S., T. Endres and V. Lessmann (2012), Postsynaptic BDNF signalling regulates long-term potentiation at thalamo-amygdala afferents. J Physiol. 590: 193-208.

Minichiello, L. (2009), TrkB signalling pathways in LTP and learning. Nat Rev Neurosci. 10: 850-860.

Mohajerani, M.H. et al. (2007), Correlated network activity enhances synaptic efficacy via BDNF and the ERK pathway at immature CA3 CA1 connections in the hippocampus. Proc Natl Acad Sci U S A. 104: 13176-13181.

Numakawa, T. et al. (2002), Brain-derived neurotrophic factor-induced potentiation of $\mathrm{Ca} 2+$ oscillations in developing J Biol Chem. 277: 6520-6529.

Takei, N. et al. (1998), Brain-derived neurotrophic factor induces rapid and transient release of glutamate through the non-exocytotic pathway from cortical neurons. J Biol Chem. 273: 27620-27624.

Yagasaki, Y. et al. (2006), Chronic antidepressants potentiate via sigma-1 receptors the brain-derived neurotrophic factor-induced signaling for glutamate release. J Biol Chem. 281: 12941-12949.

\section{Release of BDNF, Reduced leads to Cell death, N/A}

\section{How Does This Key Event Relationship Work}

BDNF influences the apoptosis occurring in developing neurons through two distinct mechanisms (Bernd, 2008). mBDNF can trigger prosurvival signaling after binding to TrkB receptor through inactivation of components of the cell death machinery and also through activation of the transcription factor cAMP-response element binding protein (CREB), which drives expression of the pro-survival gene Bcl-2 (West et al., 2001). On the other hand, proBDNF binds to the p75 neurotrophin receptor (p75NTR) and activates RhoA that regulates actin cytoskeleton polymerization resulting in apoptosis (Lee et al., 2001; Miller and Kaplan, 2001; Murray and Holmes, 2011). It is proved that reduced levels of BDNF can severely interfere with the survival of neurons in different brain regions, leading to cell death (Lee et al., 2001; Miller and Kaplan, 2001; Murray and Holmes, 2011).

\section{Weight of Evidence}

Biological Plausibility

BDNF mRNA levels dramatically increase between embryonic days 11 to 13 during rat development, playing important role in neuronal differentiation and survival (reviewed in Murray and Holmes, 2011). The latter has been supported by transgenic experiments where BNDF-/mice demonstrated a dramatic increase in cell death among developing granule cells leading to impaired development of the layers of the cerebellar cortex (Schwartz et al., 1997). BDNF has also been shown to provide neuroprotection after hypoxic-ischemic brain injury in neonates (P7) 
but not in older (P21) animals (Cheng et al., 1997; Han and Holtzman, 2000). The neuroprotective role of BDNF has been further supported by the observed correlation between elevated BDNF protein levels and resistance to ischemic damage in hippocampus in vivo (Kokaia et al., 1996) and $\mathrm{K}+$ rich medium-induced apoptosis in vitro (Kubo et al., 1995).

Empirical Support for Linkage

Several in vitro and in vivo studies on cortical neurons have demonstrated that the survival of developing neurons is closely related with the activation of the NMDA receptors and subsequent BDNF synthesis/release that fully support the BDNF neurotrophic theory (Ikonomidou et al., 1999; Yoon et al., 2003; Hansen et al., 2004).

Pb2+: Neonatal mice exposed to $\mathrm{Pb} 2+(350 \mathrm{mg} / \mathrm{kg}$ lead twice every $4 \mathrm{~h})$ and sacrificed after $8-24$ $\mathrm{h}$ show increased apoptotic neurodegeneration above that seen in normal controls. This effect has been recorded only in animals treated with Pb2+ at PND 7, but not at PND 14 (Dribben et al., 2011), confirming the importance of the time of exposure during development in order for $\mathrm{Pb} 2+$ to induce apoptosis. Two to four weeks old rats treated for 7 days with $15 \mathrm{mg} / \mathrm{kg}$ daily dose of lead acetate show increased apoptosis in hippocampus (Sharifi et al., 2002). In rats (30 PND), it has also been shown that $\mathrm{Pb} 2+(2,20$ and $200 \mathrm{mg} / \mathrm{kg} / \mathrm{d})$ can induce apoptosis (Liu et al., 2010). However, in contrast to the first two in vivo studies, the animals in this experimental approach were old enough to evaluate the most sensitive window of vulnerability of developing neurons to $\mathrm{Pb} 2+$ exposure (Liu et al., 2010), confirming that only $\mathrm{Pb} 2+$ treatment during synaptogenesis can lead to neuronal cell apoptosis. In vitro evidence of apoptosis induced by $\mathrm{Pb} 2+$ also derive from PC12 cells exposed to $\mathrm{Pb} 2+(0.1,1,10 \mu \mathrm{M})$ that have shown increased activation of caspase-3 (Xu et al., 2006). Besides PC12 cells (Xu et al., 2006; Sharifi and Mousavi, 2008), lead-induced apoptosis has also been studied in cultured rat cerebellar neurons (Oberto et al., 1996), hippocampal neurons (Niu et al., 2002) and retinal rod cells (He et al., 2000). No significant increase in LDH release was found in neuro-spheres derived from neural stem cells (NSCs) originating from E15 rat cortex (CX), striatum (ST) or ventral mesencephalon (VM) after assessing at $24 \mathrm{~h}$ intervals from day 1 through day 7 after addition of lead acetate $(0.1-10 \mu \mathrm{M})$ (Huang and Schneider, 2004). However, LDH release was increased 1 day after addition of 100 $\mu \mathrm{M}$ lead acetate (1.6-2.1 fold depending on the brain region) and 3 days after addition of $50 \mu \mathrm{M}$ lead acetate to the culture medium (1.3-1.5 fold depending on the brain region). No significant cell loss was observed in cultures exposed to $0.1-10 \mu \mathrm{M}$ lead acetate for 7 days after staining with Hoechst 33342. In contrast, significant cell loss was observed 7 days after exposure to $50 \mu \mathrm{M}(35$ $50 \%$ depending on brain region) or $100 \mu \mathrm{M}$ lead acetate (60-75\% depending on brain region) (Huang and Schneider, 2004). In primary rat hippocampal neurons exposed to $1 \mu \mathrm{M} \mathrm{Pb} 2+$ for 5 days during the period of synaptogenesis (DIV7-DIV12), decreased cellular proBDNF protein (40\% compared to control) and extracellular levels of mBDNF (25\% compared to control) have been recorded (Neal et al., 2010). Significant reductions specifically in dendritic proBDNF protein levels throughout the length of the dendrites have also been described by Stansfield et al. (2012) after exposure to the same concentration of Pb2+ using this in vitro model. In an in vivo study, mice at PND 7 with mean $\mathrm{Pb} 2+$ blood levels of $8.10 \mu \mathrm{g} / \mathrm{mL}$ have shown increased apoptosis in the cortex, hippocampus, caudate-putamen, and thalamus compared to controls with $\mathrm{F}(1,14)=19.5,8.40,4.15,4.53$, respectively (Dribben et al., 2011). These Pb2+ levels in blood (Dribben et al., 2011) were a bit higher than the levels determined in Guilarte et al. 2003 (3.90 
$\mu \mathrm{g} / \mathrm{dl})$ that served as the base to calculate in vitro doses in Neal et al. 2010 and Stansfield et al. 2012.

Uncertainties or Inconsistencies

Pb2+: A number of studies demonstrate that deletion of BDNF does not lead to significant apoptotic cell death of neurons in the developing CNS (reviewed in Dekkers et al., 2013). In an in vivo $\mathrm{Pb} 2+$ exposure study, where female rats received $1,500 \mathrm{ppm}$ prior, during breeding and lactation shows no changes at mRNA levels of BDNF in different hippocampus section derived from their pups (Guilarte et al., 2003). Regarding $\mathrm{Pb} 2+$, the pre- and neonatal exposure of rats to $\mathrm{Pb} 2+(\mathrm{Pb} 2+$ blood levels below $10 \mu \mathrm{g} / \mathrm{dL})$ show a decreased number of hippocampus neurons but no morphological or molecular features of severe apoptosis or necrosis have been detected in tested brains (Baranowska-Bosiacka et al., 2013). In contrast to the lack of apoptotic signs, reduced levels of BDNF concentration ( $\mathrm{pg} / \mathrm{mg}$ protein) of BDNF in brain homogenates has been recorded in forebrain cortex (39\%) and hippocampus (29\%) (Baranowska-Bosiacka et al., 2013). Pregnant rats have been exposed to lead acetate $(0.2 \%$ in the drinking water) after giving birth until PND 20. At PND 20, blood Pb2+ levels in pups reached at $80 \mu \mathrm{g} / \mathrm{dl}$. In these animals, the gene expression in different brain regions has been assessed and demonstrated that hippocampus is most sensitive with alterations beginning at PND 12 when caspase 3 mRNA increases after $\mathrm{Pb} 2+$ exposure (Chao et al., 2007). However, bcl-x and BDNF mRNA in the hippocampus have been significantly increased after caspase 3 increase, suggesting that the apoptotic signal activates a compensatory response by increasing survival factors like BDNF and that the temporality suggested in this AOP may not be accurate (Chao et al., 2007).

Some of the reported "inconsistencies" may be due to the lack of sufficient details in the reporting since publications vary in what they measure. Some of the referenced studies look at BDNF transcripts, others look at BDNF protein. BDNF processing is highly complex and different mRNA transcripts are known to be implicated in different cellular function.

Several studies addressing apoptosis mainly in the developing cerebral cortex have shown that more mechanism besides neurotrophic factors may be involved. Cytokines, as well as neurotransmitters can potentially activate a number of intracellular proteins that execute cell death (Henderson, 1996; Kroemer et al., 2009), meaning that further branches to this AOP might be added in the future.

Quantitative understanding of the linkage

No enough data is available to address the questions above.

\section{Evidence supporting taxonomic applicability}

The survival and antiapoptotic role of BDNF has been investigated not only in rodents but also in developing chicken neurons (Hallbook et al., 1995; Frade et al., 1997; Reinprecht et al., 1998). In invertebrates, only recently a protein with possible neurotrophic role has been identified but its influence and function in neuronal cell death of developing neurons has not been investigated yet (Zhu et al., 2008). 


\section{References}

Baranowska-Bosiacka, I. et al. (2013), Perinatal exposure to lead induces morphological, ultrastructural and molecular alterations in the hippocampus. Toxicology 303: 187-200.

Bernd, P. (2008), The role of neurotrophins during early development. Gene Expr. 14: 241-250.

Chao, S.L., J.M. Moss and G.J. Harry (2007), Lead-induced Alterations of Apoptosis and Neurotrophic Factor mRNA in the Developing Rat Cortex, Hippocampus, and Cerebellum. J Biochem Mol Toxicol. 21: 265-272.

Cheng, Y. et al. (1997), Marked age-dependent neuroprotection by brain-derived neurotrophic factor against neonatal hypoxic-ischemic brain injury. Ann Neurol 41: 521-529.

Dekkers, M.P., V. Nikoletopoulou and Barde Y.A. (2013), Cell biology in neuroscience: Death of developing neurons: new insights and implications for connectivity. J Cell Biol. 203: 385-393.

Dikranian, K. et al. (2001), Apoptosis in the in vivo mammalian forebrain. Neurobiol Dis. 8: 359-379.

Dribben, W.H., C.E. Creeley and N. Farber (2011), Low-level lead exposure triggers neuronal apoptosis in the developing mouse brain. Neurotoxicol Teratol. 33: 473-480.

Farber, N.B., C.E. Creeley and J.W. Olney (2010), Alcohol-induced neuroapoptosis in the fetal macaque brain. Neurobiol Dis. 40: 200-206.

Frade, J.M. et al. (1997), Control of early cell death by BDNF in the chick retina. Development 124: 33133320 .

Guilarte, T.R. et al. (2003), Environmental enrichment reverses cognitive and molecular deficits induced by developmental lead exposure. Ann Neurol. 53: 50-56.

Hallbook, F. et al. (1995), Neurotrophins and their receptors in chicken neuronal development. Int J Dev Biol. 39: 855-868.

Han, B.H., and D.M. Holtzman (2000), BDNF protects the neonatal brain from hypoxic-ischemic injury in vivo via the ERK pathway. J Neurosci. 20: 5775-57811.

Hansen, H.H. et al. (2004), Mechanisms leading to disseminated apoptosis following NMDA receptor blockade in the developing rat brain. Neurobiol Dis. 16: 440-453.

He, L. et al. (2000), Lead and calcium produce rod photoreceptor cell apoptosis by opening the mitochondrial permeability transition pore. J Biol Chem. 275: 12175-12184.

Henderson, C.E. (1996), Programmed cell death in the developing nervous system. Neuron 17: 579-585.

Huang, F., and J.S. Schneider (2004), Effects of lead exposure on proliferation and differentiation of neural stem cells derived from different regions of embryonic rat brain. Neurotoxicology 25: 1001-1012.

Ikonomidou, C. et al. (1999), Blockade of NMDA receptors and apoptotic neurodegeneration in the developing brain. Science 283: 70-74.

Kokaia, Z. et al. (1996), Regional brain-derived neurotrophic factor mRNA and protein levels following transient forebrain ischemia in the rat. Brain Res Mol Brain Res. 38: 139-144.

Kroemer, G. et al. (2009), Classification of cell death: recommendations of the Nomenclature Committee on Cell Death 2009. Cell Death Differ. 16: 3-11.

Kubo, T. et al. (1995), Brain-derived neurotrophic factor (BDNF) can prevent apoptosis of rat cerebellar granule neurons in culture. Brain Res Dev Brain Res. 85: 249-258.

Lee, R. et al. (2001), Regulation of cell survival by secreted proneurotrophins. Science 294: 1945-1948.

Liu, J. et al. (2010), Lead affects apoptosis and related gene XIAP and Smac expression in the hippocampus of developing rats. Neurochem Res. 35: 473-479.

Miller, F.D., and D.R. Kaplan (2001), Neurotrophin signalling pathways regulating neuronal apoptosis. Cell Mol Life Sci. 58: 1045-1053. 
Murray, P.S., and P.V. Holmes (2011), An Overview of Brain-Derived Neurotrophic Factor and Implications for Excitotoxic Vulnerability in the Hippocampus nternational. J Pept. Volume 2011 (2011), Article ID 654085, 12 pages.

Neal, A.P. et al. (2010), Lead exposure during synaptogenesis alters vesicular proteins and impairs vesicular release: Potential role of NMDA receptor-dependent BDNF signaling. Toxicol Sci. 116: 249-263.

Niu, Y. et al. (2002), Effect of lead acetate on the apoptosis and the expression of bcl-2 and bax genes in rat brain cells. Zhonghua Yu Fang Yi Xue Za Zhi. 36: 30-33.

Oberto, A. et al. (1996), Lead $(\mathrm{Pb}+2)$ promotes apoptosis in newborn rat cerebellar neurons: pathological implications. J Pharmacol Exp Ther. 279: 435-442.

Reinprecht, K. et al. (1998), Influence of BDNF and FCS on viability and programmed cell death (PCD) of developing cortical chicken neurons in vitro. J Neural Transm Suppl. 53: 373-384.

Schwartz, P.M. et al. (1997), Abnormal cerebellar development and foliation in BDNF(-/-) mice reveals a role for neurotrophins in CNS patterning. Neuron 19: 269-281.

Sharifi, A.M. et al. (2002), Investigation of acute lead poisoning on apoptosis in rat hippocampus in vivo. Neurosci Lett. 329: 45-48.

Sharifi, A.M., and S.H. Mousavi (2008), Studying the effects of lead on DNA fragmentation and proapoptotic bax and antiapoptotic bcl-2 protein expression in PC12 cells. Toxicol. Mech. Methods 18: 75-79.

Stansfield, K.H. et al. (2012), Dysregulation of BDNF-TrkB signaling in developing hippocampal neurons by $\mathrm{Pb}(2+)$ : implications for an environmental basis of neurodevelopmental disorders. Toxicol Sci. 127: 277-295.

West, A.E. et al. (2001), Calcium regulation of neuronal gene expression. Proc Natl Acad Sci U S A. 98: 11024-11031.

Xu, J., L.D. Ji and L.H. Xu (2006), Lead-induced apoptosis in PC 12 cells: involvement of p53, Bcl-2 family and caspase-3. Toxicol Lett. 166: 160-167.

Yoon, W.J. et al. (2003), Blockade of ionotropic glutamate receptors produces neuronal apoptosis through the Bax-cytochrome C-caspase pathway: the causative role of Ca2+deficiency. J Neurochem. 85: 525-533.

Zhu, B. et al. (2008), Drosophila neurotrophins reveal a common mechanism for nervous system formation. PLoS Biol. 18;6(11):e284. 


\title{
7. Dendritic morphology, Aberrant leads to Synaptogenesis, Decreased
}

\author{
How Does This Key Event Relationship Work
}

It is well-established that loss of dendritic spine density and dendrite branch complexity leads to loss of synapse formation. Indeed, huge amount of research has been performed on dendrite arbour, dendritic spines and the molecular components of these structures that led to the elucidation of their role in higher order brain functions, including learning and memory (reviewed in Sjöström et al., 2008).

\section{Weight of Evidence}

\section{Biological Plausibility}

It has been proved that the appearance of extensive dendritic arbor and new spines coincides with synapse formation (Zito et al., 2004). Zhang and Benson (2001) have investigated the role of actin (the main component of dendritic spines) during the early stages of neuronal development by introducing an actin depolymerisation protein named latrunculin A and conducting fluorescent imaging of synapse formation. At the early stages of neuronal development, it has been reported that the depolymerisation of filamentous actin (F-actin) significantly reduces the number of stable synapses and the presence of postsynaptic proteins (PSD-95, neuroligins, and Bassoon). Most importantly, pre- and postsynaptic vesicles needed for synaptogenesis have not been found at contact sites as a result of depolymerisation of F-actin (Zhang and Benson, 2001). Furthermore, synapsin I-deficient neurons have been shown to be unable to form synapses during the first week in culture even after establishing axon-dendritic contacts (Ferreira et al., 1996).

Empirical Support for Linkage

Many studies have indicated that synaptogenesis and spine formation happen in any order, meaning that not always synaptogenesis follows the spine formation but it can also happen the other way around (Bhatt et al., 2009; McAllister, 2007; Okabe et al., 2001).

Pb2+: Newborn rats exposed to $10 \mathrm{mg} / \mathrm{ml}$ of lead acetate from PND 2 up to PND 20 and 56 demonstrate significant decrease in the spine density as shown in Golgi staining of hippocampal pyramidal neurons of the CA1 region (Kiraly and Jones, 1982). Rat pups from parents exposed to $2 \mathrm{mM} \mathrm{PbCl} 23$ weeks before mating until their weaning (pre-weaning $\mathrm{Pb} 2+$ ) and weaned pups exposed to $2 \mathrm{mM} \mathrm{PbCl} 2$ for 9 weeks (post-weaning $\mathrm{Pb} 2+$ ) were assessed for the number of synapses after Morris water maze (MWM) on PND 91 (Xiao et al., 2014). The number of synapses in pre-weaning $\mathrm{Pb} 2+$ group increased significantly, but it was less compared to control group $(\mathrm{p}<0.05)$. Similarly, the number of synapses in post-weaning $\mathrm{Pb} 2+$ group was less than that of control group, although before MWM the number of synapses was almost the same between post-weaning $\mathrm{Pb} 2+$ and control groups. In both pre-weaning $\mathrm{Pb} 2+$ and post-weaning $\mathrm{Pb} 2+$ groups, synaptic structural parameters such as thickness of postsynaptic density, length of synaptic active zone and synaptic curvature increased whereas width of synaptic cleft decreased compared to controls, suggesting disturbance of synaptic structural plasticity (Xiao et al., 2014).

$\mathrm{Pb} 2+$ has been shown to decrease the levels of the vesicular proteins synaptophysin and synaptobrevin in vitro (Neal et al., 2010). 
Uncertainties or Inconsistencies

Quantitative understanding of the linkage

No enough data is available to address the questions above.

\section{References}

Bhatt, D.H., S. Zhang, and W.B. Gan (2009), Dendritic Spine Dynamics. Ann Rev Physiol. 71: 261-282.

Ferreira, A. et al. (1996), Postsynaptic element contributes to the delay in synaptogenesis in synapsin Ideficient neurons. Mol Cell Neurosci. 8: 286-299.

Kiraly, E., and D.G. Jones (1982), Dendritic spine changes in rat hippocampal pyramidal cells after postnatal lead treatment: A Golgi study. Exp Neurol. 77: 236-239.

McAllister, A.K. (2007), Dynamic aspects of CNS synapse formation. Ann Rev of Neurosc. 30: 425-450.

Neal, A.P. et al. (2010), Lead exposure during synaptogenesis alters vesicular proteins and impairs vesicular release: Potential role of NMDA receptor-dependent BDNF signaling. Toxicol Sci. 116: 249-263.

Okabe, S., A. Miwa and H. Okado (2001), Spine formation and correlated assembly of presynaptic and postsynaptic molecules. J Neurosci. 21: 6105-6114.

Sjöström, P.J. et al. (2008), Dendritic excitability and synaptic plasticity. Physiol Rev. 88: 769-840.

Xiao, Y. et al. (2014), Role of synaptic structural plasticity in impairments of spatial learning and memory induced by developmental lead exposure in Wistar rats. PLoS One. 23;9(12):e115556.

Zhang, W., and D.L. Benson (2001), Stages of synapse development defined by dependence on F-actin. J Neurosci. 21: 5169-5181.

Zito, K. et al. (2004), Induction of spine growth and synapse formation by regulation of the spine actin cytoskeleton. Neuron 44: 321-334.

\section{Presynaptic release of glutamate, Reduced leads to Synaptogenesis, Decreased}

\section{How Does This Key Event Relationship Work}

The presynaptic release of glutamate causes activation of NMDA receptors and initiates synaptogenesis through activation of downstream signalling pathways required for synapse formation (reviewed in Ghiani et al., 2007). Lack or reduced release of glutamate affects the transcription and translation of molecules required in synaptogenesis (reviewed in Ghiani et al., 2007).

\section{Weight of Evidence}

Biological Plausibility

The NMDA receptor activation by glutamate during development increases calcium influx, which acts as a secondary signal. Eventually, immediate early genes (IEG) activation is triggered by transcription factors and the proteins required for synapse formation are produced (reviewed in Ghiani et al., 2007). 
Glutamate released from entorhinal cortex neurons has been shown to promote synaptogenesis in developing targeted hippocampal neurons (Mattson et al., 1988). Similarly, glutamate has been found to regulate synaptogenesis in the developing visual system of frogs (Cline and ConstantinePaton, 1990).

The ratio of synaptic NR2B over NR2A NMDAR subunits controls spine motility and synaptogenesis, and it has been suggested a structural role for the intracellular C terminus of NR2 in recruiting the signaling and scaffolding molecules necessary for proper synaptogenesis (Gambrill and Barria, 2011).

Empirical Support for Linkage

There is no direct evidence linking reduced presynaptic release of glutamate to decreased synaptogenesis as they have not been ever measured both in the same study after exposure to stressors. However, there are findings that strongly link reduced presynaptic release of glutamate to LTP.

Indeed, measures of presynaptic function at glutamatergic synapses in chronically exposed animals have produced results that can be related to the effects of $\mathrm{Pb} 2+$ on glutamate and LTP. Focal perfusion of high $\mathrm{K}+$ is used to measure glutamate release and define the $\mathrm{Ca}+2$-dependent and $\mathrm{Ca}+2$-independent components by inclusion or removal of $\mathrm{Ca}+2$ from the perfusion fluid. Animals exposed to $0.2 \% \mathrm{~Pb} 2+$ cause decrease in $\mathrm{K}+$-evoked hippocampal glutamate release, which is an important factor in the elevated threshold and diminishes magnitude of hippocampal LTP (Gilbert et al., 1996, 1999; Lasley and Gilbert, 1996). Furthermore, the same research group showed that chronic exposure to $0.2 \% \mathrm{~Pb} 2+$ diminishes only the $\mathrm{K}+$-stimulated increase in total extracellular glutamate compared to that in control but not in animals under $\mathrm{Ca}+2$-free conditions, suggesting that the exposure-induced decrease in total glutamate release is due to $\mathrm{Pb} 2+$-related decrements in the $\mathrm{Ca}+2$-dependent component.

In animals exhibiting blood $\mathrm{Pb} 2+$ levels of $30-40 \mu \mathrm{g} / 100 \mathrm{ml}$, the perforant path stimulation to induce paired-pulse facilitation in dentate gyrus, which is a measure that is primarily mediated by enhanced glutamate release, is reduced (Lasley and Gilbert, 1996; Ruan et al., 1998). Microdialysis experiment in animals with the same $\mathrm{Pb} 2+$ values show diminished depolarizationinduced hippocampal glutamate release (Lasley and Gilbert, 1996; Lasley et al., 1999).

In another study, rats continuously exposed to $0.1-0.5 \% \mathrm{~Pb} 2+$ in the drinking water beginning at gestational day 15-16 show decrease in total $\mathrm{K}+$-stimulated hippocampal glutamate release (Lasley and Gilbert, 2002). Maximal effects have been seen in the $0.2 \%$ group (blood $\mathrm{Pb}=40$ $\mu \mathrm{g} / 100 \mathrm{ml}$ ). However, these effects have been less evident in the $0.5 \%$ group and are no longer present in the $1.0 \% \mathrm{~Pb} 2+$ group (Lasley and Gilbert, 2002). The same finding was found in hippocampal cultures and brain slices acutely exposed to Pb2+ (Braga et al., 1999; Xiao et al., 2006).

More recently, $\mathrm{Pb} 2+$ has also been shown to decrease the levels of the vesicular proteins synaptophysin and synaptobrevin and inhibit vesicular release (Neal et al., 2010). Furthermore the same group has reported that chronic in vivo exposure to $\mathrm{Pb} 2+$ during development results in a marked inhibition of Schaffer-collateral-CA1 synaptic transmission by inhibiting vesicular release 
of glutamate, an effect that is not associated with a persistent change in presynaptic calcium entry (Zhang et al., 2015).

Uncertainties or Inconsistencies

Quantitative understanding of the linkage

No enough data is available to address the questions above.

\section{References}

Braga, M.F.M., E.F.R. Pereire and E.X. Albuquerque (1999), Nanomolar concentration of lead inhibit glutamatergic and GABAergic transmission in hippocampal neurons. Brain Res. 826: 22-34.

Cline, H.T., and M. Constantine-Paton (1990), NMDA receptor agonist and antagonists alter retinal ganglion cell arbor structure in the developing frog retinotectal projection. J Neurosci. 10: 11971216.

Gambrill, A.C., and A. Barria (2011), NMDA receptor subunit composition controls synaptogenesis and synapse stabilization. Proc Natl Acad Sci U S A. 108: 5855-5860.

Ghiani, C.A. et al. (2007), Genetic program of neuronal differentiation and growth induced by specific activation of NMDA receptors. Neurochem Res. 32: 363-376.

Gilbert, M.E., C.M. Mack and S.M. Lasley (1996), Chronic developmental lead (Pb++) exposure increases the threshold for long-term potentiation in the rat dentate gyrus in vivo. Brain Res. 736: 118-124.

Gilbert, M.E., C.M. Mack and S.M. Lasley (1999a), The influence of developmental period of lead exposure on long-term potentiation in the rat dentate gyrus in vivo. Neurotoxicology 20: 57-69.

Lasley, S.M., and M.E. Gilbert (1996), Presynaptic glutamatergic function in dentate gyrus in vivo is diminished by chronic exposure to inorganic lead. Brain Res. 736: 125-134.

Lasley, S.M., and M.E. Gilbert (2002), Rat hippocampal glutamate and GABA release exhibit biphasic effects as a function of chronic lead exposure level. Toxicol Sci. 66: 139-147.

Lasley, S.M., M.C. Green and M.E. Gilbert (1999), Influence of exposure period on in vivo hippocampal glutamate and GABA release in rats chronically exposed to lead. Neurotoxicology 20: 619-629.

Mattson, M.P. et al. (1988), Interactions between entorhinal axons and target hippocampal neurons: a role for glutamate in the development of hippocampal circuitry. Neuron 1: 865-876.

Neal, A.P. et al. (2010), Lead exposure during synaptogenesis alters vesicular proteins and impairs vesicular release: Potential role of NMDA receptor-dependent BDNF signaling. Toxicol Sci. 116: 249-263.

Ruan, D.Y. et al. (1998), Impairment of long-term potentiation and paired-pulse facilitation in rat hippocampal dentate gyrus following developmental lead exposure in vivo. Brain Res. 806, 196-201.

Xiao, C. et al. (2006), Lead impairs GABAergic synaptic transmission in rat hippocampal slices: a possible involvement of presynaptic calcium channels. Brain Res. 1088: 93-100.

Zhang, X.L. et al. (2015), Presynaptic mechanisms of lead neurotoxicity: effects on vesicular release, vesicle clustering and mitochondria number. PLoS One. 10(5):e0127461. 


\title{
9. Cell death, N/A leads to Synaptogenesis, Decreased
}

\author{
How Does This Key Event Relationship Work
}

Under physiological conditions, in the developing nervous system, apoptosis occurs during the process of synaptogenesis, where competition leads to the loss of excess neurons and to the connection of the appropriate neurons (Buss et al., 2006; Mennerick and Zorumski, 2000; Oppenheim, 1991). However, when a stressor increases the number of apoptotic cells this KE has a negative effect on synaptogenesis as the reduced number of neurons (besides the ones that have been already eliminated through the physiological process of apoptosis) provides limited dendritic fields for receiving synaptic inputs from incoming axons. At the same time the loss of neurons also means that there are less axons to establish synaptic contacts (Olney, 2014), leading to reduced synaptogenesis and neuronal networking.

\section{Weight of Evidence}

Biological Plausibility

Recently, Dekkers et al. 2013 have reviewed how under physiological conditions components of the apoptotic machinery in developing brain regulate synapse formation and neuronal connectivity. For example, caspase activation is known to be required for axon pruning during development to generate neuronal network (reviewed in Dekkers et al., 2013). Experimental work carried out in Drosophila melanogaster and in mammalian neurons shows that components of apoptotic machinery are involved in axonal degeneration that can consequently interfere with synapse formation (reviewed in Dekkers et al., 2013). Furthermore, Bax mutant mice studies indicate that the lack of this pro-apoptotic protein BAX leads to disruption of intrinsically photosensitive retinal ganglion cells spacing and dendritic stratification that affects synapse localization and function (Chen et al., 2013).

\section{Empirical Support for Linkage}

Synaptogenesis and refinement of the cortical network precedes the programmed cells death of neurons during development (Innocenti and Price, 2005).

Pb2+: Elevated blood $\mathrm{Pb} 2+$ concentrations that have been evident in new-born rats prenatally exposed to 30 or $200 \mathrm{mg} / \mathrm{l} \mathrm{Pb} 2+$ caused postnatally delay in synaptogenesis (McCauley et al., 1982). In this study, $\mathrm{Pb} 2+$ treatment depresses synaptic counts in pups of PND 11 to 15 but not in older pups (McCauley et al., 1982). In rat hippocampal primary cultures, $\mathrm{Pb} 2+$ treatment has no effect on PSD95 puncta density nor has any effect on Synapsin Ia/b total gray value, puncta density, and integrated intensity but only reduces the phosphorylation of Synapsin Ia/b (Stansfield et al., 2012). $\mathrm{Pb} 2+$ exposure also represses the expression of presynaptic vesicular proteins implicated in neurotransmitter release, such as synaptobrevin (VAMP1) and synaptophysin (SYN) (Neal et al., 2010). In mouse ESCs cultured in 3D aggregates, the treatment with $0.1 \mu \mathrm{M} \mathrm{Pb} 2+$ causes around $25 \%$ of cell loss that is not attributed to apoptosis as no change in caspase 3 levels has been detected (Sánchez-Martín et al., 2013). In the same study but in an in vivo model, Pb2+ causes downregulation of Syn1 gene expression in the hippocampus of male offspring (PND 60) derived from female mice exposed to 0 or $3 \mathrm{ppm}$ of lead acetate in drinking water from 8 weeks prior to mating, through gestation and until PND 10 (Sánchez-Martín et al., 2013). 
Uncertainties or Inconsistencies

In adult nervous system, the role of apoptotic machinery in axon pruning and synapse elimination, which are necessary to refine mature neuronal network has been extensively studied (reviewed in Hyman and Yuan, 2012), whereas in developing nervous system the regulatory importance of apoptotic machinery in synapse formation and function is less clear (reviewed in Dekkers et al., 2013).

Quantitative understanding of the linkage

No enough data is available to address the questions above.

\section{Evidence supporting taxonomic applicability}

Experiments have been conducted both in Drosophila melanogaster and in mammals in order to elucidate the relationship between components of apoptotic machinery and synaptogenesis (reviewed in Dekkers et al., 2013).

\section{References}

Buss, R.R., W. Sun and R.W. Oppenheim (2006), Adaptive roles of programmed cell death during nervous system development. Annu Rev Neurosci. 29: 1-35.

Chen, S.K. et al. (2013), Apoptosis regulates ipRGC spacing necessary for rods and cones to drive circadian photoentrainment. Neuron 77: 503-515.

Dekkers, M.P.J., V. Nikoletopoulou and Y-A. Barde (2013), Death of developing neurons: New insights and implications for connectivity. J Cell Biol. 203: 385-393.

Hyman, B.T., and J. Yuan (2012), Apoptotic and non-apoptotic roles of caspases in neuronal physiology and pathophysiology. Nat Rev Neurosci 13: 395-406.

Innocenti, G.M., and D.J. Price (2005), Exuberance in the development of cortical networks. Nat Rev Neurosci. 6: 955-965.

McCauley, P.T. et al. (1982), The effect of prenatal and postnatal lead exposure on neonatal synaptogenesis in rat cerebral cortex. J Toxicol Environ Health 10: 639-651.

Mennerick, S., and C.F. Zorumski (2000), Neural activity and survival in the developing nervous system. Mol Neurobiol. 22: 41-54.

Neal, A.P. et al. (2010), Lead exposure during synaptogenesis alters vesicular proteins and impairs vesicular release: Potential role of NMDA receptor-dependent BDNF signaling. Toxicol Sci. 116: 249-263.

Olney, J.W. (2014), Focus on apoptosis to decipher how alcohol and many other drugs disrupt brain development front. Pediatr. 2: 81.

Oppenheim, R.W. (1991), Cell death during development of the nervous system. Annu Rev Neurosci. 14: 453-501.

Sánchez-Martín, F.J. et al. (2013), Lead Induces Similar Gene Expression Changes in Brains of Gestationally Exposed Adult Mice and in Neurons Differentiated from Mouse Embryonic Stem Cells. PLoS One 8: e80558.

Stansfield, K.H. et al. (2012), Dysregulation of BDNF-TrkB signaling in developing hippocampal neurons by $\mathrm{Pb}(2+)$ : implications for an environmental basis of neurodevelopmental disorders. Toxicol Sci. 127: 277-295. 


\title{
10. Synaptogenesis, Decreased leads to Neuronal network function, Decreased
}

\author{
How Does This Key Event Relationship Work
}

The ability of a neuron to communicate is based on neural network formation that relies on functional synapse establishment (Colón-Ramos, 2009). The main roles of synapses are the regulation of intercellular communication in the nervous system, and the information flow within neural networks. The connectivity and functionality of neural networks depends on where and when synapses are formed. Therefore, the decreased synapse formation during the process of synaptogenesis is critical and leads to decrease of neural network formation and function in the adult brain.

Weight of Evidence

Biological Plausibility

Neuronal connections are established via the process of synaptogenesis. The developmental period of synaptogenesis is critical for the formation of the basic circuitry of the nervous system, although neurons are able to form new synapses throughout life (Rodier, 1995). The brain electrical activity dependence on synapse formation is critical for proper neuronal communication. Alterations in synaptic connectivity lead to refinement of neuronal networks during development (Cline and Haas, 2008). Indeed, knockdown of PSD-95 arrests the functional and morphological development of glutamatergic synapses (Ehrlich et al., 2007).

Empirical Support for Linkage

Pb2+: At low $\mathrm{Pb} 2+$ levels (less than 30 micrograms/dl), slow cortical potentials have been observed to be positive in children under five years old but negative in children over five years. However, age-related polarity reversal has been observed in children with higher $\mathrm{Pb} 2+$ levels (Otto and Reiter, 1984).

In experiments carried out in Wistar rats that have been fed with lead acetate (400 micrograms lead/g body weight/day) from PND 2 until PND 60, EEG findings show statistically significant reduction in the delta, theta, alpha and beta band of EEG spectral power in motor cortex and hippocampus with the exception of the delta and beta bands power of motor cortex in wakeful state (Kumar and Desiraju, 1992).

Male Sprague-Dawley rats have been exposed to $\mathrm{Pb} 2+$ from parturition to weaning though their dams' milk that received drinking water containing $1.0,2.5$, or $5.0 \mathrm{mg} / \mathrm{ml}$ lead acetate (McCarren and Eccles, 1983). Beginning from 15 weeks of age, the characteristics of the electrically elicited hippocampal after discharge (AD) and its alteration by phenytoin (PHT) showed significant increase in primary AD duration only in the animals exposed to the higher dose of $\mathrm{Pb} 2+$, whereas all groups responded to PHT with increases in primary AD duration (McCarren and Eccles, 1983).

Uncertainties or Inconsistencies

Quantitative understanding of the linkage

No enough data is available to address the questions above. 


\section{Evidence supporting taxonomic applicability}

Colón-Ramos, 2009 has recently reviewed the early developmental events that take place during the process of synaptogenesis pointing out the importance of this process in neural network formation and function. The experimental findings reviewed in this paper derive from knowledge acquired in the field of neuroscience using invertebrates, in particular from C. elegans and Drosophila, at the same time emerging findings derived from vertebrates are also discussed (Colón-Ramos, 2009).

\section{References}

Cline, H., and K. Haas (2008), The regulation of dendritic arbor development and plasticity by glutamatergic synaptic input: A review of the synaptotrophic hypothesis. J Physiol 586: 1509-1517.

Colón-Ramos, D.A. (2009), Synapse formation in developing neural circuits. Curr Top Dev Biol. 87: 5379.

Ehrlich, I. et al. (2007), PSD-95 is required for activity-driven synapse stabilization. Proc Natl Acad Sci U S A. 104: 4176-4181.

Kumar, M.V., and T. Desiraju (1992), EEG spectral power reduction and learning disability in rats exposed to lead through postnatal developing age. Indian J Physiol Pharmacol. 36: 15-20.

McCarren, M., and C.U. Eccles (1983), Neonatal lead exposure in rats: II. Effects on the hippocampal afterdischarge. Neurobehav Toxicol Teratol. 5: 533-540.

McConnell, E.R. et al. (2012), Evaluation of multi-well microelectrode arrays for neurotoxicity screening using a chemical training set. Neurotoxicology 33: 1048-1057.

Otto, D., and L. Reiter (1984), Developmental changes in slow cortical potentials of young children with elevated body lead burden. Neurophysiological considerations. Ann N Y Acad Sci. 425: 377-383.

Rodier, P.M. (1995), Developing brain as a target of toxicity. Environ. Health Perspect. 103: 73-76.

\section{Neuronal network function, Decreased leads to Learning and memory, Impairment}

\section{How Does This Key Event Relationship Work}

Learning and memory is one of the outcomes of the functional expression of neurons and neural networks from mammalian to invertebrates. Damage or destruction of neurons by chemical compounds during development when they are in the process of synapses formation, integration and formation of neural networks, will derange the organization and function of these networks, thereby setting the stage for subsequent impairment of learning and memory. Exposure to the potential developmental toxicants during neuronal differentiation and synaptogenesis will increase risk of functional neuronal network damage leading to learning and memory impairment. 


\section{Weight of Evidence}

Biological Plausibility

Long-term potentiation (LTP) is a long-lasting increase in synaptic efficacy (not always and not always high frequency stimulation leads to LTP), and its discovery suggested that changes in synaptic strength could provide the substrate for learning and memory (reviewed in Lynch, 2004). Moreover, LTP is intimately related to the theta rhythm, an oscillation long associated with learning. Learning-induced enhancement in neuronal excitability, a measurement of neural network function, has also been shown in hippocampal neurons following classical conditioning in several experimental approaches (reviewed in Saar and Barkai, 2003).

On the other hand, memory requires the increase in magnitude of EPSCs to be developed quickly and to be persistent for few weeks at least without disturbing already potentiated contacts. Once again, a substantial body of evidence has demonstrated that tight connection between LTP and diverse instances of memory exist (reviewed in Lynch, 2004).

\section{Empirical Support for Linkage}

A series of important findings suggest that the biochemical changes that happen after induction of LTP also occur during memory acquisition, showing temporality between the two KEs (reviewed in Lynch, 2004).

Furthermore, a review on Morris water maze (MWM) as a tool to investigate spatial learning and memory in laboratory rats also pointed out that the disconnection between neuronal networks rather than the brain damage of certain regions is responsible for the impairment of MWM performance (D'Hooge and De Deyn, 2001). Functional integrated neural networks that involve the coordination action of different brain regions are consequently important for spatial learning and MWM performance.

Morris et al. 1986 found that blocking the NMDA receptor with AP5 inhibits spatial learning in rats. Most importantly, in the same study they measured brain electrical activity and recorded that this agent also inhibits LTP, however, they have not proved that spatial learning and LTP inhibition are causally related (Morris et al., 1986). Since then a number of NMDA receptor antagonists have been studied towards their ability to induce impairment of learning and memory. It is worth mentioning that similar findings have been found in human subjects, where by combining behavioural and electrophysiological data from patients with temporal lobe epilepsy exposed to ketamine, they demonstrated involvement of NMDA receptors in human memory processes (Grunwald et al., 1999).

Pb2+: Exposure to low levels of $\mathrm{Pb} 2+$, during early development, has been implicated in longlasting behavioural abnormalities and cognitive deficits in children (Needleman et al., 1975; Needleman and Gatsonis, 1990; Bellinger et al., 1991; 1992; Baghurst et al., 1992; Leviton et al., 1993; Needleman et al., 1996; Finkelstein et al., 1998; Lanphear et al., 2000; 2005; Canfield et al., 2003; Bellinger 2004; Lanphear et al., 2005; Surkan et al., 2007; Jusko et al., 2008; Neal and Guilarte, 2010) and experimental animals (Brockel and Cory-Slechta, 1998; Murphy and Regan, 1999; Moreira et al., 2001). Multiple lines of evidence suggest that $\mathrm{Pb} 2+$ can impair hippocampus-mediated learning in animal models (reviewed in Toscano and Guilarte, 2005). 
The majority of the studies addressing the effects of $\mathrm{Pb} 2+$ on hippocampal-associated spatial learning and memory processes have been carried out mainly in male rats (Cao et al., 2008, Gilbert et al., 2005); only a few studies have examined both sexes simultaneously (Jett et al., 1997, $\mathrm{Xu}$ et al., 2009). Female rats exposed to $\mathrm{Pb} 2+$ through gestation and lactation have shown more severe impairment of memory than male rats with similar Pb2+ exposures (Jett et al., 1997). De Souza Lisboa et al. (2005) have reported that exposure to Pb2+ during both pregnancy and lactation causes depressive-like behaviour (detected in the forced swimming test) in female but not male rats. A more recent study has investigated the neurobehavioral outcomes in $\mathrm{Pb} 2+-$ exposed rats $(250,750$ and $1500 \mathrm{ppm} \mathrm{Pb} 2+$ acetate in food) during gestation and through weaning and demonstrated that these outcomes are very much influenced by sex and rearing environment (Anderson et al., 2012). In females, $\mathrm{Pb} 2+$ exposure lessens some of the benefits of enriched environment on learning, whereas, in males, enrichment does help to overcome detrimental effects of $\mathrm{Pb} 2+$ on learning. Regarding reference memory, environmental enrichment has not been beneficial in females when exposure to $\mathrm{Pb} 2+$ occurs, in contrast to males (Anderson et al., 2012). Wistar rat pups were exposed to $0.2 \% \mathrm{~Pb} 2+$ via their dams' drinking water from PND 1 to PND 21 and directly via drinking water from weaning until PND 30 (Jaako-Movits et al., 2005). At PND 60 and 80, the neurobehavioural assessment has revealed that developmental $\mathrm{Pb} 2+$ exposure induces persistent increase in the level of anxiety and inhibition of contextual fear conditioning (Jaako-Movits et al., 2005). The same behavioural syndrome in rats has been described in Salinas and Huff, 2002 and is in agreement with observations on humans as children exposed to low levels of $\mathrm{Pb} 2+$ display attention deficit, increased emotional reactivity and impaired memory and learning (Finkelstein et al., 1998).

In experiments carried out in Wistar rats that were fed with lead acetate (400 micrograms lead/g body weight/day) from PND 2 until PND 60, EEG findings show statistically significant reduction in the delta, theta, alpha and beta band EEG spectral power in motor cortex and hippocampus but not in delta and beta bands power of motor cortex in wakeful state (Kumar and Desiraju, 1992). After 40 days of recovery, animals have been assessed for their neurobehaviour and revealed that $\mathrm{Pb} 2+$ treated animals show more time and sessions in attaining criterion of learning than controls (Kumar and Desiraju, 1992). Further data obtained using animal behavioral techniques demonstrate that NMDA mediated synaptic transmission is decreased by $\mathrm{Pb} 2+$ exposure (CorySlechta, 1995; Cohn and Cory-Slechta, 1993; 1994).

Rat pups from parents exposed to $2 \mathrm{mM} \mathrm{PbCl} 23$ weeks before mating until their weaning (preweaning $\mathrm{Pb} 2+$ ) and weaned pups exposed to $2 \mathrm{mM} \mathrm{PbCl} 2$ for 9 weeks (post-weaning $\mathrm{Pb} 2+$ ) were assessed for their spatial learning and memory by MWM on PND 85-90 (Xiao et al., 2014). The study revealed that both rat pups in pre-weaning $\mathrm{Pb} 2+$ and post-weaning $\mathrm{Pb} 2+$ groups performed significantly worse than those in control group (Xiao et al., 2014).

The number of synapses in pre-weaning $\mathrm{Pb} 2+$ group increased significantly, but it was still less than that of Control group ( $\mathrm{p}<0.05$ ); the number of synapses in post-weaning $\mathrm{Pb} 2+$ group was also less than that of control group $(p<0.05)$, although the number of synapses has no differences between post-weaning $\mathrm{Pb} 2+$ and control groups before MWM. In both pre-weaning $\mathrm{Pb} 2+$ and post-weaning $\mathrm{Pb} 2+$ groups, synaptic structural parameters such as thickness of postsynaptic density (PSD), length of synaptic active zone and synaptic curvature increased whereas width of synaptic cleft decreased compared to controls (Xiao et al., 2014). 
Uncertainties or Inconsistencies

One of the most difficult issues for neuroscientists is to link neuronal network function to cognition, including learning and memory. It is still unclear what modifications of neuronal circuits need to happen in order to alter motor behaviour as it is recorded in a learning and memory test (Mayford et al., 2012), meaning that there is no clear understanding about the how these two KEs are connected.

Several epidemiological studies where $\mathrm{Pb} 2+$ exposure levels have been studied in relation to neurobehavioural alterations in children have been reviewed in Koller et al. 2004. This review has concluded that in some occasions there is negative correlation between $\mathrm{Pb} 2+$ dose and cognitive deficits of the subjects due to high influence of social and parenting factors in cognitive ability like learning and memory (Koller et al. 2004), meaning that not always $\mathrm{Pb} 2+$ exposure is positively associated with learning and memory impairment in children.

Quantitative understanding of the linkage

No enough data is available to address the questions above.

Evidence supporting taxonomic applicability

\begin{tabular}{|l|l|l|l|}
\hline Name & Scientific Name & Evidence & Links \\
\hline human & Homo sapiens & Strong & NCBI \\
\hline rat & Rattus sp. & Strong & NCBI \\
\hline mouse & Mus sp. & Strong & NCBI \\
\hline
\end{tabular}

\section{References}

Anderson, D.W., K. Pothakos and J.S. Schneider (2012), Sex and rearing condition modify the effects of perinatal lead exposure on learning and memory. Neurotoxicology 33: 985-995.

Baghurst, P.A. et al. (1992), Environmental exposure to lead and children's intelligence at the age of seven years. The Port Pirie Cohort Study. N Engl J Med. 327: 1279-1284.

Bellinger, D. et al. (1991), Low-level lead exposure and children's cognitive function in the preschool years. Pediatrics. 87: 219-227.

Bellinger, D.C., K.M. Stiles and H.L. Needleman (1992), Low-level lead exposure, intelligence and academic achievement: a long-term follow-up study. Pediatrics 90: 855-861.

Bellinger, D.C. (2004), Lead. Pediatrics 113: 1016-1022.

Brockel, B.J., and D.A. Cory-Slechta (1998), Lead, attention, and impulsive behavior: changes in a fixedratio waiting-for-reward paradigm. Pharmacol Biochem Behav. 60: 545-552.

Canfield, R.L. et al. (2003), Intellectual impairment in children with blood lead concentrations below $10 \mu \mathrm{g}$ per deciliter. N Engl J Med. 348: 1517-1526.

Cao, X., S. Huang and D. Ruan (2008), Enriched environment restores impaired hippocampal long-term potentiation and water maze performance induced by developmental lead exposure in rats. Dev Psychobiol. 50: 307-313. 
Cohn, J., and D.A. Cory-Slechta (1993), Subsensitivity of lead-exposed rats to the accuracy-impairing and rate-altering effects of MK-801 on a multiple schedule of repeated learning and performance. Brain Res. 600: 208-218.

Cohn, J., and D.A. Cory-Slechta (1994), Lead exposure potentiates the effects of N-methyl-D-asparate on repeated learning. Neurotoxicol Teratol. 16: 455-465.

Cory-Slechta, D.A. (1995), MK-801 subsensitivity following postweaning lead exposure. Neurotoxicology 16: 83-95.

D'Hooge, R., and P.P. De Deyn (2001), Applications of the Morris water maze in the study of learning and memory. Brain Res Brain Res Rev. 36: 60-90.

de Souza Lisboa, S.F. et al. (2005), Developmental lead exposure induces depressive-like behavior in female rats. Drug Chem Toxicol. 28: 67-77.

Finkelstein, Y., M.E. Markowitz and J.F. Rosen (1998), Low-level lead-induced neurotoxicity in children: an update on central nervous system effects. Brain Res Rev. 27: 168-176.

Gilbert, M.E. et al. (2005), Chronic developmental lead exposure reduces neurogenesis in adult rat hippocampus but does not impair spatial learning. Toxicol Sci. 86: 365-374.

Grunwald, T. et al. (1999), Evidence relating human verbal memory to hippocampal N-methyl-D-aspartate receptors. Proc Natl Acad Sci U S A. 96: 12085-12089.

Jaako-Movits, K. et al. (2005), Developmental lead exposure impairs contextual fear conditioning and reduces adult hippocampal neurogenesis in the rat brain. Int J Dev Neurosci. 23: 627-635.

Jett, D.A. et al. (1997), Age-dependent effects of developmental lead exposure on performance in the Morris water maze. Pharmacol Biochem Behav. 57: 271-279.

Jusko, T.A. et al. (2008), Blood lead concentrations < $10 \mathrm{microg} / \mathrm{dL}$ and child intelligence at 6 years of age. Environ Health Perspect 116:243-248.

Koller, K. et al. (2004), Recent developments in low-level lead exposure and intellectual impairment in children. Environ Health Perspect. 112: 987-994.

Kumar, M.V., and T. Desiraju (1992), EEG spectral power reduction and learning disability in rats exposed to lead through postnatal developing age. Indian J Physiol Pharmacol. 36: 15-20.

Lanphear, B.P. et al. (2000), Cognitive deficits associated with blood lead concentrations $<10 \mathrm{microg} / \mathrm{dL}$ in US children and adolescents. Public Health Rep. 115: 521-529.

Lanphear, B.P. et al. (2005), Low-level environmental lead exposure and children's intellectual function: an international pooled analysis. Environ Health Perspect. 113: 894-899.

Leviton, A. et al. (1993), Pre- and postnatal low-level lead exposure and children's dysfunction in school. Environ Res 60:30-43.

Lynch, M.A. (2004), Long-term potentiation and memory. Physiol Rev. 84: 87-136.

Mayford, M., S.A. Siegelbaum and E.R. Kandel (2012), Synapses and memory storage. Cold Spring Harb Perspect Biol. 4. pii: a005751.

Moreira, E.G., I. Vassilieff and V.S. Vassilieff (2001), Developmental lead exposure: behavioral alterations in the short and long term. Neurotoxicol Teratol. 23: 489-495.

Morris, R.G. et al. (1986), Selective impairment of learning and blockade of long-term potentiation by an N-methyl-D-aspartate receptor antagonist, AP5. Nature 319: 774-776.

Murphy, K.J., and C.M. Regan (1999), Low level lead exposure in the early postnatal period results in persisting neuroplastic deficits associated with memory consolidation. J Neurochem. 72: 2099-2104.

Neal, A.P., and T.R. Guilarte (2010), Molecular Neurobiology of Lead (Pb2+): Effects on Synaptic Function. Mol Neurobiol. 42: 151-160.

Needleman, H.L. et al. (1975), Letter: Blood-lead levels, behaviour and intelligence. Lancet 1: 751-752. 
Needleman, H.L., and C.A. Gatsonis (1990), Low-level lead exposure and the IQ of children. A metaanalysis of modern studies. Jama 263: 673-678.

Needleman, H.L. et al. (1996), Bone Lead Levels and Delinquent Behavior. Jama 275: 363-369.

Saar, D., and E. Barkai (2003), Long-term modifications in intrinsic neuronal properties and rule learning in rats. Eur J Neurosci. 17: 2727-2734.

Salinas, J.A., and N.C. Huff (2002), Lead and conditioned fear to contextual and discrete cues. Neurotoxicol Teratol. 24: 541-550.

Surkan, P.J. et al. (2007), Neuropsychological function in children with blood lead levels $<10$ microg/dL. Neurotoxicology. 28: 1170-1177.

Toscano, C.D., T.R. Guilarte (2005), Lead neurotoxicity: From exposure to molecular effects. Brain Res Rev. 49: 529-554.

Xiao, Y. et al. (2014), Role of synaptic structural plasticity in impairments of spatial learning and memory induced by developmental lead exposure in Wistar rats. PLoS One. 23;9(12):e115556.

$\mathrm{Xu}$, J. et al. (2009), Effects of lead exposure on hippocampal metabotropic glutamate receptor subtype 3 and 7 in developmental rats. J Negat Results Biomed. 8: 5. 


\section{Overall Assessment of the AOP}

The aim of the present AOP is to construct a linear pathway that captures the KEs and KERs that occur after binding of antagonist to NMDA receptor in neurons during development in hippocampus and cortex. All KEs of the AOP are characterised by STRONG essentiality for the AO (learning and memory impairment). Similarly, the biological plausibility in the majority of KERs is rated STRONG as there is extensive mechanistic understanding. However, the empirical support for the present KERs cannot be rated high as in most occasions the KEup and KEdowm of a KER have not been investigated simultaneously under the same experimental protocol.

Weight of Evidence Summary

\begin{tabular}{|c|c|c|c|}
\hline Event & Description & Triggers & $\begin{array}{l}\text { Weight of } \\
\text { Evidence }\end{array}$ \\
\hline NMDARs, Binding of antagonist & $\begin{array}{l}\text { Directly Leads } \\
\text { to }\end{array}$ & NMDARs, Inhibition & Strong \\
\hline NMDARs, Inhibition & $\begin{array}{l}\text { Directly Leads } \\
\text { to }\end{array}$ & Calcium influx, Decreased & Moderate \\
\hline Calcium influx, Decreased & $\begin{array}{l}\text { Indirectly Leads } \\
\text { to }\end{array}$ & Release of BDNF, Reduced & Weak \\
\hline Release of BDNF, Reduced & $\begin{array}{l}\text { Indirectly Leads } \\
\text { to }\end{array}$ & Dendritic morphology, Aberrant & Weak \\
\hline Release of BDNF, Reduced & $\begin{array}{l}\text { Indirectly Leads } \\
\text { to }\end{array}$ & $\begin{array}{l}\text { Presynaptic release of glutamate, } \\
\text { Reduced }\end{array}$ & Weak \\
\hline Release of BDNF, Reduced & $\begin{array}{l}\text { Indirectly Leads } \\
\text { to }\end{array}$ & Cell death, N/A & Weak \\
\hline Dendritic morphology, Aberrant & $\begin{array}{l}\text { Indirectly Leads } \\
\text { to }\end{array}$ & Synaptogenesis, Decreased & Weak \\
\hline $\begin{array}{l}\text { Presynaptic release of glutamate, } \\
\text { Reduced }\end{array}$ & $\begin{array}{l}\text { Indirectly Leads } \\
\text { to }\end{array}$ & Synaptogenesis, Decreased & Weak \\
\hline Cell death, N/A & $\begin{array}{l}\text { Indirectly Leads } \\
\text { to }\end{array}$ & Synaptogenesis, Decreased & Weak \\
\hline Synaptogenesis, Decreased & $\begin{array}{l}\text { Directly Leads } \\
\text { to }\end{array}$ & $\begin{array}{l}\text { Neuronal network function, } \\
\text { Decreased }\end{array}$ & Weak \\
\hline $\begin{array}{l}\text { Neuronal network function, } \\
\text { Decreased }\end{array}$ & $\begin{array}{l}\text { Indirectly Leads } \\
\text { to }\end{array}$ & $\begin{array}{l}\text { Learning and memory, } \\
\text { Impairment }\end{array}$ & Weak \\
\hline
\end{tabular}


The table provides a summary of the biological plausibility and empirical support for each KER described in this AOP based on "Annex 1: Guidance for assessing relative level of confidence in the overall AOP based on rank ordered elements" found in User's Handbook.

More information about the evidence that support these KERs and the relevant literature can be found in each KER description.

The main reason for the overall scoring is that for the majority of KERs, the KEup and KEdown have not been investigated simultaneously in the same study.

\begin{tabular}{|c|c|c|c|c|c|}
\hline KERs WoE & $\begin{array}{l}\text { Biological } \\
\text { plausibility }\end{array}$ & $\begin{array}{c}\text { Does KEup } \\
\text { occurs at } \\
\text { lower doses } \\
\text { than } \\
\text { KEdown? }\end{array}$ & $\begin{array}{l}\text { Does KEup } \\
\text { occurs at } \\
\text { earlier time } \\
\text { points than } \\
\text { KE down? }\end{array}$ & $\begin{array}{l}\text { Is there } \\
\text { higher } \\
\text { incidence of } \\
\text { KEup than } \\
\text { of } \\
\text { KEdown? }\end{array}$ & Inconsistencies/Uncertainties \\
\hline $\begin{array}{l}\text { NMDARs, } \\
\text { Binding } \\
\text { antagonist } \\
\text { Directly Leads to } \\
\text { NMDARs, } \\
\text { Inhibition }\end{array}$ & $\begin{array}{l}\text { Extensive } \\
\text { understanding }\end{array}$ & N/A & Yes & N/A & Limited conflicting data \\
\hline $\begin{array}{l}\text { NMDARs, } \\
\text { Inhibition } \\
\text { Directly Leads to } \\
\text { Calcium influx, } \\
\text { Decreased }\end{array}$ & $\begin{array}{l}\text { Extensive } \\
\text { understanding }\end{array}$ & Same dose & Yes & $\begin{array}{l}\text { Not } \\
\text { investigated }\end{array}$ & Limited conflicting data \\
\hline $\begin{array}{l}\text { Calcium influx, } \\
\text { Decreased } \\
\text { Indirectly Leads } \\
\text { to Release of } \\
\text { BDNF, Reduced }\end{array}$ & $\begin{array}{l}\text { Extensive } \\
\text { understanding }\end{array}$ & $\begin{array}{l}\text { Not } \\
\text { investigated }\end{array}$ & $\begin{array}{l}\text { Not } \\
\text { investigated }\end{array}$ & $\begin{array}{l}\text { Not } \\
\text { investigated }\end{array}$ & Limited conflicting data \\
\hline $\begin{array}{l}\text { Release of } \\
\text { BDNF, Reduced } \\
\text { Indirectly Leads } \\
\text { to Dendritic } \\
\text { morphology, } \\
\text { Aberrant }\end{array}$ & $\begin{array}{l}\text { Extensive } \\
\text { understanding }\end{array}$ & $\begin{array}{l}\text { Not } \\
\text { investigated }\end{array}$ & Yes & $\begin{array}{l}\text { Not } \\
\text { investigated }\end{array}$ & No conflicting data \\
\hline $\begin{array}{l}\text { Release of } \\
\text { BDNF, Reduced } \\
\text { Indirectly Leads } \\
\text { to Cell death, } \\
\text { N/A }\end{array}$ & $\begin{array}{l}\text { Extensive } \\
\text { understanding }\end{array}$ & $\begin{array}{l}\text { Not } \\
\text { investigated }\end{array}$ & Yes & $\begin{array}{l}\text { Not } \\
\text { investigated }\end{array}$ & Limited conficting data \\
\hline
\end{tabular}




\begin{tabular}{|c|c|c|c|c|c|}
\hline $\begin{array}{l}\text { Release of } \\
\text { BDNF, Reduced } \\
\text { Indirectly Leads } \\
\text { to Presynaptic } \\
\text { release of } \\
\text { glutamate, } \\
\text { Reduced }\end{array}$ & $\begin{array}{l}\text { Extensive } \\
\text { understanding }\end{array}$ & $\begin{array}{l}\text { Not } \\
\text { investigated }\end{array}$ & $\begin{array}{l}\text { Not } \\
\text { investigated }\end{array}$ & $\begin{array}{l}\text { Not } \\
\text { investigated }\end{array}$ & Limited conficting data \\
\hline $\begin{array}{l}\text { Cell death, N/A } \\
\text { Indirectly Leads } \\
\text { to } \\
\text { Synaptogenesis, } \\
\text { Decreased }\end{array}$ & $\begin{array}{l}\text { Extensive } \\
\text { understanding }\end{array}$ & $\begin{array}{l}\text { Not } \\
\text { investigated }\end{array}$ & Yes & $\begin{array}{l}\text { Not } \\
\text { investigated }\end{array}$ & Limited conficting data \\
\hline $\begin{array}{l}\text { Dendritic } \\
\text { morphology, } \\
\text { Aberrant } \\
\text { Indirectly Leads } \\
\text { to } \\
\text { Synaptogenesis, } \\
\text { Decreased }\end{array}$ & $\begin{array}{l}\text { Extensive } \\
\text { understanding }\end{array}$ & $\begin{array}{l}\text { Not } \\
\text { investigated }\end{array}$ & Not always & $\begin{array}{l}\text { Not } \\
\text { investigated }\end{array}$ & No conflicting data \\
\hline $\begin{array}{l}\text { Presynaptic } \\
\text { release } \\
\text { glutamate, } \\
\text { Reduced } \\
\text { Indirectly Leads } \\
\text { to } \\
\text { Synaptogenesis, } \\
\text { Decreased }\end{array}$ & $\begin{array}{l}\text { Extensive } \\
\text { understanding }\end{array}$ & $\begin{array}{l}\text { Not } \\
\text { investigated }\end{array}$ & $\begin{array}{l}\text { Not } \\
\text { investigated }\end{array}$ & $\begin{array}{l}\text { Not } \\
\text { investigated }\end{array}$ & No conflicting data \\
\hline $\begin{array}{l}\text { Synaptogenesis, } \\
\text { Decreased } \\
\text { Directly Leads to } \\
\text { Neuronal } \\
\text { network } \\
\text { function, } \\
\text { Decreased }\end{array}$ & $\begin{array}{l}\text { Extensive } \\
\text { understanding }\end{array}$ & $\begin{array}{l}\text { Not } \\
\text { investigated }\end{array}$ & $\begin{array}{l}\text { Not } \\
\text { investigated }\end{array}$ & $\begin{array}{l}\text { Not } \\
\text { investigated }\end{array}$ & No conflicting data \\
\hline $\begin{array}{l}\text { Neuronal } \\
\text { network } \\
\text { function, } \\
\text { Decreased } \\
\text { Indirectly Leads } \\
\text { to Learning and } \\
\text { memory, } \\
\text { Impairment }\end{array}$ & $\begin{array}{l}\text { Scientific } \\
\text { understanding } \\
\text { is not } \\
\text { completely } \\
\text { established }\end{array}$ & $\begin{array}{l}\text { Not } \\
\text { investigated }\end{array}$ & Yes & $\begin{array}{l}\text { Not } \\
\text { investigated }\end{array}$ & Limited conficting data \\
\hline
\end{tabular}


Essentiality of the Key Events

\begin{tabular}{|c|l|}
\hline Molecular Initiating Event & Support for Essentiality \\
\hline NMDARs, Binding of antagonist & Strong \\
\hline
\end{tabular}

\begin{tabular}{|l|l|}
\hline \multicolumn{1}{|c|}{ Key Event } & Support for Essentiality \\
\hline NMDARs, Inhibition & Strong \\
\hline Calcium influx, Decreased & Strong \\
\hline Release of BDNF, Reduced & Strong \\
\hline Dendritic morphology, Aberrant & Strong \\
\hline Presynaptic release of glutamate, Reduced & Strong \\
\hline Cell death, N/A & Strong \\
\hline Synaptogenesis, Decreased & Strong \\
\hline Neuronal network function, Decreased & Strong \\
\hline
\end{tabular}

1) Essentiality of the MIE: binding of antagonist to NMDAR in neurons during synaptogenesis in hippocampus and cortex

The MIE is defined and described above as the binding of antagonist to NMDA receptor in neurons during development in hippocampus and cortex (the critical brain structures for learning and memory formation). Activation of NMDA receptors results in long-term potentiation (LTP), which is related to increased synaptic strength and memory formation in the hippocampus (Johnston et al., 2009). LTP induced by activation of NMDA receptors has been found to be elevated in the developing rodent brain compared to the mature brain, partially due to "developmental switch" of the NMDAR 2A and 2B subunits (Johnston et al., 2009).

Essentiality of MIE (binding of antagonist to NMDAR in neurons during synaptogenesis in hippocampus and cortex) for AO (Impairment of learning and memory) is STRONG: It is well documented that learning and memory processes rely on physiological functioning of NMDA receptors. The essentiality of the MIE has been demonstrated in both animal and human studies investigating NMDA itself, NMDA receptors antagonists and mutant mice lacking NMDA receptor subunits (reviewed in Haberny et al., 2002; Rezvani, 2006 and Granger et al., 2011). NMDA systemically administered in rats, has been shown to potentiate cognitive functions (Rezvani, 2006). There are various studies dealing with specific NMDA receptor subunit gene knock-out leading to a variety of phenotypes. Depending on the endogenous levels of NMDAR subunits, the pattern of their expression and their importance in developmental processes, the loss of a subunit may lead from early embryonic lethality, to mild neurobehavioral impairment up to neuronal disorders that manifest learning and memory deficits (reviewed in Rezvani, 2006 and Granger et al., 2011). Mutant mice lacking NR1 gene have shown perinatal lethality, whereas transgenic mice lacking NR1 subunit in the CA1 region of the hippocampus show both defective 
LTP and severe deficits in both spatial and nonspatial learning (Shimizu et al., 2000; Tsien et al., 1996). A similar impairment of LTP, long-term depression (LTD), and spatial memory has been seen with CA1-specific NR2B deletion (Brigman et al. 2010). However, LTP has been normal in postnatal forebrain knock-out of NR2A in mice, even though spatial memory has been impaired, probably because of the severe reduction observed in overall excitatory transmission (Shimshek et al., 2006), while the inactivation of the same gene has led to reduced hippocampal LTP and spatial learning (Sakimura et al., 1995). Furthermore, a NR2B transgenic (Tg) line of mice has been developed, in which the NMDA-receptor function has been increased, showing both larger LTP in the hippocampus and superior learning and memory (Tang et al., 1999). Finally, depletion of both NR2A and NR2B in single neurons has shown alteration in synaptic development (Gray et al., 2011). Interestingly, during development, especially during postnatal days (PND) 7-14 in rodents, the central nervous system (CNS) exhibits increased susceptibility to toxic insults that affect NMDA receptors (Haberny et al., 2002). This increased susceptibility has been suggested to be related to the elevated expression of specific NMDA receptor subunits (Miyamoto et al., 2001). Because of the critical role of the NMDA receptor system in brain development, the exposure to antagonists of NMDA receptors can have long-lasting and severe effects (Behar et al., 1999). NMDA-receptor antagonists such as MK-801, ketamine, phencyclidine (PCP) and 2-amino-5phosphonopentanoate (AP5 or APV) have been extensively used to study the role of NMDA in learning and memory in developing organisms. Both acute and subchronic administration of NMDA-receptor antagonists in several laboratory animals has been shown to impair performance on tasks that seem to depend upon hippocampal functions (reviewed in Rezvani, 2006; Haberny et al., 2002). The developmental neurotoxicity of several agents, including methylmercury, lead, and ethanol is also thought to result from interaction of these substances with the NMDA receptor system (Guilarte, 1997; Guilarte and McGlothan, 1998; Ikonomidou et al., 2000; Kumari and Ticku, 1998; Miyamoto et al., 2001).

Essentiality of MIE (binding of antagonist to NMDAR in neurons during synaptogenesis in hippocampus and cortex for KE (aberrant dendritic morphology) is MODERATE: The cortex-restricted knockout of NR1 causes refinement in dendritic arborisation in cortex and loss of patterning (Iwasato et al., 2000; Lee et al., 2005). Similar alteration in dendritic arbor has also been identified after depletion of both NR2A and NR2B subunits in isolated neurons (Espinosa et al., 2009). Blockade of NMDA receptor with APV has shown decrease of dendritic growth rate in some in vivo experimental approaches (Rajan et al., 1999; Rajan and Cline, 1998). However, other studies have reported increase in dendritic spine number and dendritic branching after chronic APV-treatment both in vivo and in vitro (Rocha and Sur, 1995; McAllister et al., 1996). This discrepancy is possibly attributed to the different developmental expression of NMDA receptor subunits that triggers distinct intracellular signaling pathways linking NMDAR function to different morphological findings.

Essentiality of MIE (binding of antagonist to NMDAR in neurons during synaptogenesis in hippocampus and cortex) for KE (cell death) is STRONG: The essential role of NMDA receptors in survival during early cortical development has been pointed out both in in vitro (Hwang et al., 1999; Yoon et al., 2003) and in vivo rodent studies (Ikonomidou et al., 1999). NMDA receptor deficient mice have revealed the importance of this receptor for neuronal survival during development as an approximately 2-fold increase in developmental cell death has been observed in these transgenic mice, which was caspase-3 and Bax dependent (Adams et al., 2004; Rivero Vaccari et al., 2006). 
Essentiality of MIE for KE (decreased neuronal network function) is STRONG: The NMDA receptor is associated with circuit formation and function at the developmental stage of an organism as a number of antagonists of this receptor importantly disrupt the neuronal circuit (Simon et al., 1992). Hence, the nature of evidence for the essentiality of the MIE is High (Strong).

\section{2) Essentiality of the KE (Inhibition of NMDA receptors)}

Essentiality of KE (Inhibition of NMDA receptors) for AO (Impairment of learning and memory) is STRONG: The noncompetitive antagonist MK-801 has been shown to induce dosedependent impairment of learning and memory (Wong et al., 1986) and data on rodent models has been recently reviewed in van der Staay et al. 2011. Learning impairments induced by NMDA receptor blockade using MK-801 have also been reported in nonhuman primates (Ogura and Aigner, 1993). Moreover there are human studies demonstrating that NMDA-receptor inhibition impairs learning and memory processes (reviewed in Rezvani, 2006).

\section{3) Essentiality of the KE (Decreased Calcium influx)}

Essentiality of KE (Decreased Calcium influx) for AO (Impairment of learning and memory) is STRONG: In the nervous system, many intracellular responses to modified $\mathrm{Ca} 2+$ levels are mediated by calcium/calmodulin-regulated protein kinases (CaMKs), a family of protein kinases that are initially modulated by binding of $\mathrm{Ca} 2+$ to $\mathrm{CaM}$ and subsequently by protein phosphorylation (Wayman et al., 2008). Multifunctional CaMKs, such as CaMKII and members of CaMK cascade (CaMKK, CaMKI and CaMKIV) are highly abundant in CNS and regulate different protein substrates (Soderling, 1999). Mice with a mutation in the alphaCaMKII that is abundantly found in the hippocampus have shown spatial learning impairments, whereas some types of non-spatial learning processes have not been affected (Silva et al., 1992).

\section{4) Essentiality of KE (Decreased levels of BDNF)}

Essentiality of KE (Decreased levels of BDNF) for AO (Impairment of learning and memory) is STRONG: BDNF serves essential functions in the brain development and more specific in synaptic plasticity (Poo, 2001) and is crucial for learning and memory processes (Lu et al., 2008). The action of BDNF signaling on synapses happens within seconds of its release (Kovalchuk et al., 2004) and strengthens LTP processes, a cellular model for learning and memory, via sustained TrkB activation as a result of elevated transcription of BDNF (Kang and Schuman, 1996; Nagappan and Lu, 2005). This positive transcriptional feedback happens through TrkB-mediated CREB activation and increases gene transcription of BDNF (Lu et al., 2008). Furthermore, there are experimental evidence showing that loss of BDNF through transgenic models or pharmacological manipulation leads to impaired LTP (Patterson et al., 1996; Monteggia et al., 2004) and decreased learning and memory (Lu et al., 2008). The important role for BDNF in LTP and learning and memory is suggested from numerous studies in rodents. Hippocampal LTP is impaired in mice lacking BDNF in their neurons, and BDNF enhances LTP in the hippocampus and visual cortex (reviewed in Mattson, 2008). BDNF can also be released from neurons during LTP and possibly recycled and used for LTP maintenance. In learning and memory enhancement studies, it has been found that dietary energy restriction (which enhances synaptic plasticity) increases the production of BDNF and glial cells derived neurotrophic factor (reviewed in Mattson, 2008). In humans, a common single-nucleotide polymorphism in the Bdnf gene results in poor performance on memory tasks and may contribute to the pathogenesis of 
depression and anxiety disorders (reviewed in Cohen and Greenberg, 2008). Similarly, the transgenic mice with such mutation display defects in learning and memory tasks as well as anxiety-related behaviours (reviewed in Cohen and Greenberg, 2008). BDNF has also been shown to play pivotal role in a variety of learning paradigms in a variety of animal models such as mice, monkeys, zebra finches and chicks (reviewed in Tyler et al., 2002).

\section{5) Essentiality of KE (Cell death)}

Essentiality of KE (Cell death) for AO (Impairment of learning and memory) is STRONG: Several experimental studies dealing with postnatal administration of NMDA receptor antagonists such as MK-801, ketamine or ethanol have shown a devastating cell apoptotic degeneration in several brain regions of animals models, resulting in learning deficits (reviewed in Fredriksson and Archer, 2004; Creeley and Olney, 2013). The apoptosis induced in developing brain after exposure to NMDA receptor antagonists is not reversible although the developing brain has plasticity properties that may allow to a certain degree to compensate for neuronal losses. This severe bilaterally symmetrical neuronal losses in both hemispheres that occurs by treatment with NMDA receptor antagonists leads to neurobehavioral disorders including learning and memory deficits (Creeley and Olney, 2013).

\section{6) Essentiality of the KE (Decreased presynaptic release of glutamate)}

Essentiality of KE (Decreased presynaptic release of glutamate) for AO (Impairment of learning and memory) is STRONG: Riedel et al. 2003 have reviewed data available that is related to the understanding of the role of glutamate and its different receptor subtypes in learning and memory, focusing mainly in psychopharmacological in vivo studies conducted in rodents and primates. Furthermore, this review has included literature on long-term potentiation (LTP) and long-term depression (LTD), the most commonly used models for studying the cellular mechanisms underlying memory formation in relation to glutamate rather than exploring relevant mechanistic data. Classical conditioning of a tone-shock association (commonly used to study learning and memory) causes a lasting increase in glutamate release in dentate gyrus synaptosomes, whereas blockade of NMDA receptors during learning prevents conditioning and the change in glutamate release (Redini-Del Negro and Laroche, 1993). It is worth mentioning that there are two types of LTP, the NMDA receptor-dependent and the NMDA receptorindependent. The later type of LTP is induced presynaptically and strongly activates presynaptic $\mathrm{Ca} 2+$ channels, which results in an increase in cAMP and activation of protein kinase A that is believed to be involved in the long-lasting enhancement of glutamate release from the presynaptic terminal. This type of LTP has been observed at mossy fiber-CA3 synapses in the hippocampus or at parallel fiber-Purkinje cell synapses in the cerebellum (Manabe, 2009).

\section{7) Essentiality of the KE (Aberrant dendritic morphology)}

Essentiality of KE (Aberrant dendritic morphology) for AO (Impairment of learning and memory) is STRONG: Spine morphology is considered to be an important morphological unit for establishing learning and memory (Sekino et al., 2007). As dendrites are the postsynaptic site of most synaptic contacts, dendritic development determines the number and pattern of synapses received by each neuron (McAllistair, 2000). Defects induced in dendritic growth are often leading to severe neurodevelopmental disorders such as mental retardation (Purpura, 1975). Thus, the proper growth and arborisation of dendrites are crucial for proper functioning of the nervous system. Changes in spine formation have been found to be involved in impairment of learning and memory in live animals (Yang et al. 2009; Roberts et al. 2010). Electrical activity-dependent 
changes in the number as well as in the size and shape of dendritic spines have been strongly related to some forms of learning (reviewed in Holtmaat and Svoboda, 2009). In mouse, motor cortex learning leads to dendritic spine remodeling associated with the degree of behavioral improvement suggesting a crucial role for structural plasticity during memory formation (Yang et al., 2009 and $\mathrm{Fu}$ et al., 2012). Furthermore, accumulating evidence indicates that experiencedependent plasticity of specific circuits in the somatosensory and visual cortex involves structural changes at dendritic spines (Holtmaat and Svoboda, 2009).

\section{8) Essentiality of the KE (Decreased synaptogenesis)}

Essentiality of KE (Decreased synaptogenesis) for AO (Impairment of learning and memory) is STRONG: Learning and memory result from plastic events that modify the way neurons communicate with each other (Bear, 1996). Plastic events are considered changes in the structure, distribution and number of synapses and it has been suggested that morphological events like these underlie memory formation (Rusakov et al., 1997; Woolf, 1998; Klintsova and Greenough, 1999). In mutant mice lacking PSD-95, it has been recorded increase of NMDAdependent LTP, at different frequencies of synaptic stimulation that cause severe impaired spatial learning, without thought affecting the synaptic NMDA receptor currents, subunit expression, localization and synaptic morphology (Migaud et al., 1998). Furthermore, recent genetic screening in human subjects and neurobehavioural studies in transgenic mice have suggested that loss of synaptophysin plays important role in mental retardation and/or learning deficits (Schmitt et al., 2009; Tarpey et al., 2009).

\section{9) Essentiality of the KE (Decreased neuronal network function)}

Essentiality of KE (Decreased neuronal network function) for AO (Impairment of learning and memory) is STRONG: It is well understood and documented that the ability of neurons to communicate with each other is based on neural network formation that relies on functional synapse establishment (Colón-Ramos, 2009). The connectivity and functionality of neural networks depends on where and when synapses are formed. Therefore, the decreased synapse formation during the process of synaptogenesis is detrimental and leads to decrease of neural network formation and function. The neuronal electrical activity dependence on synapse formation and is critical for proper neuronal communication. Alterations in synaptic connectivity lead to refinement of neuronal networks during development (Cline and Haas, 2008). Indeed, knockdown of PSD-95 (postsynaptic protein) blocks the functional and morphological development of glutamatergic synapses (Ehrlich et al., 2007).

Quantitative Considerations

\begin{tabular}{|l|l|l|l|}
\hline \multicolumn{1}{|c|}{ Event } & Description & \multicolumn{1}{|c|}{ Triggers } & \multicolumn{1}{c|}{$\begin{array}{c}\text { Quantitative } \\
\text { Understanding }\end{array}$} \\
\hline $\begin{array}{l}\text { NMDARs, Binding of } \\
\text { antagonist }\end{array}$ & $\begin{array}{l}\text { Directly Leads } \\
\text { to }\end{array}$ & NMDARs, Inhibition & \\
\hline NMDARs, Inhibition & $\begin{array}{l}\text { Directly Leads } \\
\text { to }\end{array}$ & Calcium influx, Decreased & \\
\hline Calcium influx, Decreased & $\begin{array}{l}\text { Indirectly } \\
\text { Leads to }\end{array}$ & Release of BDNF, Reduced & \\
\hline
\end{tabular}




\begin{tabular}{|c|c|c|c|}
\hline Event & Description & Triggers & $\begin{array}{l}\text { Quantitative } \\
\text { Understanding }\end{array}$ \\
\hline Release of BDNF, Reduced & $\begin{array}{l}\text { Indirectly } \\
\text { Leads to }\end{array}$ & $\begin{array}{l}\text { Dendritic morphology, } \\
\text { Aberrant }\end{array}$ & \\
\hline Release of BDNF, Reduced & $\begin{array}{l}\text { Indirectly } \\
\text { Leads to }\end{array}$ & $\begin{array}{l}\text { Presynaptic release of } \\
\text { glutamate, Reduced }\end{array}$ & \\
\hline Cell death, N/A & $\begin{array}{l}\text { Indirectly } \\
\text { Leads to }\end{array}$ & Synaptogenesis, Decreased & \\
\hline $\begin{array}{l}\text { Dendritic morphology, } \\
\text { Aberrant }\end{array}$ & $\begin{array}{l}\text { Indirectly } \\
\text { Leads to }\end{array}$ & Synaptogenesis, Decreased & \\
\hline Synaptogenesis, Decreased & $\begin{array}{l}\text { Directly Leads } \\
\text { to }\end{array}$ & $\begin{array}{l}\text { Neuronal network function, } \\
\text { Decreased }\end{array}$ & \\
\hline $\begin{array}{l}\text { Neuronal network function, } \\
\text { Decreased }\end{array}$ & $\begin{array}{l}\text { Indirectly } \\
\text { Leads to }\end{array}$ & $\begin{array}{l}\text { Learning and memory, } \\
\text { Impairment }\end{array}$ & \\
\hline Release of BDNF, Reduced & $\begin{array}{l}\text { Indirectly } \\
\text { Leads to }\end{array}$ & Cell death, N/A & \\
\hline $\begin{array}{l}\text { Presynaptic release of } \\
\text { glutamate, Reduced }\end{array}$ & $\begin{array}{l}\text { Indirectly } \\
\text { Leads to }\end{array}$ & Synaptogenesis, Decreased & \\
\hline
\end{tabular}

A quantitative structure activity relationship (QSAR) model has been developed based on various molecular parameters that have been calculated for a series of competitive NMDA antagonists with known activity values and these parameters have been applied to make a regression analysis which provides a model that relates the computationally calculated parameters to experimentally determined activity values (Korkut and Varnali, 2003).

Recently, a QSAR model for non- competitive antagonists of NMDA receptor based on a series of 48 substituted MK-801 derivatives has been established (Chtitaa et al., 2015). In this paper, a quantitative model has been proposed and there has also been an attempt to interpret the activity of the compounds relying on the multivariate statistical analyses. By this approach, they have been able to predict the inhibitory activity of a set of new designed compounds (Chtitaa et al., 2015).

2D- and 3D-QSAR models have also been developed to establish the structural requirements for pyrazine and related derivatives for being NR2B selective NMDA receptor antagonists (Zambre et al., 2015). 
Applicability of the AOP

Life Stage Applicability

\begin{tabular}{|l|l|}
\hline \multicolumn{1}{|c|}{ Life Stage } & Evidence \\
\hline During brain development & Strong \\
\hline
\end{tabular}

Taxonomic Applicability

\begin{tabular}{|l|l|l|l|}
\hline \multicolumn{1}{|c|}{ Name } & \multicolumn{1}{|c|}{ Scientific Name } & Evidence & Links \\
\hline human & Homo sapiens & Strong & NCBI \\
\hline mouse & Mus sp. & Strong & NCBI \\
\hline Monkey sp. & unidentified monkey & Strong & NCBI \\
\hline rat & Rattus sp. & Strong & NCBI \\
\hline
\end{tabular}

Sex Applicability

\begin{tabular}{|l|l|}
\hline \multicolumn{1}{|c|}{ Sex } & Evidence \\
\hline Male & Strong \\
\hline Female & Strong \\
\hline
\end{tabular}

Life Stage Applicability: This AOP is applicable only for specific period of brain development that is the time of synaptogenesis. This vulnerable period of synaptogenesis appears to happen in different developmental stages across species. For example, in rodents primarily synaptogenesis occurs during the first two weeks after birth. For rhesus monkeys, this period ranges from approximately 115-day gestation up to PND 60. In humans, it starts from the third trimester of pregnancy and continues 2-3 years following birth (Bai et al., 2013). Furthermore, synaptogenesis does not happen in a uniform way in all brain regions and there are important differences between the times of appearance of the main two types of synapses (reviewed in Erecinska et al., 2004). For example, in rat hippocampus excitatory synapses are well established or fully mature within the two first postnatal weeks, whereas inhibitory synapses cannot be found prior to PND 18, after which it increases steadily to reach adult levels at PND 28. In addition, in rat neostriatal neurons the excitatory responses to both cortical and thalamic stimuli can be observed by PND 6, but the long-lasting hyperpolarization and late depolarization is never seen before PND 12.

Taxonomic Applicability: The data used to support the KERs in this AOP derives from experimental studies conducted in rats and mice or cell cultures of similar origin as well as from human epidemiological studies. The majority of the KEs in this AOP seem to be highly conserved across species. It remains to be proved if these KERs of the present AOP are also applicable for other species rather than human, primates, rats and mice.

Sex Applicability: The majority of the studies addressing the KEs and KERs of this AOP were carried out mainly in male laboratory animals. Few studies are available in females and some of 
them compare the effects between females and males. It appears that this AOP is applicable for both females and males.

\section{Considerations for Potential Applications of the AOP}

Exposure to xenobiotics can potentially affect the nervous system resulting in neurobehavioral alterations and/or neurological clinical symptoms. To assess the neurotoxic properties of compounds, current testing largely relies on neurobehavioural tests in laboratory animals, histopathological analysis, neurochemical and occasionally electrophysiological observations. Throughout the years, a significant number of methods have been developed to assess neurobehaviour in laboratory animals and a comprehensive summary of them can be found in OECD Series on testing and assessment, number 20, Guidance Document for Neurotoxicity Testing (2004). Learning and memory is an important endpoint and a wide variety of tests to assess chemical effects on cognitive functions is available and used for the study of neurotoxicity in adult and young laboratory animals. Some of these tests that allow the appreciation of cognitive function in laboratory animals are: habituation, ethologically based anxiety tests (elevated plus maze test, black and white box test, social interaction test), conditioned taste aversion (CTA), active avoidance, passive avoidance, spatial mazes (Morris water maze, Biel water maze, Tmaze), conditional discrimination (simple discrimination, matching to sample), delayed discrimination (delayed matching-to-sample, delayed alternation) and eye-blink conditioning.

The US EPA and OECD Developmental Neurotoxicity (DNT) Guidelines (OCSPP 870.6300 and OECD 426, respectively) require testing of learning and memory. These DNT Guidelines have been used to identify developmental neurotoxicity and adverse neurodevelopmental outcomes (Makris et al., 2009). Also in the scope of the OECD Test Guideline for Combined Repeated Dose Toxicity Study with Reproduction/Developmental Toxicity Screening Test (422) and OECD Test Guideline for Extended One-Generation Reproductive Toxicity Study (443), learning and memory testing may have potential to be applied in the context of DNT studies. These DNT guidelines are based entirely on in vivo experiments, which are costly, time consuming, and unsuitable for testing a larger number of chemicals. For these reasons, there is currently no regulatory request for DNT studies prior to registration of new chemicals and recommendations for DNT testing are only based on certain triggers such as structural similarity with known reproductive toxicants, concerns for endocrine disruption, results from other toxicity studies, and the anticipated use and human exposure patterns. At the same time the published data strongly suggest that environmental chemicals contribute to the observed increase in children neurodevelopmental disorders such as lowered IQ, learning disabilities, attention deficit hyperactivity disorder (ADHD) and, in particular, autism. This highlights the pressing need for standardised alternative methodologies that can more rapidly and cost-effectively screen large numbers of chemicals for their potential to cause cognitive deficit in children.

The present AOP can encourage the development of new in vitro assays test battery and the use of these alternatives to assess NMDAR inhibitors as chemicals with potential to induce impairment of children cognitive function and at the same time reduce the use of in vivo studies. Some of the KEs presented in this AOP have already been identified as endpoints to be measured during the mapping of available in vitro and alternative DNT testing methods by EFSA (Fritsche et al., 2015). In addition, the majority of KEs in this AOP has strong essentiality to induce the AO 
(impairment of learning and memory) and established indirect relationship with the AO that would allow not only the development of testing methods that address these specific KEs but also the understanding of the relationship between the measured KEs and the AO. The present AOP can potentially provide the basis for development of a mechanistically informed IATA for DNT. The construction of IATA for predicting DNT effects is expected to make use of more than one AOP within an interconnected network in order to take into consideration all possible biological processes that may contribute to impairment of learning and memory in developing organisms. Through this network, common KEs can emerge that should be considered during IATA construction and that may inform also assay development.

Results derived from assays based on the KEs of this AOP can serve to interpret and accept results that derive from non-standard test methods. Omics data from toxicogenomic, transcriptomic, proteomic, and metabolomic studies can be interpreted in a structured way following this AOP as a guide. Finally, this AOP could provide the opportunity to group chemicals using not only chemical properties but also mechanistic information that can later inform data gap filling by read-across.

\section{References}

Adams, S.M. et al. (2004), Pronounced cell death in the absence of NMDA receptors in the developing somatosensory thalamus. J Neurosci. 24: 9441-9450.

Bai, X., D. Twaroski and Z.J. Bosnjak (2013), Modeling anesthetic developmental neurotoxicity using human stem cells. Semin Cardiothorac Vasc Anesth. 17: 276-287.

Bear, M.F. (1996), A synaptic basis for memory storage in the cerebral cortex. Proc Natl Acad Sci USA 93: $13453-13459$.

Behar, T.N. et al. (1999), Glutamate acting at NMDA receptors stimulates embryonic cortical neuronal migration. J Neurosci. 19, 4449-4461.

Brigman, J.L. et al. (2010), Loss of GluN2B-containing NMDA receptors in CA1 hippocampus and cortex impairs long-term depression, reduces dendritic spine density, and disrupts learning. J Neurosci. 30:4590-4600.

Chtitaa, S. et al. (2015), DFT-based QSAR Studies of MK801 derivatives for non competitive antagonists of NMDA using electronic and topological descriptors. Journal of Taibah University for Science. 9: 143-154.

Cohen, S., and M.E. Greenberg (2008), Communication between the synapse and the nucleus in neuronal development, plasticity and disease. Annu Rev Cell Dev Biol. 24: 183-209.

Colon-Ramos, D.A. (2009), Synapse formation in developing neural circuits. Current topics in developmental biology 87: 53-79.

Cline, H., and K. Haas (2008), The regulation of dendritic arbor development and plasticity by glutamatergic synaptic input: a review of the synaptotrophic hypothesis. J Physiol 586: 1509-1517.

Creeley, C.E., and J.W. Olney (2013), Drug-Induced Apoptosis: Mechanism by which Alcohol and Many Other Drugs can Disrupt Brain Development. Brain Sci. 3: 1153-1181.

Ehrlich, I. et al. (2007), PSD-95 is required for activity-driven synapse stabilization. Proceedings of the National Academy of Sciences of the United States of America 104: 4176-4181.

Erecinska, M., S. Cherian and I.A. Silver (2004), Energy metabolism in mammalian brain during development. Prog Neurobiol. 73: 397-445. 
Espinosa, J.S. et al. (2009), Uncoupling dendrite growth and patterning: single-cell knockout analysis of NMDA receptor 2B. Neuron 62: 205-217.

Fredriksson, A., and T. Archer (2004), Neurobehavioural deficits associated with apoptotic neurodegeneration and vulnerability for ADHD. Neurotox Res. 6: 435-456.

Fritsche, E. et al. (2015), Literature review on in vitro and alternative Developmental Neurotoxicity (DNT) $\begin{array}{llll}\text { testing methods. } & \text { EFSA }\end{array}$ http://www.efsa.europa.eu/en/supporting/pub/778e.

$\mathrm{Fu}, \mathrm{M}$. et al. (2012), Repetitive motor learning induces coordinated formation of clustered dendritic spines in vivo. Nature 483: 92-95.

Granger, A.J. et al. (2011), Genetic analysis of neuronal ionotropic glutamate receptors subunits. J Physiol. 589: 4095-4101.

Gray, J.A. et al. (2011), Distinct modes of AMPA receptor suppression at developing synapses by GluN2A and GluN2B: single-cell NMDA receptor subunit deletion in vivo. Neuron 71:1085-1101.

Guilarte, T.R. (1997), Glutamatergic system and developmental lead neurotoxicity. Neurotoxicology 18: 665-672.

Guilarte, T.R., and J.L. McGlothan (1998), Hippocampal NMDA receptor mRNA undergoes subunitspecific changes during developmental lead exposure. Brain Res. 790: 98-107.

Haberny, K.A. et al. (2002), Ontogeny of the N-methyl-D-aspartate (NMDA) receptor system and susceptibility to neurotoxicity. Toxicol Sci. 68: 9-17.

Holtmaat, A., and K. Svoboda (2009), Experience-dependent structural synaptic plasticity in the mammalian brain. Nat Rev Neurosci. 10: 647-658.

Hwang, J.Y. et al. (1999), N-Methyl-D-aspartate receptor blockade induces neuronal apoptosis in cortical culture. Exp Neurol. 159: 124-130.

Ikonomidou, C. et al. (1999), Blockade of NMDA receptors and apoptotic neurodegeneration in the developing brain. Science 283: 70-74.

Ikonomidou, C. et al. (2000), Ethanol-induced apoptotic neurodegeneration and fetal alcohol syndrome. Science 287: 1056-1060.

Iwasato, T. et al. (2000), Cortex-restricted disruption of NMDAR1 impairs neuronal patterns in the barrel cortex. Nature 406: 726-731.

Johnston, M.V. et al. (2009), Plasticity and injury in the developing brain. Brain Dev. 31:1-10.

Kang, H., and E.M. Schuman (1996), A requirement for local protein synthesis in neurotrophin-induced hippocampal synaptic plasticity. Science 273:1402-1406.

Klintsova, A.Y., and W.T. Greenough (1999), Synaptic plasticity in cortical systems. Curr Opin Neurobiol. 9: 203-208.

Korkut, A., and T. Varnali (2003), Quantitative structure activity relationship (QSAR) of competitive Nmethyl-D-aspartate (NMDA) antagonists. Mol Phys 101: 3285-3291.

Kovalchuk, Y., K. Holthoff and A. Konnerth (2004), Neurotrophin action on a rapid timescale. Curr Opin Neurobiol 14: 558-563.

Kumari, M., and M.K. Ticku (1998), Ethanol and regulation of the NMDA receptor subunits in fetal cortical neuron. J Neurochem. 70: 1467-1473.

Lee, L.J. et al. (2005), Exuberant thalamocortical axon arborization in cortex-specific NMDAR1 knockout mice. J Comp Neurol. 485: 280-292.

Lu, Y., K. Christian and B. Lu (2008), BDNF: a key regulator for protein synthesis dependent LTP and long-term memory? Neurobiol Learn Mem. 89: 312-323.

Makris, S.L. et al. (2009), A retrospective performance assessment of the developmental neurotoxicity study in support of OECD test guideline 426. Environ Health Perspect. 117:17-25. 
Manabe, T. (2009), LTP. Encyclopedia of neuroscience. M D. Binder, N. Hirokawa and U. Windhorst (Eds). Springer-Verlag GmbH Berlin Heidelberg. pp 2188-2190.

Mattson, M.P. (2008), Glutamate and neurotrophic factors in neuronal plasticity and disease. Ann N Y Acad Sci. 1144: 97-112.

McAllister, A.K., L.C. Katz and D.C. Lo (1996), Neurotrophin regulation of cortical dendritic growth requires activity. Neuron 17: 1057.

McAllistair, A.K. (2000), Cellular and molecular mechanisms of dendrite growth. Cereb Cortex 10: 963 973.

Migaud, M. et al. (1998), Enhanced long-term potentiation and impaired learning in mice with mutant postsynaptic density-95 protein. Nature 396: 433-439.

Miyamoto, K. et al. (2001), Involvement of enhanced sensitivity of N-methyl-D-aspartate receptors in vulnerability of developing cortical neurons to methylmercury neurotoxicity. Brain Res. 901: 252258.

Monteggia, L.M. et al. (2004), Essential role of brain-derived neurotrophic factor in adult hippocampal function. Proc Natl Acad Sci USA 101: 10827-10832.

Nagappan, G., and B. Lu (2005), Activity-dependent modulation of the BDNF receptor TrkB: mechanisms and implications. Trends Neurosci. 28: 464-471.

OECD (1996) Guideline 422 on Combined Repeated Dose Toxicity Study with the Reproduction/Developmental Toxicity Screening Test, Organisation of Econimic Cooperation and Development, Paris.

OECD (2007), Guideline 426 on Developmental Neurotoxicity, Organisation of Econimic Cooperation and Development, Paris.

OECD (2011), Guideline 443 on Extended One-Generation Reproductive Toxicity Study, Organisation of Econimic Cooperation and Development, Paris.

OECD (2004), Series on testing and assessment number 20, Guidance document for neurotoxicity testing, Organisation of Econimic Cooperation and Development, Paris.

Ogura, H., and T.G. Aigner (1993), MK-801 impairs recognition memory in rhesus monkeys: comparison with cholinergic drugs. J Pharmacol Exp Ther. 266: 60-64.

Patterson, S.L. et al. (1996), Recombinant BDNF rescues deficits in basal synaptic transmission and hippocampal LTP in BDNF knockout mice. Neuron 16: 1137-1145.

Poo, M.M. (2001), Neurotrophins as synaptic modulators. Nat Rev Neurosci. 2: 24-32.

Purpura, D.P. (1975), Dendritic differentiation in human cerebral cortex: normal and aberrant developmental patterns. Adv Neurol. 12: 91-134.

Rajan, I., S. Witte and H.T. Cline (1999), NMDAR activity stabilizes presynaptic retinotectal axons and postsynaptic optic tectal cell dendrites in vivo. J Neurobiol. 38: 357.

Rajan, I., and H.T. Cline (1998), Glutamate receptor activity is required for normal development of tectal cell dendrites in vivo. J Neurosci. 18: 7836.

Redini-Del Negro, C., and S. Laroche (1993), Learning-induced increase in glutamate release in the dentate gyrus is blocked by the NMDA receptor antagonist AP5. Neurosci Res Commun. 13:157165.

Rezvani, A.H. (2006), Involvement of the NMDA System in Learning and Memory. In: Levin ED, Buccafusco JJ, editors. Animal Models of Cognitive Impairment. Boca Raton (FL): CRC Press; Chapter 4. Available from: http://www.ncbi.nlm.nih.gov/books/NBK2532/

Riedel, G., B. Platt and J. Micheau (2003), Glutamate receptor function in learning and memory. Behav Brain Res. 140: 1-47. 
Rivero Vaccari, J.C. et al. (2006), NMDA receptors promote survival in somatosensory relay nuclei by inhibiting Bax-dependent developmental cell death. Proc Natl Acad Sci USA. 103: 16971-16976.

Roberts, T.F. et al. (2010), Rapid spine stabilization and synaptic enhancement at the onset of behavioural learning. Nature 463: 948-952.

Rocha, M., and M. Sur (1995), Rapid acquisition of dendritic spines by visual thalamic neurons after blockade of N-methyl-D-aspartate receptors. Proc Natl Acad Sc. USA. 92: 8026.

Rusakov, D.A. et al. (1997), Ultrastructural synaptic correlates of spatial learning in rat hippocampus. Neuroscience 80: 69-77.

Sakimura, K. et al. (1995), Reduced hippocampal LTP and spatial learning in mice lacking NMDA receptor epsilon 1 subunit. Nature 373: 151-155.

Schmitt, U. et al. (2009), Detection of behavioral alterations and learning deficits in mice lacking synaptophysin. Neuroscience 162: 234-243.

Sekino, Y., N Kojima and T. Shirao (2007), Role of actin cytoskeleton in dendritic spine morphogenesis. Neurochem Int. 51: 92-104.

Shimizu, E. et al. (2000), NMDA receptor-dependent synaptic reinforcement as a crucial process for memory consolidation. Science 290: 1170-1174.

Shimshek, D.R. et al. (2006), Forebrain-specific glutamate receptor B deletion impairs spatial memory but not hippocampal field long-term potentiation. J Neurosci. 26: 8428-8440.

Silva, A.J. et al. (1992), Impaired spatial learning in alpha-calcium-calmodulin kinase II mutant mice. Science 257: 206-211.

Simon, D.K. et al. (1992), N-methyl-d-aspartate receptor antagonists disrupt the formation of a mammalian neural map. Proc Natl Acad Sci USA 89: 10593-10597.

Soderling, T. R. (1999), Ta Ca-calmodulin-dependent protein cascade. Trends Biochem Sci. 24: 232-236.

Tang, Y.P. et al. (1999), Genetic enhancement of learning and memory in mice. Nature 401: 63-69.

Tarpey, P.S. et al. (2009), A systematic, large-scale resequencing screen of X-chromosome coding exons in mental retardation. Nat Genet. 41: 535-543.

Tsien, J.Z., P.T. Huerta and S. Tonegawa (1996), The essential role of hippocampal CA1 NMDA receptordependent synaptic plasticity in spatial memory. Cell 87: 1327-1338.

Tyler, W.J. et al. (2002), From acquisition to consolidation: on the role of brain-derived neurotrophic factor signaling in hippocampal-dependent learning. Learn Mem. 9: 224-237.

van der Staay, F.J. et al. (2011), Effects of the cognition impairer MK-801 on learning and memory in mice and rats. Behav Brain Res. 220: 215-229.

Wayman, G.A. et al. (2008), Calmodulin-kinases: modulators of neuronal development and plasticity. Neuron 59: 914-931.

Wong, E.H. et al. (1986), The anticonvulsant MK-801 is a potent N-methyl-D-aspartate antagonist. Proc Natl Acad Sci U S A. 83: 7104-7108.

Woolfm, N.J. (1998), A structural basis for memory storage in mammals. Prog Neurobiol. 55: 59-77.

Yang, G., F. Pan and W.B. Gan (2009), Stably maintained dendritic spines are associated with lifelong memories. Nature 462: 920-924.

Yang, J. et al. (2009), Neuronal release of proBDNF. Nat Neurosci. 12: 113-115.

Yoon, W.J. et al. (2003), Blockade of ionotropic glutamate receptors produces neuronal apoptosis through the Bax- cytochrome C-caspase pathway: the causative role of Ca2+deficiency. J Neurochem. 85: 525-533.

Zambre, V.P. et al. (2015), Structural investigations by in silico modeling for designing NR2B subunit selective NMDA receptor antagonists. RSC Adv. 5: 23922-23940. 